GAO

Report to the Chairman, Committee on Science, Space, and Technology,

House of Representatives

December 1994

\title{
ELECTRIC VEHICLES
}

Likely Consequences of U.S. and Other

Nations' Programs and Policies

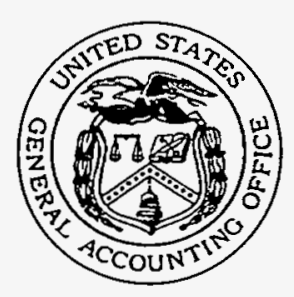




\section{DISCLAIMER}

This report was prepared as an account of work sponsored by an agency of the United States Government. Neither the United States Government nor any agency thereof, nor any of their employees, make any warranty, express or implied, or assumes any legal liability or responsibility for the accuracy, completeness, or usefulness of any information, apparatus, product, or process disclosed, or represents that its use would not infringe privately owned rights. Reference herein to any specific commercial product, process, or service by trade name, trademark, manufacturer, or otherwise does not necessarily constitute or imply its endorsement, recommendation, or favoring by the United States Government or any agency thereof. The views and opinions of authors expressed herein do not necessarily state or reflect those of the United States Government or any agency thereof. 


\section{DISCLAIMER}

Portions of this document may be illegible in electronic image products. Images are produced from the best available original document. 


\section{Program Evaluation and \\ Methodology Division}

B-250142

December 30, 1994

The Honorable George E. Brown, Jr.

Chairman, Committee on Science, Space, and Technology

House of Representatives

Dear Mr. Chairman:

This report responds to your request that we examine international electric vehicle development and commercialization programs. Our study encompassed a review of current barriers to widespread electric vehicle implementation, field visits in seven nations and the United States to examine electric vehicle programs and policies, and analyses of electric vehicle effects on economics, energy, and the environment. Our purpose in providing this review is to assist the Committee as it considers policies for an effective federal role in researching, developing, testing, and deploying electric vehicles.

We will be sending copies of this report to the Secretary of Energy, and we will also make copies available to others upon request. If you have any questions or would like additional information, please call me at (202) 512-3092. Major contributors to this report are listed in appendix IV.

Sincerely yours,

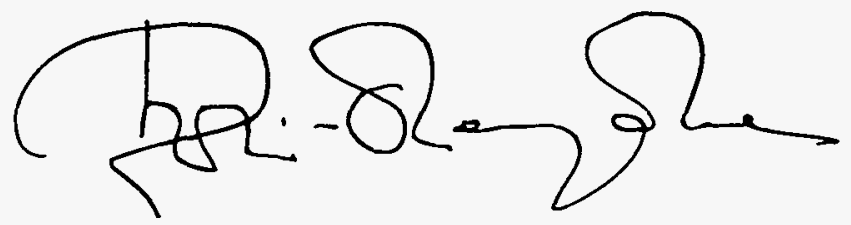

Kwai-Cheung Chan

Director for Program Evaluation

in Physical Systems Areas 


\section{Executive Summary}

\section{Purpose}

California and several northeastern states have adopted or are considering legislation that would require automobile manufacturers-both foreign and domestic-to supply some 70,000 electric vehicles in 1998 and nearly a million by 2003 . Uncertainties about the readiness of electric vehicle technology led the House Committee on Science, Space, and Technology to ask GAO to compare electric vehicle development and commercialization programs internationally. In particular, the Committee asked GAO to review other nations' programs that might inform current and proposed U.S. policies and programs to support electric vehicles. Reviewing programs in France, Germany, Italy, Japan, Sweden, Switzerland, and the United Kingdom, as well as the United States, GAO sought to answer the following questions: (1) What are the current barriers to the widespread introduction of electric vehicles? (2) What are the nature and extent of other nations' policies and programs for developing, producing, and promoting electric vehicles? (3) What are the likely effects of introducing electric vehicles in terms of costs to the individual, national energy savings, and effects on the environment?

\section{Background}

The Federal Clean Air Act Amendments of 1990 requires states to alleviate regional air pollution. Electric vehicles emit no direct air pollutants and are therefore seen as an environmentally friendly substitute for internal combustion engine vehicles, particularly in urban areas where poor ambient air quality is believed to pose a serious health threat. Thus, some states are including electric vehicles in their efforts to reduce air pollution.

The largest government initiative anywhere to support the widespread introduction of electric vehicles is in California legislation that requires that 2 percent of vehicles marketed in that state be zero-emission vehicles by 1998 , with increases to 10 percent by 2003 . Eleven northeastern and mid-Atlantic states have adopted or are considering similar legislation. At the federal level, electric vehicle programs with various funding levels and scopes have been initiated through the Intermodal Surface Transportation Efficiency Act of 1991, the Energy Policy Act of 1992, and the National Defense Authorization Act of 1993. In the most ambitious federal effort, the Department of Energy (DOE) is in a $\$ 262$ million partnership with the U.S. automobile industry to develop advanced batteries for electric vehicles.

\section{Results in Brief}

The ultimate viability of electric vehicles for widespread transportation cannot now be predicted or ensured. Five major barriers to the immediate 
introduction of electric vehicles are limitations of current battery technology, gaps in required infrastructure, uncertain safety, uncertain market potential, and high initial purchase price. Extensive efforts to eliminate these barriers are inherently risky and will require substantial money, time, and attention.

The U.S. policy toward electric vehicles is fragmented in two ways. First, already limited funds are divided into several small programs across three different federal departments. Second and more importantly, the lack of emphasis on the barriers that can be addressed before a battery breakthrough and that ultimately must be resolved to market a viable vehicle-namely, issues of infrastructure support, market development, and production-leaves a gap between state policies mandating electric vehicle markets and federal policies supporting battery technology initiatives.

The fragmented U.S. approach, when coupled with other nations' more comprehensive focus on infrastructure, marketing, and production, raises the specter of past U.S. technological successes better commercialized by foreign competitors. The United States may fund the successful development of an advanced battery that other countries could quickly incorporate into marketable, low-cost, performance-tested vehicles. The case of electric vehicles, moreover, could pose a unique risk because of the artificial U.S. market created by state mandates.

The potential benefits of introducing electric vehicles are not uniform across all nations. The range and diversity of electric vehicles' economic, energy, and environmental effects suggest that they could not solve all transportation and environmental problems even if they were available immediately. Yet, without comprehensive support, they are not likely to achieve enough success to contribute at all to increasing energy security and decreasing air pollution.

\section{Principal Findings}

\section{Barriers}

State-of-the-art batteries typically have a range of about 80 to 100 miles, acceleration power that is somewhat less than that of a traditional vehicle, and a maximum operating life of 500 to 2,000 charges. Current battery types vary in performance and other criteria important to their ultimate 

production feasibility, and price.

Infrastructure requirements can be met, but most major components of recharging, service, and toxic battery recycling support are not in place. Electric vehicles also present some unique safety hazards from the chemical constituents and high voltages and operating temperatures of some batteries. Battery mass may also affect vehicle maneuverability and crashworthiness.

Electric vehicles face an uncertain market potential until consumers adjust to their unfamiliar performance characteristics. However, corporate and government fleets typically travel within narrow daily ranges and return to a central garage, suggesting that electric vehicles could be first introduced into such fleets. Currently quoted initial purchase prices and production costs vary widely, from under $\$ 20,000$ to more than $\$ 350,000$ for an electric van. However, the initial purchase price of vehicles that meet the reasonable demands of consumers will most likely remain at least two to three times higher than comparable internal combustion engine vehicle prices in the near term. government and industry research consortia and targeting government and commercial fleets for an initial market. Swiss manufacturers are developing high-performance, lightweight vehicles to meet international crash test standards. France, Germany, Japan, and Switzerland assess infrastructure needs and market characteristics through large national and local demonstration projects that include public recharging stations and maintenance facilities as well as through public education and familiarization programs.

The United States has focused on two ends of the commercialization process: research and development and market establishment. In contrast, efforts to pilot, demonstrate, and develop empirically based assessments of how best to introduce electric vehicles have been rather limited, particularly in comparison with the emphasis placed on these processes in other countries. Funds have not been appropriated for two major authorized electric vehicle programs in the Energy Policy Act, and demonstration programs funded by defense appropriations are located primarily on military bases. Demonstration program officials cite 
considerable difficulty obtaining electric vehicles in sufficient numbers for adequate field testing.

Several foreign manufacturers potentially subject to California-type legislation are now producing and testing electric vehicles using limited-performance batteries, in part to avoid duplicating the work and expected products of the U.S. Advanced Battery Consortium. If successful, some may well have low-cost, performance-tested vehicles ready to be fitted with the advanced batteries now being developed by the consortium.

National and Regional Effects
The high initial costs of electric vehicles and batteries produced at low volumes outweigh any benefits from their reduced maintenance and fueling costs. When electric vehicles and batteries are produced in high volume, however, consumers in all nations except the United States could expect to pay less to own and operate an electric vehicle than they would pay for a comparable gasoline vehicle. Consumers in the United States pay less for gasoline than those in any other nation. Thus, the United States has the least favorable electricity-to-gasoline price ratio for reducing operating costs.

While currently available electric vehicles use 20 to 35 percent more primary energy than gasoline vehicles, advanced technology electric vehicles are anticipated to reduce U.S. primary energy consumption by 30 to 35 percent in 2010 . The United States would save more annually ( $\$ 2.5$ billion) by replacing 10 percent of its vehicle numbers with electric vehicles than any other nation GAO reviewed, while Italy would save the least (approximately $\$ 300$ million).

Electric vehicles eliminate the direct emissions of hydrocarbons and carbon monoxide associated with urban smog. However, nations that rely heavily on coal and oil for electricity production, including the United States, could see substantial increases in sulfur dioxide emissions (a major component of soot, smoke, and acid deposits) and no change or even moderate increases in carbon dioxide and nitrogen oxides. The feasibility and costs of monitoring and containing these added emissions would have to be considered in the implementation of effective electric vehicle programs.

Electric vehicles-or any single technology-will not solve the world's assorted transportation-related problems. This nation's fuel-neutral energy policy divides funding among many fuel types, in part to ensure that viable 
alternative fuels will be developed and commercialized. Electric vehicles receive disproportionately less funding compared to other alternatives. They are not fully developed on any dimension and will likely remain so without a balanced national policy that supports all aspects of EV development and infrastructure. While inherent risks are associated with sizable investments in a nascent technology, a more tentative U.S. approach carries another risk: investing the millions of dollars in battery research and then losing early market share in mandated state markets. with its findings and conclusions. Points of disagreement included estimates of likely vehicle costs and energy efficiency as well as the effect of U.S. power plant emission regulations (see appendix D). DOE also provided a number of technical and editorial comments, which GAO incorporated into the report as appropriate. 


\section{Contents}

Executive Summary

Chapter 1 Introduction

Introduction

Objectives, Scope and Methodology 13

Limitations of Our Study 16

Organization of This Report $\quad 17$

Chapter 2

Current Barriers to

Current Limitations of EV Batteries

the Widespread Use of

Current EV Infrastructure Barriers

Safety Considerations

Uncertain Market Potential

Electric Vehicles

High Initial Purchase Prices $\quad 34$

Summary and Conclusions $\quad 35$

Chapter 3

Electric Vehicle

Policies and Programs
Status of Diffusion and Promotion Policies $\quad 41$

Major Production Efforts 49

Infrastructure Development and Demonstration $\quad 60$

Vehicle and Battery Research and Development 68

$\begin{array}{ll}\text { Summary and Conclusions } & 72\end{array}$
Chapter 4

National and Regional Effects: Economics, Energy, and the Environment
Introduction 74

Costs to Own and Operate EVs in Different Nations $\quad 74$

EV Effects on Energy Independence

EV Effects on Air Quality 93

Environmental Effects of EVs in Four U.S. Cities 106

Summary and Conclusions 111
Chapter 5

Summary and

Conclusions
Current Barriers to Widespread EV Use

National Electric Vehicle Programs

National and Regional Concerns

Conclusions 
Table 1.1: Projected EV Sales 13

Table 2.1: Advantages and Disadvantages of Current EV Batteries 20

Table 3.1: Key Elements of Electric Vehicle Programs $\quad 39$

Table 3.2: Japan's Electric Vehicle Production Goals 46

Table 4.1: Initial Purchase Price of Electric Citistromers as a $\quad 75$

Function of Annual Production Level

Table 4.2: Battery Cost Per Driving Distance $\quad 77$

Table 4.3: Transportation Statistics for Eight Nations, 1990

Table 4.4: Changes in Primary Energy Consumption by EVs 88

Relative to ICEV Energy Consumption

Table 4.5: Nations' Oil Use Statistics and Projected Annual 90

Savings in Oil If EVs Replace 10 Percent of ICEVs

Table 4.6: Health Problems Commonly Associated With Air 93

Pollutants

Table 4.7: Percentage Share of Global Greenhouse Gas Emissions 95 and Per Capita Emissions With Greenhouse Index Rankings, 1989

Table 4.8: Percentage of Emissions Attributable to Various End 96 Use Sectors

Table 4.9: Projected Electricity Generation Mixes in Eight 97 Nations in 2005

Table 4.10: Projected Marginal Power Plant Mix for EV 107 Recharging

Table 4.11: Attainment of EPA's Ambient Air Quality Standards in 109 Four Cities

Table 4.12: Estimated Avoided Pollution Costs of EVs in Four $\quad 110$ U.S. Cities

Table 5.1: Battery Issues to Be Resolved 113

Table III.1: Primary Criteria With Mid-Term and Long-Term Goals 136

Table III.2: Secondary Criteria With Mid-Term and Long-Term 136 Goals

Figure 3.2: Composite Body Platform $\quad 57$ 
Figure 4.1: Total Lifetime Purchase Costs to Travel 100,000 Miles in a Citistromer by Battery Type and Production Volume

Figure 4.2: Near-Term Life-Cycle Costs of EVs and ICEVs

Figure 4.3: Final Life-Cycle Costs of EVs and ICEVs

Figure 4.4: Percent Change in Emissions of Greenhouse Gases: Low-Efficiency EV Versus High-Fuel-Economy ICEV

Figure 4.5: Percent Change in Emissions of Greenhouse Gases: High-Efficiency EV Versus Low-Fuel-Economy ICEV

Figure 4.6: Percent Change in Emissions of Sulfur Dioxide: Low-Efficiency EV Versus High-Fuel-Economy ICEV

Figure 4.7: Percent Change in Emissions of Sulfur Dioxide: High-Efficiency EV Versus Low-Fuel-Economy ICEV

Figure 4.8: Percent Change in Emissions If an EV Replaces an ICEV

\begin{tabular}{|c|c|}
\hline \multicolumn{2}{|c|}{ Abbreviations } \\
\hline $\mathrm{ABB}$ & $\begin{array}{l}\text { Asea Brown Boveri Hochenergiebatterie, GmbH (German } \\
\text { high energy battery company) }\end{array}$ \\
\hline ADEME & $\begin{array}{l}\text { Agence de l'Environnement et de la Maîtrise de l'Energie } \\
\text { (French Agency for Environment and Energy Management) }\end{array}$ \\
\hline AFV & Alternative fuel vehicle \\
\hline ARPA & Advanced Research Projects Agency \\
\hline AVERE & $\begin{array}{l}\text { Association Europeenne des Vehicules Electriques Routiers } \\
\text { (European Association of Electric Road Vehicles) }\end{array}$ \\
\hline BMFT & $\begin{array}{l}\text { Bundesministerium für Forschjung und Technologie } \\
\text { (German Ministry for Research and Technology) }\end{array}$ \\
\hline CARB & California Air Resources Board \\
\hline CAT & Clean Air Transport, Inc. \\
\hline CITELEC & $\begin{array}{l}\text { European Association of Cities Interested in Electric } \\
\text { Vehicles }\end{array}$ \\
\hline CNG & Compressed natural gas \\
\hline CNR & Italian National Council of Research \\
\hline DAUG & $\begin{array}{l}\text { Deutschen Automobilgesellschaft mbH (German } \\
\text { Automobile Society) }\end{array}$ \\
\hline DOD & U.S. Department of Defense \\
\hline DOE & U.S. Department of Energy \\
\hline EDF & Electricité de France (French national utility) \\
\hline ENEA & $\begin{array}{l}\text { Ente per le Nuove Tecnologie, L'Energia e l'Ambiente } \\
\text { (Italian Agency for New Technology, Energy, and the } \\
\text { Environment) }\end{array}$ \\
\hline ENEL & Italian Public Electricity Board \\
\hline
\end{tabular}


EPA

EPRI

EV

EVOC

GAO

GSA

ICEV

IEA

JEVA

LEV

MITI

NEDO

NHTSA

NUTEK

OECD

PNGV

SEER

SMUD

USABC
U.S. Environmental Protection Agency

Electric Power Research Institute

Electric vehicle

Japanese Electric Vehicle Community System

U.S. General Accounting Office

General Services Administration

Internal combustion engine vehicle

International Energy Association

Japan Electric Vehicle Association

Low-emission vehicle

Japanese Ministry of International Trade and Industry

Japanese New Energy and Industrial Technology

Development Organization

U.S. National Highway Traffic Safety Administration

Swedish National Board for Industrial and Technical

Development

Organization for Economic Cooperation and Development

Partnership for a New Generation of Vehicles

French Société Européenne des Electromobiles Rochelaises

Sacramento Municipal Utility District

U.S. Advanced Battery Consortium 


\section{Introduction}

In many respects, electric vehicles (EVS) have the potential to reduce the transportation sector's adverse effect on environmental quality and petroleum independence. Experts widely agree that Evs could be a cleaner alternative to conventional internal combustion engine vehicles (ICEvs), particularly in highly polluted and congested urban areas where poor ambient air quality poses a serious health threat. Electricity can be produced by many fuels, including some that are nonpolluting, and renewable resources, such as geothermal energy and hydropower. Moreover, the energy efficiency of ICEvs is severely reduced in the typical stop-and-go traffic of urban areas, whereas Evs are less hampered by such real world driving conditions. Further, evs are nearly silent when running, an attribute that could greatly alleviate the noise pollution that lowers the quality of life in many urban and suburban places.

Thus, Evs are playing a vital role in some regional responses to the federal Clean Air Act Amendments of 1990, which requires the states to alleviate air pollution. Although Evs are not yet being widely produced, there is already a legislative requirement in California that in 1998 a total of 2 percent of vehicles marketed in that state must be zero-emission vehicles, with percentage increases in subsequent years up to 10 percent by 2003 . This timetable has understandably fueled a race among the world's largest automobile manufacturers to become the first to introduce a viable $\mathrm{EV}$ in the California marketplace. ${ }^{1}$ Even greater incentives have recently arisen as 11 northeastern and mid-Atlantic states have adopted or are considering similar legislation.

The potential effect of these imposed mandates can be seen in table 1.1, which presents projected EV sales from 1998 through 2003 as calculated by the Electric Power Research Institute (EPRI) based on total 1990 car and light truck sales. If all 11 states and the District of Columbia adopt California-type legislation, 70,600 Evs would be required in 1998; in 2003, when 10 percent of all new cars in California must be zero-emission, that figure rises to 353,600 .

${ }^{1}$ The mandate currently applies only to manufacturers with sales of 35,000 or more vehicles in California. Smaller manufacturers are exempt but can produce EVs and sell zero-emission credits to larger manufacturers, which can then use them in lieu of actual vehicles. 
Table 1.1: Projected EV Sales ${ }^{a}$

\begin{tabular}{|c|c|c|c|c|c|c|c|}
\hline State & $\begin{array}{r}\text { Total new cars } \\
\text { and light trucks } \\
\text { registered in } 1990\end{array}$ & 1998 & 1999 & 2000 & 2001 & 2002 & 2003 \\
\hline California & $1,221,800$ & 24,400 & 24,400 & 24,400 & 61,100 & 61,100 & 122,200 \\
\hline Delaware & 47,100 & 900 & 900 & 900 & 2,400 & 2,400 & 4,700 \\
\hline Maine & 44,300 & 900 & 900 & 900 & 2,200 & 2,200 & 4,400 \\
\hline Maryland & 290,000 & 5,800 & 5,800 & 5,800 & 14,500 & 14,500 & 29,000 \\
\hline Massachusetts & 255,800 & 5,100 & 5,100 & 5,100 & 12,800 & 12,800 & 25,600 \\
\hline New Hampshire & 55,800 & 1,100 & 1,100 & 1,100 & 2,800 & 2,800 & 5,600 \\
\hline New Jersey & 405,600 & 8,100 & 8,100 & 8,100 & 20,300 & 20,300 & 40,600 \\
\hline New York & 644,700 & 12,900 & 12,900 & 12,900 & 32,200 & 32,200 & 64,500 \\
\hline Pennsylvania & 490,400 & 9,800 & 9,800 & 9,800 & 24,500 & 24,500 & 49,000 \\
\hline Rhode Island & 37,400 & 700 & 700 & 700 & 1,900 & 1,900 & 3,700 \\
\hline Vermont & 24,300 & 500 & 500 & 500 & 1,200 & 1,200 & 2,400 \\
\hline Washington, D.C. & 19,200 & .400 & 400 & 400 & 1,000 & 1,000 & 1,900 \\
\hline Total & $3,536,400$ & 70,600 & 70,600 & 70,600 & 176,900 & 176,900 & 353,600 \\
\hline
\end{tabular}

Source: The Electric Power Research Institute.

Whether these Evs are merely supplied by the manufacturer (as the current California legislation reads) or whether Evs are actually purchased will ultimately be determined by consumers. But it is generally believed that many barriers must be overcome before Evs are a viable transportation option.

\section{Objectives, Scope, and Methodology}

Uncertainties about the readiness of $\mathrm{Ev}$ technology led the House Committee on Science, Space, and Technology to ask us to undertake a study of international Ev development and commercialization programs. The Committee was particularly interested in the aspects of other industrialized nations' electric vehicle programs that might inform current and proposed U.S. policies and programs to support electric vehicles. Thus, our overall objective in this report was to examine international efforts to identify and resolve barriers to widespread EV use, so that the accumulated experience and lessons learned could help the United States identify both electric vehicle goals that are achievable and the means for 
achieving them. In consultation with committee staff, we agreed on the following evaluation questions to guide our work:

1. What are the main current barriers to the widespread introduction of Evs?

2. What are the nature and extent of industrialized nations' policies and programs to develop, produce, and promote Evs?

3. What are the likely effects of introducing Evs in a nation or region in terms of costs to the individual, national energy savings, and environmental effects?

We used several methods to obtain our primary data. These included interviews with experts in the field of electric vehicles, literature reviews of technical reports and government documents, field studies in the seven foreign nations and the United States, and analysis of data concerning the effect of electric vehicles on consumer costs, energy consumption, and pollution.

In order to understand the general issues that surround Ev research and development, we conducted interviews with government officials who manage or otherwise influence Ev programs. These typically included officials in the ministries of environment, energy, transportation, and industry. We also met with scientists, researchers, and managers from private corporations with an interest in Evs, including persons representing electric utility companies, automobile manufacturers, and battery companies. We attended the eleventh international electric vehicle symposium in Florence, Italy, in September 1992, where we gathered additional information and interviewed experts. journals, government research reports, and proceedings from $\mathrm{EV}$ conferences and symposia. From these studies, we identified additional sources of relevant information on Evs. These often went beyond technical issues surrounding the vehicle itself to include, for example, market studies and infrastructure development. We also gathered government documents relating to national and local Ev policies and programs. 
We conducted site visits in France, Germany, Italy, Japan, Sweden, Switzerland, and the United Kingdom, as well as in the United States. Although Ev activities exist in other nations, we determined that the efforts in the seven foreign industrialized nations were among the largest and most comprehensive and, therefore, could best inform current understanding and activities in the United States. We also identified several supranational organizations that play an active role in $\mathrm{EV}$ development. The Association Europeenne des Vehicules Electriques Routiers (AVERE) supports efforts to use electric road vehicles throughout Europe. The European Association of Cities Interested in Electric Vehicles (CITELEC) is an association of European cities interested in promoting Evs in urban areas. The Organization for Economic Cooperation and Development (OECD) and the International Energy Association (IEA) continue to support research and collect information in the area. Whenever possible, we visited active Ev production and demonstration sites and reviewed official documents provided by a nation's officials.

Before making each site visit, we contacted staff working in Washington, D.C., embassies of these nations in order to obtain the names of agencies and staff responsible for Ev programs. When we notified them of our impending visit, they often provided additional contacts or sources of information about public and private Ev programs. The goal of the international site visits was to obtain a better understanding of environmental, energy, transportation, and industrial policies and programs abroad, including the extent of interagency and international cooperation and coordination regarding Evs.

\section{Data Analysis} questions regarding the potential effect of introducing Evs: in particular, (1) the likely costs to individuals of owning and operating Evs in different nations, (2) the likely effects of introducing EVs on a nation's energy savings, (3) the likely effects of introducing Evs on a nation's dependence on imported petroleum, and (4) the likely effects of introducing Evs on a nation's air pollution environment. The major sources of information we used were government documents, published academic and government research articles, and interviews with experts.

With respect to cost, we considered likely purchase prices in both the near term and the more distant future, as well as costs to operate and maintain an EV. To do this, we reanalyzed and synthesized data from three distinct sources: the first proposed likely vehicle costs as anticipated by a major 
automobile manufacturer, the second projected likely costs of different $\mathrm{EV}$ batteries, and the third presented electricity and gasoline costs in the nations under study. Our analysis of energy savings to be gained by introducing Evs compared the energy use of an $\mathrm{EV}$ in the form of electricity to the energy use of a comparable ICEV in the form of petroleum. We posited likely reductions in imported petroleum for the eight nations under study, based on their reliance on imported petroleum and the proportion of the nation's electricity generated by oil. We analyzed environmental effects as a function of each nation's electricity generation mix: coal, oil, gas, hydropower, geothermal power, and nuclear power. We also considered a number of studies of the potential environmental effects of introducing Evs into specific regions that vary in terms of the fuel used to generate electricity. For example, we analyzed published statistics on each nation's electricity generation sources and oil imports to infer the likely effects of Evs on pollution reduction and energy independence.

We gathered our program data between September 1992 and July 1994 and updated our information wherever possible through December 1994, in accordance with generally accepted government auditing standards.

\section{Limitations of Our Study}

Given the proprietary nature of many Ev research efforts, we were not always able to obtain information on all aspects of a program. For example, we cannot present cost estimates for all prototypes nor can we discuss the number of planned or actual vehicles produced for some programs. For similar reasons, we were not able to verify independently all the information we obtained on these proprietary efforts. Currently quoted initial purchase prices and production costs vary so widely as to make them essentially meaningless for either comparative or predictive purposes. To maximize the usefulness of our report, we present such information only where it was provided and when we were reasonably confident of its accuracy.

Although this report can contribute to a discussion of the broad issues surrounding Evs, many aspects of these issues are sufficiently complex that a full understanding cannot be achieved in any one report. For example, we do not consider the potential effect of state and federal tax losses resulting from reduced gasoline sales nor do we make projections of the economic effect of shifting demands from the petroleum industry to the electricity industry. We do not compare electric vehicles to other alternatively fueled vehicles. The multifaceted nature of this study led us to use a broad, descriptive approach to present the technical and 
programmatic aspects of introducing a widespread system of Evs. Yet, the field of electric vehicles is constantly changing, and although we include recent developments wherever possible, the fast pace of EV development should be considered when using the information contained in this report.

Organization of This Report
In chapter 2, we discuss current barriers to widespread EV use. In chapter 3 , we describe what we learned about the policies and programs that the United States and other nations use to develop, produce, and promote EVs. In chapter 4 , we consider the likely economic, energy, and environmental effects of introducing Evs into a nation or region. Chapter 5 contains our general summary and conclusions. 


\section{Current Barriers to the Widespread Use of Electric Vehicles}

We identified five major activities that must be completed before Evs become a viable transportation option: overcoming limitations of battery technology, building EV infrastructure, ensuring EV safety, identifying and developing a market, and reducing purchase costs. In this chapter, we present major issues and questions that have been identified for each of them.

Current Limitations of EV Batteries
Limitations in the range, power, recharging capabilities, and life of batteries remain the largest technical obstacles for the commercialization of Evs. ${ }^{1}$ The typical range of prototype and limited production Evs is approximately 60 to 150 miles on a single battery charge but depends greatly on variations in driving speed and the use of heating and air conditioning. However, most of the Evs that are commercially available have substantially lower ranges - from 30 to 50 miles under city driving conditions.

Current EV batteries are technically unable to store enough energy in a unit of reasonable size and weight. Their size-as large as 20 cubic

feet-makes them hard to fit into a vehicle without severely limiting cargo or passenger space, and their weight-as much as 2,800 lbs for a one-ton cargo van-requires ample energy to accelerate the vehicle. Thus, increasing the energy held in the battery without substantially increasing its weight and volume is a significant challenge that must be met before the range and sustainable power of Evs can compete with those of conventional ICEVS.

A battery's range relates directly to its specific energy, the ratio of its energy capacity to its weight, usually expressed in watt hours per lilogram (Wh/kg). Range is also affected by a battery's energy density, the ratio of its energy capacity to its volume, usually expressed in watt hours per liter $(\mathrm{Wh} / \mathrm{l})$.

The specific energy of gasoline is more than 350 times, and its energy density about 120 times, that of a lead acid battery. For example, gas provides 10,000 units of energy (watt hours) per kilogram while the most efficient electrochemical cell provides 81 units of energy per kilogram-a proportion of 123 to 1 . Traveling 100 miles in the General Motors Impact would require 5.67 liters of gasoline weighing $10 \mathrm{lbs}$ and containing 50.1 kilowatt hours of energy or $880 \mathrm{lbs}$ of a lead acid battery occupying 172

${ }^{1}$ Cost is also considered a technical obstacle. We address cost separately in the final section of this chapter and again in chapter 4 . 
Chapter 2

Current Barriers to the Widespread Use of

Electric Vehicles

liters (or 6 cubic feet) of space and containing 13.6 kilowatt hours of energy. ${ }^{2}$ However, an electric motor is three to four times more efficient than the internal combustion engine, so the system can make better use of the smaller amounts of energy onboard in terms of actual power output. ${ }^{3}$

Yet, even under the best development scenarios, Evs may always be inferior to ICEvs in specific energy and energy density. That is, they will require more space and more weight to store energy. Department of Energy (DOE) goals for maximum battery volume for a lightweight, aerodynamic van that could travel 75 to 100 miles between charges range from 400 to 550 liters ( 14 to 20 cubic feet) and for maximum battery weight from about $970 \mathrm{lbs}$ to $1,550 \mathrm{lbs}$, depending on battery type. ${ }^{4}$

Evs currently require a long time to recharge batteries, especially when compared to the 5-minute refueling of ICEvs. Most recharging systems take at least 5 to 7 hours to recharge, using standard 120 or 220 volt outlets. A "quick" recharge system that takes 6 to 12 minutes has been developed, but the safety of using such high-powered systems is still uncertain.

Today's Ev batteries can be recharged a finite number of times. Nickel cadmium and nickel iron batteries can be expected to tolerate 2,000 recharges, whereas sodium sulfur and lead acid batteries last for about 500 cycles. For example, sodium sulfur batteries currently require replacement as often as every 1-1/2 years at estimated costs of $\$ 60,000$ to $\$ 80,000$.

As table 2.1 indicates, each battery type has its individual positive and negative attributes. For example, lead acid's low price, abundant raw materials, and well-established production and recycling technology are offset by its less than desirable range, service life, and acceleration power. The nickel cadmium battery has a high power ratio for acceleration and a long cycle life that would reduce the high cost of repeatedly replacing worn batteries. However, both nickel and cadmium are expensive, thus making the initial cost of the battery relatively high. Moreover, cadmium is

${ }^{2}$ See R. J. Nichols, "The United States Advanced Battery Consortium: Making Longer Life Batteries Affordable," and J. Dabels, "Environmental Requirements and the Impact Prototype Vehicle," in Organization for Economic Cooperation and Development, The Urban Electric Vehicle: Policy Options, Technology Trends, and Market Prospects (Paris, France: 1992), and J. P. Cornu, "Nickel-Cadmium, a Major Advantage for Cities," in EVs-11 Florence: The 11th International Electric Vehicle Symposium (Florence, Italy: 1992).

${ }^{3}$ The overall fuel efficiency-from primary energy extraction through vehicle end use-is projected to be about 10 percent for gasoline ICEVs and 14-20 percent for EVs in 2001. J. J. Brogan and S. R. Venkateswaran, "Diverse Choices for Electric and Hybrid Motor Vehicles: Implications for National Planners," in The Urban Electric Vehicle.

${ }^{4}$ U.S. Department of Energy, Mission Directed Goals for Electric Vehicle Battery Research and Development (Washington, D.C.: 1987). 
Chapter 2

Current Barriers to the Widespread Use of

Electric Vehicles

quite toxic, and nickel cadmium battery recycling facilities have not been

established.

Table 2.1: Advantages and Disadvantages of Current EV Batteries

\begin{tabular}{|c|c|c|}
\hline Type & Advantage & Disadvantage \\
\hline Lead acid & $\begin{array}{l}\text { Low price } \\
\text { Based on established technology } \\
\text { Abundant raw materials } \\
\text { Adequate cycle life } \\
\text { Maintenance free, sealed versions } \\
\text { available } \\
\text { Recycling system }\end{array}$ & $\begin{array}{l}\text { Low specific energy and energy density } \\
\text { increases weight and volume and } \\
\text { decreases range } \\
\text { Power decreases as battery discharges } \\
\text { Decreased capacity at low atmospheric } \\
\text { temperatures } \\
\text { Limited possibility of fast charging }\end{array}$ \\
\hline Nickel cadmium & $\begin{array}{l}\text { High cycle life } \\
\text { High power even after partial discharge } \\
\text { Very good performance at low } \\
\text { atmospheric temperatures } \\
\text { Fast charge technology developed }\end{array}$ & $\begin{array}{l}\text { Expensive } \\
\text { Cadmium is rare and highly toxic } \\
\text { Poor chargeability at high atmospheric } \\
\text { temperatures } \\
\text { Charging memory effect can } \\
\text { systematically reduce capacity } \\
\text { No recycling system }\end{array}$ \\
\hline
\end{tabular}

Nickel metal hydrides

Very high specific energy and energy density decreases weight and volume and increases range

High power

Good performance at low atmospheric temperatures

\section{Expensive}

Use of rare metals in some instances

Very sensitive to high temperatures (thermal management required)

No recycling system

Very high specific energy and energy density decreases weight and volume and increases range

High power

Abundant raw materials
Expensive

Premature failures and self-discharges

Must maintain permanently high temperatures

High internal resistance reduces specific power

Safety issues regarding chemical composition and high temperatures

No recycling system

Metal air

High specific energy decreases weight and increases range

Consistently high power

Fast mechanical recharge

High safety potential

Manufacturing ease

Abundant and low-cost raw materials

Currently high cost

Hydrogen build up with overcharge

Poor performance at low temperatures

Low cell efficiency

Requires carbon dioxide scrubber

\begin{tabular}{ll}
\hline Ambient temperature lithium & High specific energy decreases weight \\
and increases range \\
High power \\
Abundant lithium supply \\
Low maintenance
\end{tabular}

\author{
igh specific energy decreases weight \\ High power \\ Low maintenance
}

\author{
Carbon version expensive \\ Solid version has low power at room \\ temperature \\ Questionable safety of recharge \\ Limitations in quick charging \\ No recycling system
}



capability in an integrated cell system is currently being evaluated. The sodium sulfur battery has relatively high energy and power ratios for maximum range and acceleration, yet it requires a constant maintenance temperature of $540^{\circ}$ to $600^{\circ}$ Fahrenheit and its active ingredients are both corrosive and explosive. ${ }^{5}$ Metal air batteries have the potential for very high performance and quick rechargeability. These batteries create energy by reacting a metal (aluminum, zinc, or iron) with atmospheric oxygen. The safety and environmental benefits of such a system are clear, but their successful development is very uncertain. The lithium battery is considered by experts to be the best candidate to meet the long-term goals of the U.S. Advanced Battery Consortium (USABC) from both technical and cost viewpoints. Still, much research and development are required to make the lithium battery a viable power source for Evs. Most experts do not anticipate this development before 2010.

\section{Current EV Infrastructure Barriers}

The second barrier to widespread EV use that we identified is infrastructure development and standardization. Some proponents of Evs argue that infrastructure will develop smoothly as EVs are marketed. However, others point to the need to convince potential customers that Evs will not impose major operating and travel inconveniences. We see it as a major barrier because so many issues remain unresolved concerning the various components of $\mathrm{EV}$ infrastructure and implementing them will require ample time, attention, and effort. These include recharging equipment; residential, commercial, and public charging facilities; maintenance, service, and battery recycling; and electricity service and supply.

\section{Recharging Equipment}

Current recharging technology includes traditional plug-in systems and an innovative inductive charger. The plug-in systems vary in the type of plug they employ and the level of charge they can transmit (120 volts, 240 volts, or 480-plus volts). Recharging equipment may be permanently attached to the vehicle, permanently attached to the area where the vehicle is typically parked, or completely removable to either stay behind or travel with the

\footnotetext{
${ }^{5}$ The molten sodium and sulfur are capable of generating large quantities of heat, explosive and toxic gases, and other caustic chemical compounds. Two fires have occurred when the thermal management system failed as a battery was being heated prior to shipping or installation in a vehicle. The extent to which such a hazard could occur under real operating conditions is not currently known. Current U.S. regulations consider both liquid sodium and sulfur as hazardous cargo and their transport currently requires special exemptions.
} 
Chapter 2

Current Barriers to the Widespread Use of

Electric Vehicles

vehicle. The inductive charger uses a paddle-shaped inductive coupler to transfer electricity to an Ev's charging port by means of a magnetic induction. One benefit of inductive charging is that it can be accomplished with fewer safety concerns in wet weather. Regardless of the technology used to recharge Evs, key issues in developing connector technology include whether or not to standardize plugs and outlets, as well as establishing the environmental ruggedness, safety, and human factors considerations of recharging.

EVs will most likely need the ability to refuel away from home at retail or commercial charging stations, especially to achieve consumer acceptance. Charging stations will probably be configured one of two ways-that is, slow and fast-depending on the rate of recharge and consequent voltages involved. Low-voltage ( 120 to 240 volts) charging stations will be much the same as the home charging station and will probably use the battery-charging electronics already on board the Ev. Standard charging should also be available and practical in parking lots or garages where multiple-hour parking is typical. (See figure 2.1.) Key issues for low-voltage stations include equipment safety and reliability, low capital and maintenance costs to encourage widespread installation, and establishing convenient and accurate methods of revenue collection. 
Chapter 2

Current Barriers to the Widespread Use of

Electric Vehicles

Figure 2.1: Charging Station

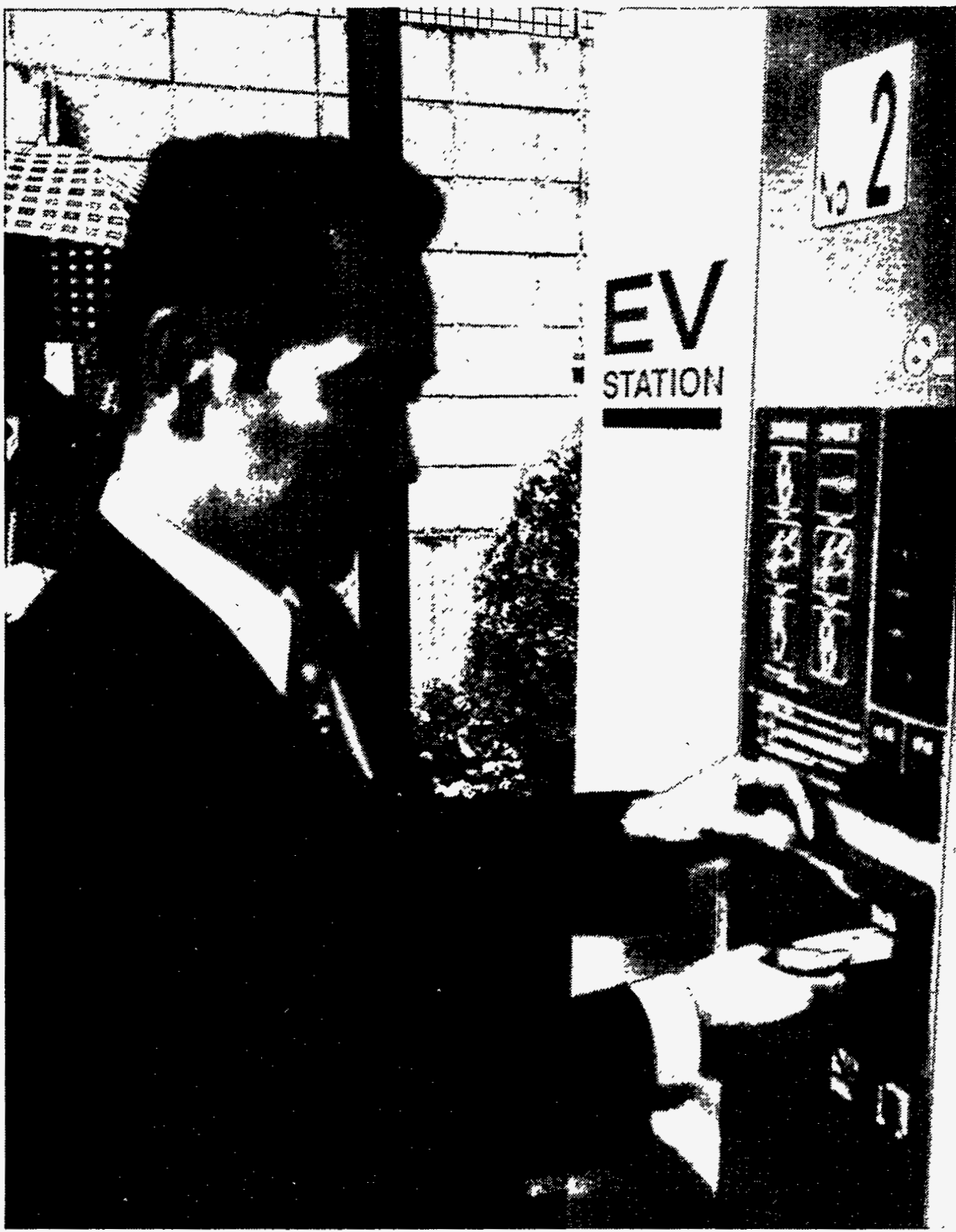

Note: Government officials in Osaka, Japan, insert the EVOC identification card to access the recharging cord. The charging connector has an electronic sensor to automatically activate the correct charging voltage. 
Chapter 2

Current Barriers to the Widespread Use of

Electric Vehicles

Fast charging stations represent a different challenge. According to recent claims, some batteries can now receive a 40-percent recharge (equivalent to 50 to 90 miles of range extension) in 6 to 12 minutes. Such rapid recharging rates will require at least 480-plus volts of power. Primarily for safety reasons, the electronics will most likely not be in the vehicle, thus increasing capital and operating costs for charging stations. It is not now known how different battery types will react to high-energy charging. For example, rapid recharging of some batteries may cause overheating, emission of gases, or shortened lifetimes. Without answers to these questions, the technology to monitor and deliver rapid recharging cannot be established. Nor is it known whether additional rapid recharge monitoring or control equipment will be needed on board the vehicle and how that might affect cost, weight, and range.

EVs use large amounts of electricity from the outlet and their batteries produce large amounts of electrochemical energy, both of which could have dangerous health and safety effects. Thus, research must demonstrate that Evs and recharging equipment are effectively benign electrically and electrochemically in any areas in which they are likely to operate. Such demonstration would include testing for power quality and electromagnetic field effects, as well as compliance with both electric and building codes.

Maintenance, Service, and Recycling
The maintenance and service-both routine and emergency-of Evs may pose unique circumstances, considering that most advanced Ev batteries contain large amounts of electrochemical energy captured in highly toxic and reactive substances. For similar reasons, their ultimate effect on the environment throughout their life cycles has yet to be determined. The type and amount of infrastructure that would be required to recycle these large batteries is a serious outstanding concern. Also not yet considered is the environmental effect of additional radioactive waste if Evs are powered by nuclear power plants.
Electricity Service and Supply
Electric utilities can justify expansion and achieve more efficient use of current capacity if substantial numbers of Evs recharge during off-peak hours. Understandably, then, they have exhibited marked interest in EV developments. Utility roles in consumer familiarization and education could contribute substantially to the public acceptance of Evs. Toward this end, electricity utilities are striving to determine the best mechanism for introducing them. Currently, utilities are the primary users of Evs with the 
Chapter 2

Current Barriers to the Widespread Use of

Electric Vehicles

dual intention of assessing vehicle and infrastructure performance and promoting the viability of Evs to their customers.

In the future, utilities may provide incentives to speed EV acceptance by consumers. These will almost certainly include lower residential night rates if Evs acquire a sizable market. Utilities are also considering the leasing of vehicles or batteries to private citizens, as well as possible installation, ownership, and operation of charging, servicing, and recycling stations. Reports from EPRI suggest that the extent to which utilities provide such incentives will probably depend, at least in part, on whether state and federal regulators allow them to recover costs associated with utility-sponsored Ev subsidies or programs.

The minimal number of evs expected in the near future is not considered likely to create excessive burdens on utility loads. Utility companies plan to provide customers with incentives and devices to manage their recharging activities in ways that promote efficient use of current capacity. That is, utilities want the bulk of standard recharging to be done during off-peak periods.

Fast charging, however, represents a significant utility load management challenge as it is designed to be used primarily during daytime commercial hours. Several practical concerns can be raised about fast-charging effects on utility load management and systems. For example, storage facilities may be needed at service stations to manage large short-duration demand surges (for example, load leveling batteries that store excess nighttime electricity). The total utility peak power requirements that will be needed to recharge a reasonable number of vehicles and how this might vary over the course of the day, season, and year have yet to be determined. Even very basic questions remain unanswered, such as the number of charging stations needed now and in the future.

\section{Safety Considerations}

Evs present several unique hazards that are not present or do not occur to the same degree in ICEVS. Moreover, ICEVs have benefitted from decades of development and refinement, whereas Evs are developmentally still a new technology. We previously noted hazards pertaining to battery recharging and the general safety concerns relating to battery recycling in our discussion of infrastructure supports. The special hazards associated with 
Chapter 2

Current Barriers to the Widespread Use of

Electric Vehicles

EVs can be classified into one of two main types: (1) electrical, chemical, and thermal hazards and (2) mechanical and operational hazards. ${ }^{6}$

Electrical, Chemical, and Thermal Hazards
All Ev batteries present some safety hazards. Of the major battery types, the sodium sulfur battery appears to present the most serious hazard and thus receives more attention and concern. The typical sodium sulfur battery operates at between 200 and 300 volts. In contrast to the typical 12-volt ICEV starter battery, this poses a potentially lethal shock hazard, particularly during charging and maintenance and in the event of a severe collision. A related electrochemical hazard is that of fire resulting from short-circuiting, overheating, or cell rupture. Short-circuiting could be caused by a poor connection during charging or operation as well as the failure of connectors or damage to the battery pack during collision. Overheating might result from overcharging, cell failure, or a failure of the thermal management system. Cell ruptures can be caused by an overvoltage supplied to a cell during charging, which could rupture the ceramic electrolyte and allow the sodium and sulfur to mix directly. Through a variety of potential reactions, the molten sodium and sulfur are capable of generating large quantities of heat, explosive and toxic gases, and other caustic chemical compounds.

Maintaining optimal battery temperature requires a sophisticated thermal management system that provides initial heatup of the battery, controls waste heat buildup, and insulates the system. Two fires recently occurred in sodium sulfur batteries when the thermal management system failed as the batteries were being heated. Fortunately, neither battery was actually in a vehicle; one fire took place at the battery manufacturing plant and the other at the vehicle production plant. The battery manufacturer recognized the potential problems and stopped all scheduled deliveries and is currently working to improve the thermal management system. However, the problem is potentially serious, and the extent to which this particular failure could occur in real-world operating conditions is not known. In June 1994, Ford reported to the National Highway Traffic Safety Administration (NHTSA) that two fires had occurred in the sodium sulfur batteries that power their EV vans. As a result, Ford has ordered all the vans parked until the cause of the fire can be determined.
Mechanical and Operational Hazards
The replacement of the typical internal combustion engine with an electric propulsion system has several important mechanical and operational

${ }^{6}$ National Renewable Energy Laboratory, Environmental, Health, and Safety Issues of Sodium-Sulfur Batteries for Electric and Hybrid Vehicles, vol. 4, In-Vehicle Safety (Golden, Colo.: November 1992). 
ramifications. For example, some Evs may not have the acceleration performance needed to merge effectively onto a highway at high speeds. However, since most Evs are generally considered to be within the range of performance of today's ICEVs, we do not consider performance deficits to be a major safety concern at this time.

Vehicle accessories, such as windshield wipers, defoggers, lights, and indicators, are driven by electricity in both ICEVs and EVS. If an ICEV runs out of fuel, these accessories continue to function; if an EV runs out of electricity, it must have a secondary source of electricity to drive accessories. Most Evs have such a source. However, some designs run accessories off the primary, propulsion battery.

From a safety perspective, the conversion of an ICEV to an EV can add substantial mass to a vehicle; batteries can weigh as much as a fourth to half of the total unladen vehicle weight. This added weight could affect a converted Ev's maneuverability as well as increase its inertial force, which would hamper its ability to make sudden stops or avoid a collision. Some EV batteries are placed lengthwise under the car. This configuration is considered less of a safety concern than others in which the batteries are placed in the trunk or behind the rear seat of cars or on the cargo floor of vans. This is because excessive movement of the battery pack into the passenger compartment could be fatal in the event of a collision. The effect of converting ICEVs to EVs on crashworthiness has not been thoroughly examined.

Future Evs will likely be purpose-built-rather than converted from ICEVs-using lightweight, nonpropulsion components to increase range. It is possible that these lighter-weight components will lower an Ev's crash energy management capacity. That is, the vehicle will be less able to absorb and direct the energy of a collision. A lower capacity (which is not necessarily related to vehicle weight alone) would result in more deformation of the vehicle and less protection of the occupants. In the early 1980's, DOE conducted some crash testing of two EVs: one designed with some lighter-weight components (ETV-1) and the other with a fiber-reinforced plastic for maximum strength-to-weight ratio (ETV-2). ETV-1 was tested on a "mule" vehicle derived from a 1977 Chrysler Omni-Horizon; ETV-2 was tested on a half-scale model. Both were reported to demonstrate crashworthiness.

In 1993, NHTSA crash tested two converted Evs equipped with lead acid batteries located in both the front and rear vehicle compartments. In both 
Chapter 2

Current Barriers to the Widespread Use of

Electric Vehicles

$30 \mathrm{mph}$ frontal crashes, the front batteries sustained substantial damage. One EV leaked 10.4 liters of electrolyte; the other leaked 17.7 liters of electrolyte. Several electrical arcs were observed under the hood of one vehicle during the crash. In November 1994, NHTSA tested the crashworthiness of five batteries that were not in vehicles, and it plans to crash test a Chevy S-10 converted pick-up truck in December 1994. Final results were not available for inclusion in this report.

Swiss manufacturers are conducting extensive EV safety research on lightweight vehicles. ${ }^{7}$ The Swiss effort to design crashworthy Evs is quite different from conventional approaches. Current efforts to improve crashworthiness of ICEvs focus on increasing the energy absorption potential of vehicles while ensuring passenger protection-for example, by incorporating "crumple zones" into the front hood, nonpenetrable passenger zones, and passenger restraint systems that decelerate the occupant within established injury tolerance limits.

Swiss officials believe that the EV of the future will incorporate many lightweight components and, thus, requires a different approach to crashworthiness to compensate for its low mass and the reduced length of its car front. The Swiss are designing very rigid, "nondeformable" Ev car bodies made of high-strength, lightweight composite materials such as fiberglass and resins. Following an impact, the stiffness of these materials reduces the ability of the Ev's outer structure to absorb energy. The force is therefore transferred to the passenger compartment, which decelerates at a much higher rate than is common in an ICEV. This implies that the occupants will need a much larger space in which to move forward and then backward without hitting the dashboard or windshield. Passenger restraint systems will require modifications, and steering column airbags may be a necessity.

The Swiss have conducted several crash tests with lightweight Evs reinforced in various ways. (See figure 2.2.) These include frontal collisions with a solid wall at a top speed of $25 \mathrm{mph}$, frontal collisions at a speed of $32 \mathrm{mph}$ with an Audi 100 weighing twice as much and traveling at $16 \mathrm{mph}$, and side collisions with stationary barriers at $31 \mathrm{mph}$. Although we were told that data were collected on both vehicle damage and injury to a dummy in the driver's position, we were unable to obtain data that were comparable to U.S. crashworthiness standards and therefore cannot

${ }^{7} \mathrm{R}$. Kaeser, Institute for Lightweight Structures, Swiss Federal Institute of Technology, "Safety Potential of Urban Electric Vehicles in Collisions," in The Urban Electric Vehicle: Policy Options, Technology Trends, and Market Prospects (Paris, France: 1992). 
Chapter 2

Current Barriers to the Widespread Use of

Electric Vehicles

speak at all to the crashworthiness of such vehicles. ${ }^{8}$ Although more tests are needed to demonstrate $\mathrm{EV}$ crashworthiness, the existence of this research certainly shows the feasibility of conducting early safety assessments of Evs in order to improve designs for crashworthiness.

Figure 2.2: Crash Testing

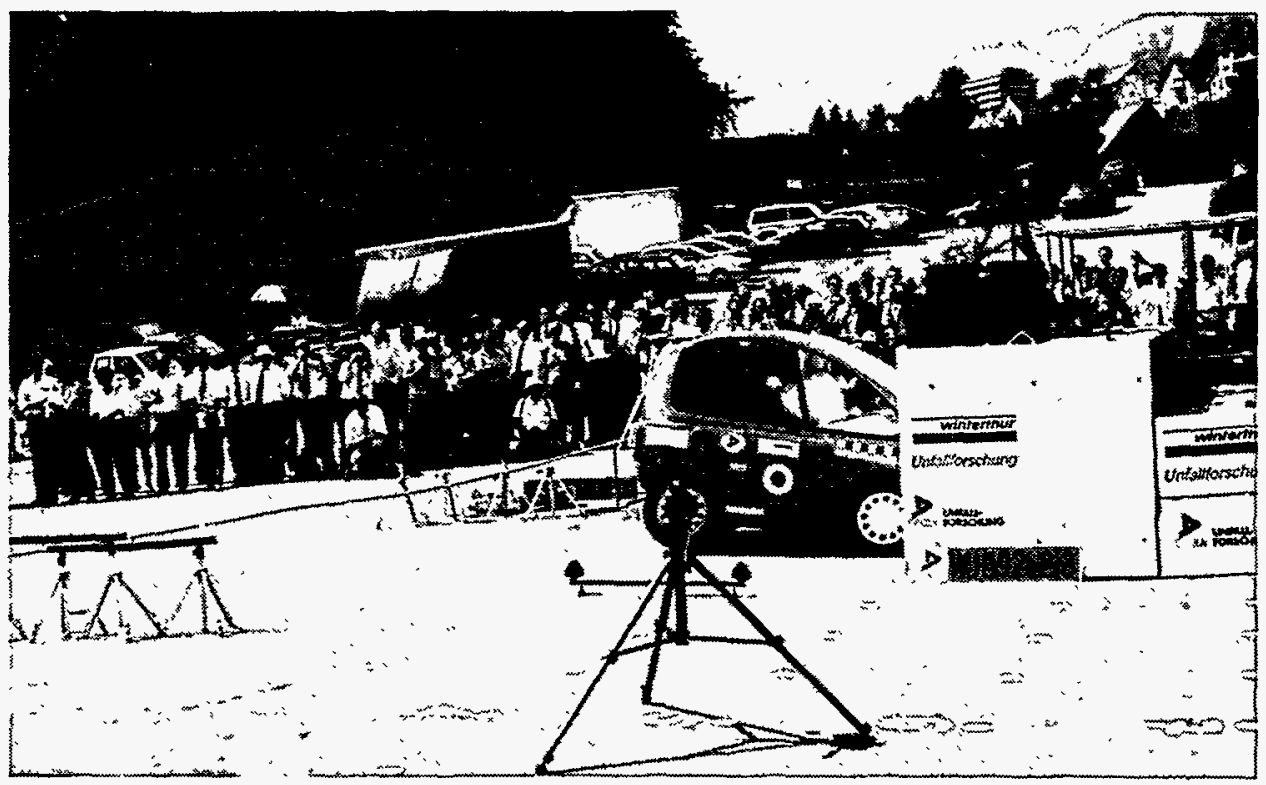

Note: Swiss manufacturers crash test small, lightweight EVs such as the one pictured here. Results are used to improve designs for safety and crashworthiness.

In the United States, the NHTSA granted exemptions for four 1989 Chrysler TEVans that were converted from Dodge Caravans and Plymouth Voyagers. The ICEV versions complied with all standards that apply to multipurpose passenger vehicles; however, the manufacturer argued, and NHTSA agreed, that once the vehicles were converted to battery power, certain standards were no longer relevant. These included regulations governing the transmission, braking system, seating systems, seat belt assembly anchorages, windshield mounting, windshield zone intrusion, and fuel system integrity. Again in September 1992, NHTSA granted 2-year exemptions for 1991-94 TEVans on some of but not all these regulations.

${ }^{8}$ One Swiss manufacturer, Horlacher, Inc., is reportedly developing a light cargo van to meet U.S. crash-test standards. 
Whether these or any future exemptions might compromise vehicle integrity or passenger safety is uncertain without systematic testing. Evs and ICEVs are dissimilar on many dimensions. In all likelihood, new or revised regulations will be necessary to ensure Ev crashworthiness. For example, fasteners and enclosures for batteries are likely to require special attention to minimize the hazards and risks associated with high voltages and reactive chemicals. In September 1994, NHTSA requested public comments on safety issues surrounding Ev fuel systems, such as battery shock hazards and electrolyte spillage. NHTSA had previously published an advanced notice of proposed rule making on these issues in 1991. After reviewing the 46 public comments, NHTSA had concluded that it was premature to initiate rulemaking for EV safety standards at that time.

A decision on the current initiative will probably not be made until 1995 . The experts we interviewed universally stated that Evs can be designed to meet current U.S. vehicle safety standards and thus should not be granted special exemptions from vehicle crashworthiness standards.

\section{Uncertain Market Potential}

Efforts to forecast potential EV markets continue to multiply and expand as the California 1998 deadline nears. Two major approaches have been tried and each reaches widely different conclusions. In this section, we discuss the methods used to assess the private EV market, summarize major findings from these market studies, and consider the characteristics of commercial and government fleets in terms of potential $\mathrm{EV}$ penetration.

Technical constraint studies have looked at how current limitations in EV technology (for example, short range and long recharge times) fashion the $\mathrm{EV}$ market and have found a large potential market for EVs. Deshpande estimated that 60 percent of U.S. households drive fewer than 96 miles on 348 days of the year, a range within the limits of current Ev technology. ${ }^{9}$ Nesbitt and colleagues further constrained this estimate by adding the assumption that only home owners were likely to have a safe and reliable recharging site for an $\mathrm{Ev}^{10}$ They also included only households with two or more cars and only those whose members drive at least one car fewer than 70 miles per day (which would leave a "range buffer" for emergencies). They found that 28 million households in the United States could

${ }^{9}$ G. K. Deshpande, "Development of Driving Schedules for Advanced Vehicle Assessment," SAE Technical Paper Series 840360, Society of Automotive Engineers, Warrendale, Pa, 1984.

${ }^{10} \mathrm{~K}$. Nesbitt, K Kurani, and M. DeLuchi, "Home Recharging and the Household Electric Vehicle Market: A Constraints Analysis," Transportation Research Record (1992). In Nesbitt's model, the constraints analysis defines the potential market to be surveyed about attitudes and beliefs surrounding the purchase of EVs. 
Chapter 2

Current Barriers to the Widespread Use of

Electric Vehicles

substitute an EV for one of the vehicles held by their household. Thus, even the most conservative technical constraint study concludes that a substantial percentage of U.S. households could find an EV useful in their daily travels.

Opponents of Evs often counter the promising market potentials derived from technical constraint studies with estimates of the nature and extent of the EV market based on consumer preferences. Market researchers argue that because consumers will not be willing to pay more for an EV that forfeits the unlimited driving range and fast refueling of ICEVs, the EV market will be considerably smaller than even the most conservative estimate of technical constraint studies. The results of two recent consumer surveys support such claims.

In a 1993 automotive consumer profile study, only 6 percent of 4,512 respondents indicated they definitely would consider purchasing an $\mathrm{EV}$ with a stated range of 100 miles and a top speed of $65 \mathrm{mph}$ for their next car purchase. ${ }^{11}$ The median price respondents expected to pay for an EV with a 100-mile range and top speed of $65 \mathrm{mph}$ was $\$ 14,200 \_\$ 2,200$ less than the median price they expected to pay for a new ICEV. Only 10 percent of respondents expected to pay between $\$ 20,000$ and $\$ 24,999$ for an electric four-door sedan. While no high-performance electric four-door sedans are on the market, the Japanese Cedric and Gloria sedans have anticipated near-term prices of between $\$ 179,000$ and $\$ 269,000$, or more than ten times the cost consumers would be willing to pay. The study authors concluded further that early Ev purchasers will likely be younger, more educated, and higher paid and more likely to own a foreign-made vehicle than the average car owner.

In another survey that assessed consumers' knowledge, opinions, and attitudes about EVs, three factors emerged as important purchasing considerations: initial cost, performance and range, and recharging convenience. ${ }^{12}$ The initial cost of an Ev was the most frequently cited purchase consideration. Two out of five consumers said that total ownership costs would have to be 30 cents or less per mile-compared to stated ownership costs of 33.5 cents per mile for a four-door gasoline-powered sedan-before they would consider purchasing an electric four-door sedan. Only 8 percent would be willing to pay the 40

${ }^{11} \mathrm{~J}$. D. Power and Associates, Automotive Consumer Profile Study, The Power Report (May 1993).

${ }^{12}$ Based on a national consumer and public opinion telephone survey conducted by Cambridge Reports/Research International in April 1993. Survey respondents $(n=1,250)$ were selected to represent the U.S. population 18 years old or older. See Automotive NewS, June 7, 1993, p. 1. 
cents or more per mile that Evs could cost in the near to midterm. Assuming that some Ev costs (such as maintenance) would be lower and some incentives would be applied (such as reduced license and registration fees), Automotive News calculates that the Ev market price underlying a consumer response of 28.5 cents per mile was $\$ 11,900$, or $\$ 500$ more than a 1993 Ford Escort four-door hatchback. While it is likely that most automobile consumers do not think in terms of costs per mile when considering various alternative automobiles, this finding is nonetheless discouraging from a market perspective.

With respect to performance, the median expectation for an Ev's range was 186 miles on a single battery charge, with 23 percent stating that Evs should at least match an ICEv's range of 300 miles. ${ }^{13}$ Finally, the convenience of recharging appears crucial to the Ev market: 76 percent of respondents said that they would not buy an EV until quick recharging stations became widely and publicly available.

We believe that neither the relatively optimistic market estimates reported by technical constraint studies nor the relatively pessimistic market estimates reported by consumer preference studies provide much insight into the likely size and characteristics of the near-term EV market. Technical constraint studies are only the first step in pinpointing the relatively small "niche" markets commonly associated with new technologies. Consumer preference studies about such an unfamiliar technology as Evs probably measure little more than consumers' underlying uncertainties about the reliability and stability of Ev technology itself and the relative importance of certain attributes of current ICEV technology that have previously received little consideration (for example, the value of a 300 -mile range on a single tank of gas).

Better identification of potential Ev markets will probably require some combination of both methods: sampling consumers who meet the technical constraint assumptions and then modeling those consumers' transportation needs and automobile purchase decisions to determine who will be likely to purchase an EV and why. Studies that use this approach generally conclude that consumers know relatively little about EV technology ${ }^{14}$ Using such an approach, Turrentine and colleagues found

${ }^{13}$ Despite their assertion that an EV should match an ICEV's range, other studies have demonstrated that consumers often do not actually know the range of their current ICEV.

${ }^{14}$ For example, see T. Turrentine et al., "Household Decision Behavior and Demand for Limited Range Vehicles: Results of PIREG, a Diary Based, Interview Game for the Evaluation of the Electric Vehicle Market," Institute of Transportation Studies, University of California, Davis, Calif., 1992. 
that consumers who had no previous experience with Evs reported that a test drive greatly improved their opinions about Evs. Travel logs of daily driving habits coupled with a simulation game demonstrated how participants can make knowledgeable tradeoffs to accommodate Evs into their daily schedules. Thus, the development of information and the accumulation of experience are two key processes underlying the emergence of a private EV market. Until EVs have been integrated-at least at some basic level-into mainstream traffic and the public has become familiarized with their different performance characteristics, a sizable personal consumer EV market is not likely.

Limited range and long recharging times may be significant drawbacks for personally owned Evs but not necessarily for commercial and government-owned Evs. The average daily range of most commercial and government fleets is well within the capability of current battery technology. For example, Cohen and Commoner report that the 1988 average daily mileage of federal government light-duty vehicles ranged from 25 to 50 miles. ${ }^{15}$ Mader and Bevilaqua surveyed commercial fleet operators representing 50 percent of the total U.S. market, and they determined that Evs with a 90-mile range could replace up to 283,000 , or 80 percent, of fleet vans. ${ }^{16}$ Most commercial and government fleets are centrally garaged overnight so that recharging would be both convenient and inexpensive. The limitation of high initial costs remains, but these costs can be depreciated over a shorter interval than private consumer costs. Moreover, from an environmental perspective, replacing gasoline-powered delivery and service vehicles with Evs would reduce the amount of pollution emitted by these vehicles as they stand idle in traffic or while making deliveries.

In Japan, the national government estimates that 5 percent of the 72 million vehicles expected to be in operation in 2000 would be replaceable by Evs. Light trucks and vans are predicted to constitute most of these vehicles with as much as 25 percent replaceable by EVs; EVs are expected to replace only 1 percent of passenger cars. Estimates from the Ministry of Environment in France suggest that replacing 10 percent of vehicles in that country with Evs would be an ambitious effort. The goal in

\footnotetext{
${ }^{15} \mathrm{M}$. Cohen and B. Commoner, "How Government Purchase Programs Can Get Electric Vehicles on the Road," Center for the Biology of Natural Systems, Queens College, City University of New York, Flushing, New York, 1993.

${ }^{16}$ G. H. Mader and O. Bevilaqua, "Strategies for EV Commercialization," Electric Vehicle Development Corp., Cupertino, Calif., 1989.
} 
Chapter 2

Current Barriers to the Widespread Use of

Electric Vehicles

Germany is to have 1 million Evs in operation by 2003 , or 2 percent to 3 percent of the total vehicle inventory.

High Initial Purchase Prices
The development-through-production cycle of a successful new technological commodity is typically characterized by economies of scale and economies of learning. Economies of scale are factors that enable a company or industry to produce large volumes of goods at lower prices than small volumes. These economies arise as production volume for a given time period increases-a situation that is usually the outcome of production and design standardization or high market demand or both.

Three types of factors may affect economies of scale: (1) fixed cost factors, (2) factors of external economies, and (3) technological factors. ${ }^{17}$ With respect to Evs, economies of scale would arise and prices would be reduced as (1) production startup costs and research and development costs are diffused over more vehicles, (2) manufacturers obtain lower prices on larger volumes of parts and supplies, and (3) factory and personnel efficiency are maximized. For example, in interviews with Swiss manufacturers of Evs composed of plastic resin composite materials, we learned that the molds used to form the body of the EV are very expensive. Thus, the more Ev bodies that are molded, the greater the diffusion of the original cost of the mold and, ultimately, the lower the cost to the consumer of the finished $\mathrm{EV}$. With respect to research and development costs, many of today's new EV models are presumed to subsume substantial research and development costs into their prices: a General Motors Impact is currently priced at more than $\$ 500,000$, but its ultimate price is expected to be about $\$ 25,000$.

EV prices may also be affected by economies from learning or cost reductions as cumulative output increases. That is, as the total number of units a firm manufactures increases, the number of direct labor hours required to produce a single unit decreases at a uniform rate. ${ }^{18}$ Learning economies are the result of gains in knowledge about the flexibility and constraints of the manufacturing process itself. In the Swiss example, as more $\mathrm{EV}$ bodies are molded, the manufacturer gains experience in how long the process takes, thus avoiding bottlenecks in the manufacturing process. Learning economies arise only with time and experience, and

${ }^{17}$ T. R. Howell et al., The Microelectronics Race: The Impact of Government Policy on International Competition (London: Westview Press, 1988).

${ }^{18}$ Frank J. Andress, "The Learning Curve as a Production Tool, " Harvard Business Review, January-February 1954, pp. 87-97. 
Chapter 2

Current Barriers to the Widespread Use of

Electric Vehicles

they can be a primary factor in competitively pricing a product. For this reason, a firm that acquires an early market share (cumulative volume) of a new commodity is often at a significant advantage relative to its competitors.

The automobile industry has historically achieved cost reductions as a result of these factors. A price comparison, using 1989 dollars, is illustrative. In 1907, when a total of 43,000 passenger cars were produced, their average wholesale price was $\$ 30,000$; in 1914 , when 550,000 cars were built, that price dropped to $\$ 10,000$; in 1917 , when annual production reached $1,750,000$, the price stabilized at $\$ 5,500$. $^{19}$

Currently quoted initial purchase prices and production costs for Evs vary so widely as to make them essentially meaningless for either comparative or predictive purposes. In general terms, today's Evs cost two to three times more than comparable ICEVs; future costs are expected to be about 20 percent higher.

Because vehicle and battery technology are still under development and most Evs are constructed by hand, high cost is the largest obstacle for consumers willing to purchase Evs. EV designs and production technology will continue to evolve over the next few decades. Neither standardization (design or production) nor high market demand has been achieved. This implies that EV production and price will most likely follow the path of other technology-intensive commodities, such as semiconductors and integrated circuits, which are characterized by significant economies of scale and learning.

Summary and Conclusions
We opened our discussion of barriers to widespread $\mathrm{EV}$ use with the limitations of current battery technology. EV performance is limited today by the inability to incorporate sufficient energy into a battery of reasonable weight and size. Research continues to improve upon this condition, but Evs powered by batteries will most likely always have shorter ranges and longer refueling times than comparable ICEVs.

Major infrastructure support currently not in place includes residential and commercial fleet charging facilities, public charging stations, battery recycling facilities, emergency road service, and electric service and supply. The level and type of infrastructure that is sufficient is unknown,

${ }^{19} \mathrm{M}$. Cohen and B. Commoner, "How Government Purchase Programs Can Get Electric Vehicles on the Road"; U.S. Department of Commerce, Historical Statistics of the United States, Colonial Times to 1970 (Washington, D.C.: U.S. Government Printing Office, 1975). 
but it is clear that some additional support is necessary for consumer acceptance of EVs. Gaps in EV infrastructure support can be overcome technically but will require considerable thought, time, and attention.

Many safety issues remain unresolved. Assurances of the crashworthiness of EVs converted from ICEVs and purpose-built Evs are likely to require different design solutions, testing procedures, and safety regulations. For example, fasteners and enclosures for batteries are likely to require special attention to minimize the hazards and risks associated with high voltages and reactive chemicals. The experts we interviewed universally stated that Evs should not be exempted from vehicle crashworthiness standards.

The extent of the personal consumer EV market remains uncertain. Technical constraint studies offer optimistic Ev market estimates that suggest that as many as 60 percent of U.S. households could substitute an $\mathrm{EV}$ for their current vehicle. Consumer preference studies predict that current limitations in Ev technology will restrict the private Ev market to as few as 6 percent of automobile consumers. But we believe that both of these types of studies have limited validity as forecasts of new technology markets because the constraint forecasts ignore the normal small-market development of new technological commodities and the consumer preference forecasts queried consumers who appeared to know relatively little about EV technology. Methods that use a constraints analysis to identify the potential market to be surveyed about attitudes and beliefs surrounding Evs are more appropriate in this context. Such studies find that the development of information and the accumulation of experience are two key processes underlying the emergence of a private EV market. Until EVs are integrated-at least at some basic level-into mainstream traffic, consumers will remain unaccustomed to Evs and a sizable personal consumer EV market is unlikely in the near future. However, many vehicles in corporate and government fleets travel within narrow daily ranges and are centrally garaged overnight, two facts that would accommodate current limitations in EV range and recharging.

Initial purchase costs two to three times higher than comparable ICEvs will remain the largest obstacle to consumers willing to purchase Evs. EV designs and production technology will continue to evolve over the next few decades. Neither standardization (design or production) nor high market demand has been achieved. However, if production volumes do increase, purchase prices can be expected to decline depending on the economies of scale and learning that are typical in developing and 
Chapter 2

Current Barriers to the Widespread Use of

Electric Vehicles

producing successful new technology. Nevertheless, Ev purchase prices will likely remain 20-percent higher-and could be substantially higher-than those of comparable ICEVS. 


\section{Electric Vehicle Policies and Programs}

In this chapter, we answer our second evaluation question: What are the nature and extent of industrialized nations' policies and programs to develop, produce, and promote Evs? We include programs that are conducted both nationally and locally. We found that EV programs generally encompass four main areas that we discuss in separate sections of the report. Diffusion and promotion policies include tax credits, purchase incentives, rebates, fleet purchase commitments, and other mechanisms to encourage the widespread introduction of Evs. Production efforts include industry efforts and plans as well as government goals to produce Evs. Vehicle and infrastructure demonstrations focus on field tests of $\mathrm{EV}$ performance, recharging stations, and consumer characteristics. We identified efforts ranging from multicity public demonstrations to EV rental agencies. The vehicle and battery research and development programs we discuss are primarily those sponsored by national governments.

Generally, the nations we reviewed had one or more programs that specifically addressed Evs. In some instances, particularly in the United States, programs addressed Evs within the broader context of alternatively fueled vehicles. We include these programs where appropriate but caution the reader that although such "fuel-neutral" programs are broad in scope, their ultimate effect may be affected by economic and technical issues particular to different alternative fuels. ${ }^{1}$ We begin our presentation of EV programs with table 3.1, depicting key elements of these programs: estimates of the number of Evs on the road, major initiatives for encouraging or subsidizing EV purchases, production efforts, EV and infrastructure demonstrations, and vehicle and battery research and development. Table 3.1 is followed by detailed descriptions of these key elements in each of the eight nations.

'For a more thorough discussion of alternative fuel vehicle programs, see U.S. General Accounting Office, Alternative-Fueled Vehicles: Progress Made in Accelerating Federal Purchases, but Benefits and Costs Remain Uncertain, GAO/RCED-94-161 (Washington, D.C.: July 19, 1994). 
Table 3.1: Key Elements of Electric Vehicle Programs

\begin{tabular}{|c|c|c|c|c|c|}
\hline Nation & $\begin{array}{r}\text { Number of } \\
\text { vehicles }\end{array}$ & $\begin{array}{l}\text { Purchase programs } \\
\text { and incentives }\end{array}$ & Production efforts & $\begin{array}{l}\text { Vehicle and } \\
\text { infrastructure } \\
\text { demonstrations } \\
\end{array}$ & $\begin{array}{l}\text { Vehicle and battery } \\
\text { research and } \\
\text { development }\end{array}$ \\
\hline France & 500 & $\begin{array}{l}\text { Federal purchase } \\
\text { subsidy averages } \\
\$ 3,030\end{array}$ & $\begin{array}{l}2 \text { major auto } \\
\text { manufacturers } \\
\text { producing commercial } \\
\text { and prototype EVS } \\
\text { (total planned } \\
\text { production by } 1995= \\
51,750 \text { vehicles) }\end{array}$ & $\begin{array}{l}\text { 10-city public } \\
\text { demonstration } \\
\text { program with } 20-50 \\
\text { EVs at each site }\end{array}$ & $\begin{array}{l}\text { Federally sponsored } \\
\text { battery and fuel cell } \\
\text { research }\end{array}$ \\
\hline Germany & $\begin{array}{r}1,000- \\
2,000\end{array}$ & $\begin{array}{l}\text { Free from tax for } 5 \\
\text { years; no federal } \\
\text { purchase incentives } \\
\text { identified; some } \\
\text { state subsidies (up } \\
\text { to } 30 \% \text { ) }\end{array}$ & $\begin{array}{l}2 \text { major auto } \\
\text { manufacturers } \\
\text { beginning pilot } \\
\text { production of } 100 \text { each }\end{array}$ & $\begin{array}{l}\text { Public demonstration } \\
\text { of infrastructure and } \\
\text { vehicles in Rügen } \\
\text { includes } 60 \text { vehicles }\end{array}$ & $\begin{array}{l}\text { Federally sponsored } \\
\text { lithium battery } \\
\text { research }\end{array}$ \\
\hline Italy & 400 & $\begin{array}{l}\text { Free from circulation } \\
\text { tax for } 5 \text { years; } 50 \% \\
\text { discount on } \\
\text { insurance tariffs }\end{array}$ & $\begin{array}{l}\text { Major auto } \\
\text { manufacturer has } \\
\text { produced } 400 \mathrm{EVs} \text { (no } \\
\text { public production } \\
\text { plans) }\end{array}$ & $\begin{array}{l}\text { Some small urban } \\
\text { demonstrations of } \\
\text { buses }\end{array}$ & $\begin{array}{l}\text { Federally sponsored } \\
\text { battery research }\end{array}$ \\
\hline Japan & 1,600 & $\begin{array}{l}50 \% \text { federal cost } \\
\text { subsidy; } \\
\text { some municipal cost } \\
\text { subsidies (up to } \\
50 \% \text { ); reduced } \\
\text { purchase and } \\
\text { possession taxes; } \\
7 \% \text { business tax } \\
\text { credit; subsidized } \\
\text { leasing programs }\end{array}$ & $\begin{array}{l}\text { National production } \\
\text { goals of } 200,000 \mathrm{EVs} \\
\text { by } 2000 ; 6 \text { major auto } \\
\text { manufacturers and } 3 \\
\text { utility companies } \\
\text { producing commercial } \\
\text { or prototype EVs (total } \\
\text { scheduled to be } \\
\text { produced by } 1995= \\
10,680 \text { ) }\end{array}$ & $\begin{array}{l}\text { National Ecostation } \\
2000 \text { Program; several } \\
\text { nationally and locally } \\
\text { sponsored } \\
\text { demonstrations }\end{array}$ & Lithium battery project \\
\hline Sweden & 380 & $\begin{array}{l}\$ 500 \text { purchase } \\
\text { rebate; } \\
\text { significantly reduced } \\
\text { municipal parking } \\
\text { fees }\end{array}$ & $\begin{array}{l}1 \text { major auto } \\
\text { manufacturer has } \\
\text { produced prototype } \\
\text { gas turbine hybrid } \\
\text { vehicle (no public } \\
\text { production goals) }\end{array}$ & $\begin{array}{l}\text { 3-city public } \\
\text { demonstration } \\
\text { program; Gothenberg } \\
\text { the largest with } \\
\text { short-term goal of } 200 \\
\text { EVs and long-term } \\
\text { goal of } 1,000 \mathrm{EVs}\end{array}$ & $\begin{array}{l}\text { Primary funding focus } \\
\text { is electric drive } \\
\text { systems and } \\
\text { quick-charge } \\
\text { infrastructure }\end{array}$ \\
\hline Switzerland & 1,000 & $\begin{array}{l}\text { No federal purchase } \\
\text { incentives identified }\end{array}$ & $\begin{array}{l}2 \text { small auto } \\
\text { manufacturers } \\
\text { producing unique, } \\
\text { lightweight EVs (no } \\
\text { public production } \\
\text { goals) }\end{array}$ & $\begin{array}{l}\text { Urban EV rental and } \\
\text { repair shops; annual } \\
\text { Tour de Sol EV races } \\
\text { and exhibit }\end{array}$ & $\begin{array}{l}\text { Small federal budget } \\
\text { to support safety and } \\
\text { crash testing of } \\
\text { Swiss-manufactured } \\
\text { lightweight EVs }\end{array}$ \\
\hline
\end{tabular}




\begin{tabular}{|c|c|c|c|c|c|}
\hline Nation & $\begin{array}{r}\text { Number of } \\
\text { vehicles }\end{array}$ & $\begin{array}{l}\text { Purchase programs } \\
\text { and incentives }\end{array}$ & Production efforts & $\begin{array}{l}\text { Vehicle and } \\
\text { infrastructure } \\
\text { demonstrations }\end{array}$ & $\begin{array}{l}\text { Vehicle and battery } \\
\text { research and } \\
\text { development }\end{array}$ \\
\hline United Kingdom & 25,000 & $\begin{array}{l}\text { Exemption from road } \\
\operatorname{tax}(\$ 150)\end{array}$ & $\begin{array}{l}\text { Major auto } \\
\text { manufacturer has } \\
\text { produced } 475 \mathrm{EVs} \text { (no } \\
\text { public production } \\
\text { plans) }\end{array}$ & $\begin{array}{l}\text { No demonstration } \\
\text { programs identified }\end{array}$ & $\begin{array}{l}\text { No federally funded } \\
\text { research and } \\
\text { development identified }\end{array}$ \\
\hline United States & 1,000 & $\begin{array}{l}\$ 4,000 \text { federal tax } \\
\text { credit for fleets; } \\
\text { some state programs } \\
\text { with incentives or } \\
\text { alternative fuel fleet } \\
\text { requirements; } \\
\text { California-type } \\
\text { mandates ( } 6 \text { states) }\end{array}$ & $\begin{array}{l}3 \text { major auto } \\
\text { manufacturers } \\
\text { produce small } \\
\text { numbers of EVs (total } \\
\text { planned production = } \\
180 \text { vehicles) }\end{array}$ & $\begin{array}{l}\text { Small fleet } \\
\text { demonstrations; some } \\
\text { small public } \\
\text { demonstrations with } \\
\text { commuter cars or } \\
\text { buses }\end{array}$ & $\begin{array}{l}\text { U.S. Advanced } \\
\text { Battery Consortium }\end{array}$ \\
\hline
\end{tabular}

Several points are to be considered when reviewing these elements. Data on the number of vehicles on the road can be difficult to obtain and validate. We present estimates gathered from three general sources: national ministries of environment, energy, or the like; supranational organizations such as OECD; and EV advocacy and support groups such as CITELEC. We note the instances in which we found discrepancies. No precise or standard definition has been established for "electric vehicle." Therefore, national estimates of the number of Evs on the road may vary depending on the types of vehicles included. For example, the total number of Evs can include vehicles that are converted from ICEVs at relatively low prices or very small golf-cart-like Evs used in resort areas. For example, most of the 25,000 Evs in the United Kingdom are slow-moving milk delivery vans.

We reiterate that production and price details are proprietary; often, little support for such information exists publicly. In particular, the paucity of data on manufacturer costs and consumer prices inhibits any meaningful comparison of different EVs. That is, while costs may range from $\$ 19,000$ to more than $\$ 350,000$ for an EV van, we are unable to speak directly and conclusively to the reasons behind these differences. Generally, Ev prices vary as a result of their level of technological sophistication and whether and how much they include research and development costs. Many manufacturers are developing Evs, and our review of production efforts is not meant to be comprehensive. We present information on some of the larger and more unique programs; however, we do not include a large number of small entrepreneurs, particularly in the United States, who are producing converted Evs. 


\section{Status of Diffusion and Promotion Policies}

United States
Here we discuss initiatives at both the national and regional levels to support the purchase of Evs. Typically, these might include tax exemptions and credits, purchase rebates, fleet purchase commitments, and laws mandating production.

The United States has about 1,000 Evs on the road. The federal government offers a tax credit of up to $\$ 4,000$ for the purchase of Evs, and some states also have tax credits and purchase incentives. Most Evs in the United States today are conversions in which the traditional internal combustion engine has been removed and replaced by a battery. Approximately 200 limited-production vehicles are expected to undergo field testing in 1994.

At present, the primary force for developing lower-emission vehicles in the United States and abroad stems from the California Low Emission Vehicle Program, which prescribes the maximum emissions permitted from new vehicles sold in that state. Lower vehicle emission requirements are part of California's overall strategy for reducing regional air pollution-a general goal of the federal Clean Air Act Amendments of 1990. The legislation requires that, in 1998, 2 percent of all new cars marketed in that state by large-volume manufacturers be zero-emission vehicles; the percentage increases in subsequent years to 10 percent in 2003 . The legislation does not specifically mandate that these zero-emission vehicles be electric. In practical terms, however, the Ev is the only current transportation technology that emits no source pollutants. ${ }^{2}$

This mandate has been weakened from its original form in which manufacturers were required to sell, not simply supply, zero-emission vehicles. The California mandate in its new form has been adopted in some form by five other states in the Northeast: Maine, Maryland, Massachusetts, New Jersey, and New York. Other northeastern states may follow shortly. It is estimated that 20 percent of the entire U.S. new car market is presently covered by these mandates, a figure that could rise to 33 percent as states that have announced their intention to adopt such standards pass the necessary legislation. ${ }^{3}$ In 1998 , as many as $70,600 \mathrm{EVs}$ may be required; in 2003 , that figure rises to 353,600 with a total accumulation of $919,200 \mathrm{Evs}$.

\footnotetext{
${ }^{2}$ Hydrogen fuel cell vehicles would also emit no source pollutants since their primary byproduct is water. However, fuel cell vehicles will not be available by 1998 .

${ }^{3}$ Vehicle sales in these states are a disproportionately large portion of all vehicle sales in the United States.
} 
In general, the state programs and policies we identified can be divided into four distinct categories: (1) laws mandating that automobile manufacturers produce a certain percentage of Evs for sale (as in California); (2) laws providing financial incentives for purchasers of alternatively fueled vehicles, including Evs; (3) laws that require that new state fleet purchases be alternatively fueled vehicles, including EVs; and (4) demonstration programs to develop and assess vehicles and infrastructure. ${ }^{4}$ See appendix II for additional information on these state programs.

State officials indicated that mandated fleet conversion legislation often did not have sufficient power to ensure the purchase of alternatively fueled vehicles, especially Evs. In particular, it was noted that legislation authorizing incentives sometimes remains unfunded, and laws may identify reformulated gasoline and low-sulfur diesel fuels as "alternative" fuels that can power current vehicles without any conversions.

At the national level, the Energy Policy Act of 1992 requires the federal government to purchase 22,500 alternatively fueled vehicles between 1993 and 1995. Beginning in 1996, requirements to purchase a certain number of alternatively fueled vehicles are replaced by requirements to purchase a certain percentage of these vehicles: from 25 percent of new federal fleet purchases in 1996 to 75 percent in 1999 and thereafter.

The act also mandates alternatively fueled vehicle purchase percentages beginning in 1996 for state fleets and fleets operated by organizations that make and sell alternative fuels. The secretary of DOE will then determine by December 1996 and again by January 2000 whether additional fleet requirement programs for municipal and private fleets are necessary to achieve the motor fuel displacement goals of the act-10 percent by 2000 and 30 percent by 2010 . Fleets that wait until the later DOE rulings will be required to purchase alternative fuel vehicles (AFvs) at a more accelerated pace than those that begin purchasing AFvs following the first ruling. Currently, 11 cities and 12,000 vehicles are participating voluntarily in the Clean Cities program; a total of 25 cities and 70,000 vehicles is anticipated by the end of 1994 .

The other primary considerations for the rulemakings as outlined in the Energy Policy Act include whether there exist sufficient fuel supplies and needed infrastructure in fleet areas subject to the rule as well as whether

${ }^{4}$ These legislative initiatives were identified and reported by the Electric Transportation Coalition through October 11, 1993. 
Chapter 3

Electric Vehicle Policies and Programs

there will be sufficient number of new AFvs from original equipment manufacturers. Fleet owners will not be required to purchase converted vehicles, even if there are no purpose-built vehicles yet available. Moreover, the possibility still remains that DOE may determine during its rulemaking that reformulated gasoline should be treated as an alternative fuel for municipal and private fleet vehicles. If so, it is likely that many of these fleets would opt to use reformulated gasoline in lieu of more costly alternatives that require conversion equipment.

In April 1993, an executive order (E.O. 12844) committed the federal government to a 50-percent increase in purchases of alternatively fueled vehicles for a total of 33,750 from 1993 to 1995. Appropriations for the incremental costs associated with purchasing AFvs for the federal fleet program for 1994 were $\$ 18$ million; DOE requested $\$ 30$ million for 1995 but will receive only $\$ 20$ million. The 10,200 AFvs in the federal fleet are currently divided fairly evenly between natural gas and alcohol-based fuels (ethanol and methanol). The 1995 goal for federal fleet purchases is 15,000 alternatively fueled vehicles. GSA will purchase 9,000 vehicles; plans include 6,400 natural gas vehicles, 1,600 methanol vehicles, 1,000 ethanol vehicles, 100 liquid petroleum gas vehicles, and no electric vehicles.

Federal officials overseeing the program advised that the varying levels of commercialization of these AFVs are the primary reasons for the balance of vehicle types planned for the federal fleet. Thus, as in the state programs we reviewed, the lower availability and higher costs to convert to Evs limit the likelihood that fleets will choose electricity from a broader array of less expensive and more convenient alternatives. ${ }^{5}$ Moreover, these findings suggest that the fuel-neutral intent of congressional legislation as demonstrated in the Energy Policy Act may be limited by the inability of its programs to provide equitable support or cost-sharing for all alternative fuels.

Furthermore, the future of state-legislated mandates remains uncertain. U.S. automobile manufacturers generally oppose such mandates because they believe that $\mathrm{EV}$ technology is not sufficiently mature for widespread implementation. The industry agreed in October 1993 to a Partnership for a New Generation of Vehicles (PNGV) with the federal government to

${ }^{5}$ The life-cycle prices to own and operate different AFVs appear to cover a wide range. For example, the breakeven price of gasoline (the retail gasoline price that equates the full life-cycle cost per mile of the AFV with that of a gasoline ICEV) could be as high as $\$ 4.80$ for EVs. That is, gasoline would need to cost $\$ 4.80$ per gallon before an EV could be competitive with a gasoline ICEV. It could be as low as $\$ 1.70 \$ 1.90$ for methanol and compressed or liquid natural gas vehicles. (Sperling, Deluchi, and Wang, 1991). 
develop the "clean car of the future. ${ }^{\text {" }}$ Reports suggest that industry is prepared to accelerate its production of alternatively fueled vehicles if the northeastern states abandon versions of the California mandate.

The technical goal of PNGV is to develop a range of technologies that will improve the efficiency and reduce emissions of standard vehicles, such as technologies that reduce vehicle weight, improve aerodynamics, or improve the efficiency of accessories such as air conditioning. Its economic goal is to promote competitiveness by developing and introducing manufacturing technologies and practices that will reduce the time and cost associated with designing a new vehicle and bringing it to the marketplace. PNGV's long-term goal is the development of a vehicle that will be up to three times more fuel efficient than today's vehicles (up to 80 mpg) but that (1) costs no more to own and operate; (2) offers comparable characteristics relating to performance, spaciousness, and utility; and (3) meets or exceeds all safety and emissions requirements.

The initiative will pursue simultaneously the development of a number of possible technologies. The five primary areas of focus are advanced lightweight materials; energy conversion, such as gas turbines, fuel cells, and advanced diesel engines; energy storage devices, such as batteries, flywheels, and ultracapacitors; more efficient electrical systems; and exhaust recovery systems. ${ }^{7}$

The concept vehicle is planned for development before 2001 and a production prototype is planned for development during 2002-2004. While it is too early to know if and how Evs will be included in PNGV, they will again be competing with a broad array of alternative fuels and energy conversion devices.

In short, while EVs are included in broader AFv initiatives, no federal plan has been implemented in the United States that is specifically designed to diffuse and promote Evs. Actions are limited to state legislation of various

${ }^{6} \mathrm{PNGV}$ is headed by the Department of Commerce and includes government officials from the Department of Transportation, the Environmental Protection Agency, the Department of Energy, the Department of Defense, the National Aeronautics and Space Administration, and the National Science Foundation. Industry participation is coordinated through the vice presidents for research, development, and testing at the three major U.S. automobile manufacturers and the U.S. Council for Automotive Research. The program plans to include initiatives targeted to independent contributors, such as universities and private inventors.

${ }^{7}$ Fuel cells combine hydrogen from fuel with oxygen from air to produce energy, heat, and water. Flywheels provide energy by means of momentum. Ultracapacitors are electrical devices that could serve as peak-power sources for EVs. 
development of the infrastructure needed to make Evs more attractive to those consumers. The fourth phase of the program extends beyond 2001, when the government's goal is to have an autonomous demand for Evs. Planned production for the next 8 years is shown in table 3.2.

Table 3.2: Japan's Electric Vehicle Production Goals

\begin{tabular}{lr}
\hline Year & Number of units produced \\
\hline 1993 & 1,400 \\
\hline 1994 & 4,000 \\
\hline 1995 & 7,000 \\
\hline 1996 & 10,000 \\
\hline 1997 & 14,000 \\
\hline 1998 & 25,000 \\
\hline 1999 & 55,000 \\
\hline 2000 & 100,000 \\
\hline
\end{tabular}

Source: Machinery and Information Industries Bureau, Japanese Ministry of International Trade and Industry.

However, according to one Ministry of International Trade and Industry (MITI) official we interviewed, the more important intent of the council's current plan is not to have produced a targeted number of evs by 2000 but to have developed a consensus that allows the identification of desirable research and development activities for industry to pursue. The plan assumes that if certain technological targets were met, the demand for evs in Japan would expand. Technical goals include a range of about 155 miles at $25 \mathrm{mph}$ (current performance is 75 miles), a top speed of $75 \mathrm{mph}$ (current speed is $50 \mathrm{mph}$ ), a battery life of 4 years (current life is 1-1/2 to 2), and a cost 1.2 times a comparable ICEv's (current cost is three times an ICEV's).

Municipal governments throughout Japan have committed to fleet purchases in a move toward both popularizing EVs and reducing production costs. At the national level, MITI subsidizes 50 percent of the price of EVs with a budget limit of $\$ 910,000$ per year. In its 5-year plan (1992-96) to popularize EVs, MITI has also given $23 \mathrm{EVs}$ to three companies as a way to develop vehicles for road use. MITI has asked the New Energy and Industrial Technology Development Organization (NEDO) to conduct the program (budgeted at $\$ 29,090$ for fiscal year 1993), which will monitor Ev use. ${ }^{8}$ The plan also includes quick-recharging stations for each company for use both day and night. MITI will incorporate results from the project

${ }^{8}$ NEDO is a public corporation under MITI's Agency of Natural Resources and Energy. 
into its Ecostation 2000 plan, which we discuss below. Japan's Environment Agency also provided subsidies to local governments to buy low-emission vehicles with a $\$ 645,000$ budget in fiscal year 1992 . Tax incentives include reduced taxes when the vehicle is purchased and reduced annual possession taxes. Businesses may receive a 7-percent tax credit or a 30-percent depreciation allowance on EV purchases. However, officials from the Japan Electric Vehicle Association (JEVA) noted that tax credits are not a major incentive because EV batteries are heavy and some taxes are based on vehicle weight. Consequently, the taxes on Evs are typically higher than those on a lighter ICEV and the tax credit brings the ultimate cost close to that of an ICEV.

MITI established JEVA in 1976 to promote the research and development of Evs. Partially funded by MIT, it consists of 110 private businesses and organizations, including automobile manufacturers, public utilities, and battery companies. JEVA's fiscal year 1990 budget was $\$ 348$ million with $\$ 130$ million of that total received in the form of subsidies from public organizations. One of JEVA's primary activities is its Ev leasing project. Since the project began in 1978, JEVA has leased more than 400 EVs to local governments and private organizations throughout Japan. Currently, JEVA counts about 300 units in its program. The Environment Agency also leases EVs to businesses free of charge to identify areas for which Evs are best suited.

Locally, the Tokyo metropolitan government leases Evs to businesses as a way to popularize them. As of May 1993, 123 vehicles had been leased. The government also subsidizes 50 percent of the cost of EV purchases; $5 \mathrm{EVS}$ have been bought through the program. In total, Tokyo has 462 AFvs, including 279 Evs and 12 hybrids. Tokyo's fiscal year 1993 budget allocated $\$ 1.5$ million in EV purchase subsidies. Saitama prefecture has a 3-year plan (1993-95) to purchase 15 Diahatsu EV vans, provide Evs free of charge to its 92 cities and towns, and subsidize Ev leases for private corporations. Aichi prefecture, at the center of Japan's automobile industry, has a similar plan to increase its Evs from the present 26 to 100. 1,000 and 2,000 Evs are on the road in Germany today. Evs are free from taxes for 5 years. The federal government offers no financial purchase support for Evs. Officials from the environment and transport ministries stated that the federal government is not actively supporting Evs. Some local regions in Germany are actively promoting evs. Hamburg has $\mathbf{7 0}$ 
prescriptive types, some limited financial incentives, and, especially, research on new battery development funded partially by DOE. from about 1,285 in March 1992. During fiscal year 1991, 357 units were produced, and during fiscal year 1992, between 500 and 600 EVs were produced. Japanese officials cite current technical limitations and high cost as reasons why they do not foresee a large, immediate personal consumer Ev market in their own country since (unlike the United States) most Japanese families own only one car that they use for both short trips and long-range driving. The Japanese automobile manufacturers do, however, plan to market in the United States.

However, in October 1991, the Electric Vehicle Council of Japan announced its Long-Term Program for Market Expansion of Electric Vehicles, with a target of 200,000 Evs on the road in Japan by 2000. This plan is the third EV market expansion program developed by the council. The council's first plan was devised in 1977 and revised in 1983 with a target date of 1990. The current plan has expanded the goals and extended the time.

In its third plan, the council aims not only to have 200,000 Evs on the road by 2000 but also plans a progressive increase in production to achieve a 100,000 annual production rate by 2000 . To promote expansion, the program is divided into four phases. The aim of the first phase (1991-93) was to introduce Evs into national and municipal government agencies and, in parallel, to enhance technological improvements of Evs in terms of performance and quality. Promotion measures include financial supports such as subsidies, tax incentives, or financial assistance, as well as the construction of an extensive recharging and maintenance infrastructure to enhance public acceptance of Evs.

The second phase (1994-97) focuses on the public utilities for water, gas, and electricity and other private delivery and service companies that can use them for most applications and that are expected to take a leading role in environmental protection efforts. Such large-scale introduction of Evs is expected to create broad public demand for Evs as well as drive down production prices.

The third phase (1998-2000) targets ordinary consumers as Ev purchasers with heavy emphasis on mass production to reduce costs and on 
registered Evs and at least one public charging station and some German states (Bavaria and Baden-Württemberg) provide financial support up to 30 percent of an Ev's purchase price. RWE Energie AG, a battery company located in Essen, has provided $20 \mathrm{EV}$ vans through a leasing program to city authorities in which an EV van can be leased for the same price as a conventional vehicle.

\section{France}

OECD estimates that France has $500 \mathrm{EVs}$ on the road today. In 1991, the French Agency for Environment and Energy Management (ADEME) created a special fund to subsidize the purchase of the first 1,000 Evs by local communities. Total funds amounted to $\$ 3$ million, or an average of $\$ 3,030$ per vehicle. However, the program has not been as successful as expected. The agency earmarked only $\$ 404,000$ for the program and, as of September 1992 , had spent only $\$ 242,000$. It is not clear whether this is the result of a lack of available funds, a lack of consumer interest, or an inability to locate Evs in sufficient numbers.

\section{Switzerland}

Today, approximately 1,000 Evs are in use in Switzerland, which has the largest number of Evs per capita in Europe. In addition, 8 resort areas are closed to all traffic except Evs, where approximately 500 low-speed vehicles are in use. The Swiss government does not offer Ev purchase incentives. The original impetus for Evs came from the Ministry of the Interior, which declared a goal of 200,000 Evs in Switzerland by 2010 . The Tour de Sol, an internationally recognized race for solar and lightweight Evs, and the Electric Vehicle Grand Prix are held every year in Switzerland and contribute substantially to the promotion of Evs.

Sweden has approximately $380 \mathrm{Evs}$ on the road today. In an effort to reduce transportation-related pollution, Sweden has instituted a three-tiered rebate program for new cars: purchasers of class I cars (equivalent to California 1996 emissions standards) receive about $\$ 550$ in rebates, purchasers of class II cars (equivalent to U.S. federal 1994 standards) receive no rebate, and purchasers of class III cars (equivalent to current U.S. federal standards) must pay an additional $\$ 275$. Evs are considered class I vehicles. 
falling, however, as supermarket purchases encroach on home milk deliveries. In 1989 , approximately 25,000 Evs were in use: 33 were electric buses, 25,138 were goods and delivery vans, and 79 were passenger automobiles. Evs receive a road tax exemption of about $\$ 150$.

Italy

Officials in Italy estimated that about 400 Evs were registered in 1993. Most of these vehicles are converted ICEVS. EVs in Italy are free from circulation (transportation or traffic) tax for the first 5 years and discounted 50 percent on insurance tariffs. The Lombardia region of Northern Italy has proposed legislation to contribute 30 percent of the total cost of EVs with the intention to subsidize a yearly market of 1,000 Evs.

\section{Major Production Efforts}

In this section, we discuss what we learned about major international EV production efforts. Since production plans are often proprietary, limited information was available in some instances on these efforts.

Chrysler delivered five Dodge Caravan Evs to utilities on the East Coast in April 1993, making Chrysler the first of the major U.S. auto manufacturers to reach the market in 1993. In prototype, the car is officially known as the Chrysler TEVan, but all 50 evs planned for 1993 were to be based on the Dodge Caravan and sold through Dodge dealers who were also to provide service. Priced at $\$ 120,000$, the car is powered by a nickel-iron battery and a 65-horsepower DC motor with a range of 80 miles on a charge and a top speed of $70 \mathrm{mph}$. (Chrysler announced in March 1994 that 1994 prices for the TEVan would be reduced by 15 percent to $\$ 100,000$.) Chrysler's cost is estimated at $\$ 250,000$ to $\$ 300,000$ per vehicle.

As late as April 1993, Ford still planned to deliver 81 Ecostar minivans to U.S., Mexican, and European utilities in August of that year. However, Ford announced shortly thereafter that foreign manufacturers (in Germany and the United Kingdom) were unable to supply sufficient numbers of sodium sulfur batteries. Thus, delivery of the complete vehicles would be delayed indefinitely. In November 1993, the first six demonstration Ecostars were delivered to fleets in six U.S. cities. Nine of the 81 vans-all for the California Air Resources Board (CARB)-are planned to be hybrid vehicles. That is, they will be fitted with small gasoline engines to drive the generator that will increase the range of a van. The 72 others will be pure Evs. Prototype Ecostars have a range of 95 miles and a top speed of $70 \mathrm{mph}$. In the past, Ford leased the Ecostar for 
In 1990, General Motors unveiled the Impact, a sports car purpose-built prototype slated for large-scale production in 1993. The Impact uses lead acid batteries and has a range of 50 to 70 urban and 70 to 90 highway miles, has a top speed of 75 miles per hour, and accelerates to $60 \mathrm{mph}$ in 8.0 seconds. It will cost the equivalent of about $\$ 3.00$ per gallon of gasoline to own and operate the Impact, and its retail price when it finally reaches the showroom is expected to be $\$ 25,000$ or more. The car features several innovations to offset the considerable weight of its battery $(1,100 \mathrm{lbs})$, such as an aluminum body structure 40-percent lighter than steel, and magnesium seats that reduce mass by 64 percent. In addition, its aerodynamic drag coefficient (.19) is 30-percent better than that of current cars; its tires roll with a resistance 25-percent lower than current tires; and its heat pump both heats and cools, using an environmentally benign refrigerant. (See figure 3.1.) 
Chapter 3

Electric Vehicle Policies and Programs

Figure 3.1: Energy Efficiency

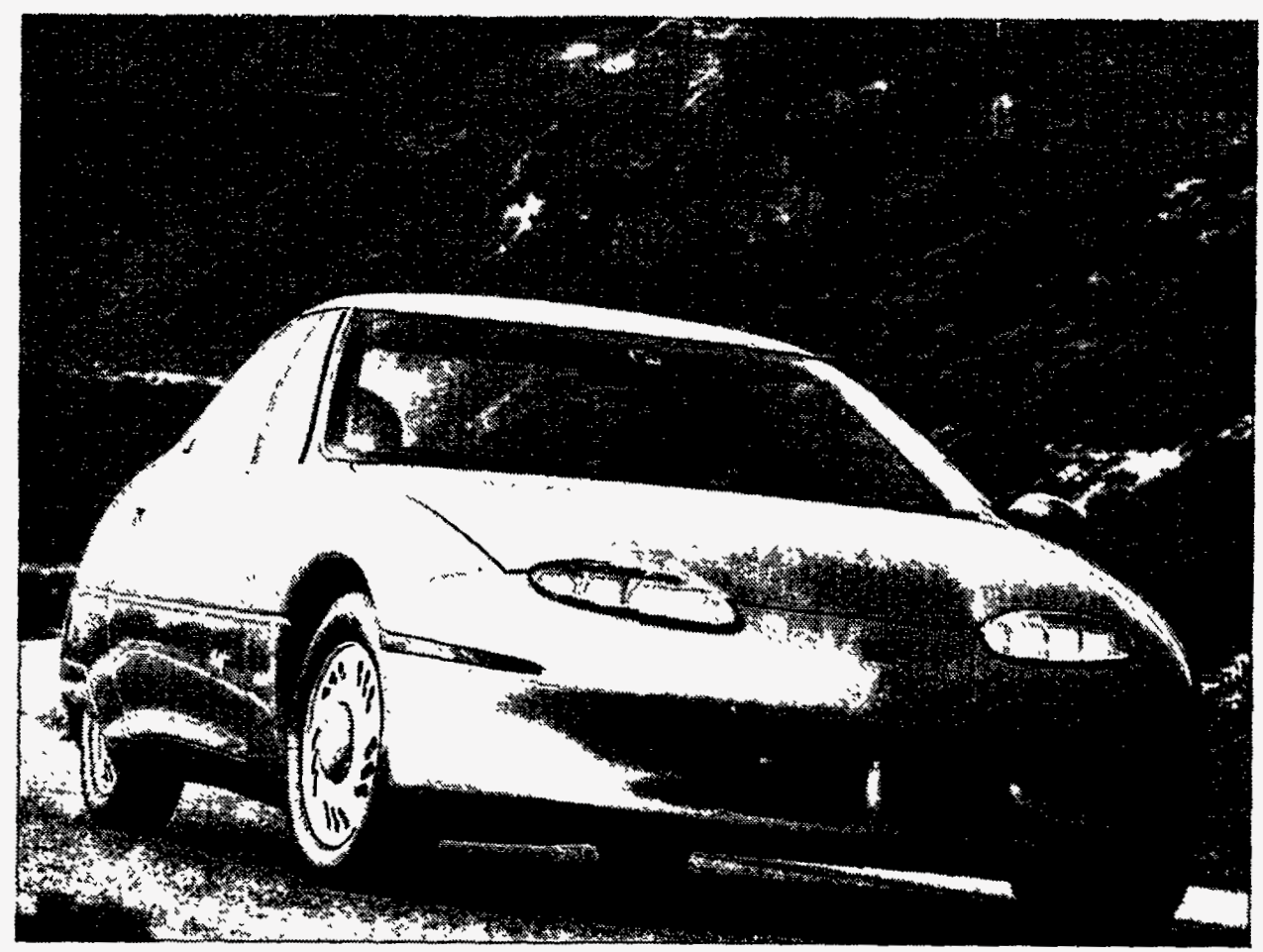

Note: The GM Impact is aerodynamically designed to improve energy efficiency.

However, citing market and profit concerns, General Motors determined about 18 months later, in December 1992, that it would not mass produce the Impact. Recently, General Motors modified this decision with the announcement of the $\$ 30$ million PrEView Drive Program to produce 50 test Impacts. Early plans suggest that the vehicles will be deployed for 2 years in 12 U.S. regions where more than 1,000 private motorists will have the opportunity to drive the cars for 1 to 2 weeks. While the project appears to focus mostly on assessing market potential, performance data will also be collected by onboard data collection systems. The $\$ 30$ million price for the 50 Evs includes the cost of installing (and removing) recharging capabilities at the proposed test sites. DOE officials stated that one of General Motors' major interests is in the capability of its own Hughes inductive coupler, a recently introduced recharging technology that will most likely vie for market acceptance along with more traditional plug-in rechargers. 

customer orders. Suzuki, Toyota, Daihatsu, and Isuzu have all produced models for sale, and Nissan and Mitsubishi soon plan mass production based on orders from govermment agencies and private corporations. Electric utilities and research organizations have also developed their own prototypes.

Nissan has introduced its prototype two-door coupe, the Future Electric Vehicle, powered by nickel cadmium batteries with a range of 155 miles at $25 \mathrm{mph}$ (100 at $45 \mathrm{mph}$ ), a top speed of $80 \mathrm{mph}$, and an acceleration with two occupants of 0 to $25 \mathrm{mph}$ in 3.6 seconds. This $\mathrm{EV}$ is highly aerodynamic with a drag coefficient matching the Impact's 0.19 . Nissan states that the vehicle can receive a rapid recharge to 40 percent of battery capacity in 6 minutes. It was developed in consortium with Japan Storage Battery over 18 months at an estimated cost of $\$ 897,000$.

Nissan also produces the Cedric EV and the Gloria Ev. Both are powered with sealed lead acid batteries developed by Japan Storage Battery and have a range of 75 miles at $25 \mathrm{mph}$, a top speed of about $60 \mathrm{mph}$, and a recharging time of 5 hours. Nissan began leasing the sedans to central government agencies in February 1993 and plans to sell 50 in December 1993 to the Environment Agency; local governments in Tokyo, Osaka, and Nagoya; electric power companies; and other large corporations. Planned prices are between $\$ 179,000$ and $\$ 269,000$ for each EV.

Toyota has sold 42 Townace passenger vans to Chiba and Osaka prefectures, Hirakata City, Sumida ward, Tokyo, and Kawasaki City. The vans sold for $\$ 71,700$ without recharging equipment, and all purchases were subsidized by the Environment Agency. The Townace is powered by lead acid batteries with a range of about 100 miles at $25 \mathrm{mph}$, a top speed of $68 \mathrm{mph}$, and an acceleration of 0 to $25 \mathrm{mph}$ in 6.5 seconds. Toyota is also developing the Crown Majesta passenger van, to be powered by a sealed lead acid battery with performance characteristics similar to the Townace. Two test vans were due in 1993, and Toyota plans to lease the vans to municipal governments.

The Daihatsu Hijet, a light van, appears to be the most widely used Ev by businesses and government. Daihatsu is the only known manufacturer with a production line dedicated to Evs. (However, Daihatsu currently produces the EVs by hand, since the relatively low volume of cars does not warrant using the production line.) Daihatsu has developed its own 
production schedule and expected to produce $400 \mathrm{Evs}$ in fiscal year 1993. The Hijet is powered by a lead acid battery with a range of about 80 miles at $25 \mathrm{mph}$ and a top speed of about $50 \mathrm{mph}$. In past years, Daihatsu has produced about 300 vans per year for local governments, utility companies, and large corporations. OECD reports that Daihatsu sells the vans for $\$ 19,730$ and has announced plans for annual production of 10,000 by 1995 . MTI officials quoted a consumer price of about $\$ 36,400$, and Daihatsu officials told us they sell the van for about $\$ 27,300$. We were unable to reconcile these different price quotes but assume that they reflect, in part, the inclusion (or exclusion) of government purchase subsidies discussed in the previous section.

Mitsubishi produces the Libero Ev, a light cargo van powered by either lead acid or nickel cadmium batteries. Its range is 100 miles at $25 \mathrm{mph}$ with lead acid and 155 miles at $25 \mathrm{mph}$ with nickel cadmium; top speed is about $80 \mathrm{mph}$, and recharging time is 8 hours. Mitsubishi delivered 28 vehicles to TEPCO power company in the first half of 1993 and plans mass production based on government orders of 40 to 50 vehicles in the first year and annual production of 100 shortly after. The Libero is priced at $\$ 89,700$ for the lead acid version and $\$ 161,500$ with a nickel cadmium battery.

Mazda has unveiled the Roadster Ev based on the U.S. two-seater MX-5 model. The Roadster EV uses nickel cadmium batteries and has a range of 112 miles at $25 \mathrm{mph}$, a top speed of $80 \mathrm{mph}$, and an acceleration of 0 to 25 in 4.2 seconds. The company has produced three vehicles for a 2-year road test in cooperation with its development partner, Chugoku Electric Power Company.

Several electric utility companies in Japan have developed their own Evs. The most notable example is the TEPCO IZA, a two-door coupe that uses nickel cadmium batteries, which holds the reported world records for range ( 340 miles at $25 \mathrm{mph}$ ) and top speed (109 $\mathrm{mph}$ ). The IZA can accelerate to a distance of one fourth mile in 18 seconds. MTT has chosen the IZA as its own Ev test car. acid batteries. The Citistromer's top speed is about $65 \mathrm{mph}$ with a range of 75 miles and a price of $\$ 42,700$. Volkswagen is working with ASEA Brown Boveri (ABB), one of Germany's large battery manufacturers, to develop a sodium sulfur version for additional range. Citistromers have been 
purchased and delivered to Sweden for its three-city demonstration program. The Citistromer II is also priced at $\$ 42,700$ and is based on the Golf model. With lead acid batteries, the car has a range of 35 to 50 miles and a top speed of $62 \mathrm{mph}$. Volkswagen is also working on a parallel hybrid, nickel cadmium version of the Golf.

Citing the California market, BMW recently announced its E-1 and E-2 models, which will have the option of being delivered with a sodium sulfur battery that accelerates from 0 to $30 \mathrm{mph}$ in 6 seconds, travels for 135 miles at $30 \mathrm{mph}$, and has a top speed of $75 \mathrm{mph}$.

Mercedes Benz has electrified its 190E four seater with sodium nickel chloride batteries that recharge in 12 hours. Its range is about 110 miles at a constant speed of $30 \mathrm{mph}$ and a top speed of $75 \mathrm{mph}$. In March 1994, Mercedes Benz announced that it would manufacture the Swatchmobile, a concept car developed by Swatch, a leading Swiss watch manufacturer. The two-seater vehicle is expected to be ready for testing by 1996 and is anticipated to be less than 10 feet in length, demonstrate crashworthiness, and cost under $\$ 10,000$. car, the CITELA, which it hopes to launch by the end of the decade. According to expectations, the CITELA's engine will last 620,000 miles and its nickel cadmium battery life is 10 years. The car's maximum speed is 68 $\mathrm{mph}$ (continuous maximum speed is about $55 \mathrm{mph}$ ), and it can travel about 130 miles between charges when operated continuously at $25 \mathrm{mph}$, about 70 miles under regular urban driving conditions. The CITELA's price has not been announced, but PSA expects that at mass production levels, its price would be about 10 percent more than equivalent ICEVs. The company's president has stated publicly that mass production would be possible only with financial assistance from the French government.

PSA has also announced production goals of the electric series-which are vans retrofitted with lead acid batteries-of 10,000 in 1997 at a cost $\$ 3,500$ more than an equivalent ICEV. PSA has the only production line that can accommodate both ICEVs and EVs. They estimate that they would need to sell a series of 50,000 Evs to break even on the project. Although officials in France noted that Peugeot would produce these vehicles only if they have a viable market, we were informed that the company has taken the initial steps to production, including preliminary negotiations with battery and engine suppliers. PSA's long-term objective is to produce and 
market 50,000 urban fleet Evs with advanced batteries at sales prices equivalent to and operating costs lower than those of ICEVS.

To date, about 600 vehicles have been produced; customers include 17 French cities, 8 other European countries, and Hong Kong. Beginning in 1995, PSA plans to commercialize several thousand EVs for fleets and private consumers. PSA is also developing a coupe model for French demonstration projects beginning in 1995. Long-term development projects include generating electric energy by a gas turbine driving a turbogenerator at high speed.

Renault's strategy for Evs is based on three types of goals: (1) marketing utility Evs derived from existing fleet vehicles, (2) developing partnerships with other European industries and research firms, and (3) commercializing passenger vehicles in 1994 followed in 1995-96 with purpose-built Evs. ${ }^{10}$

Renault has produced 50 to 100 Master and Express vans with either lead acid or nickel cadmium batteries. Renault recently delivered some of these EVs to Sweden for its three-city demonstration project. Swedish EV program officials reported that they purchased Renault vans powered by nickel cadmium batteries at the price of about $\$ 40,000$, or about a third of the selling price of the least expensive U.S.-produced electric van.

Renault is also preparing an electric version of the Clio for production in 1995 and general sale in 1996 with an annual production volume of 1,000. The Zoom, a purpose-built EV in prototype, is currently under development with the manufacturing firm, Matra. Its nickel cadmium battery provides about 90 miles of range and a top speed of $75 \mathrm{mph}$. The batteries require 8 hours for a complete recharge but can be charged to 80 percent of capacity in 2 hours.

SEER, a component manufacturer, has produced more than 50 Volta vans powered by lead acid batteries and sold at a reported price of $\$ 22,700$ to municipal corporations, which receive a subsidy of $\$ 2,730$. officials estimate that 20 small manufacturers and importers offer two-seat

${ }^{10}$ Renault cooperates with battery manufacturers (Italy's CEAC and FIAMM, France's SAFT, and Germany's ABB), engine and electronics manufacturers (Germany's ABB, Siemens, and Magnet Motor), and research laboratories and institutes (EUREKA programs and the National Polytechnic Institute in Grenoble, France). 
compact Evs on the Swiss market. The prices for these vehicles are between $\$ 12,580$ and $\$ 24,820$, or 50-percent to 100 -percent higher than prices for corresponding ICEVs. The Swiss cars are unique in that a large majority are specially designed as Evs and are made primarily from lightweight, high-strength plastic resins.

Horlacher produces two EV models and has several others in development. The Horlacher Sport is a purpose-built, two-door coupe powered by sodium sulfur batteries. ${ }^{11}$ The Sport is reported to have a range of 185 to 310 miles, depending on driving conditions and speed, a top speed of 77 $\mathrm{mph}$, an acceleration of 0 to $50 \mathrm{mph}$ in 14.5 seconds, and a 4-to-5-hour recharge time. This company also produces the purpose-built Horlacher City for urban use. The City is powered by lead acid batteries with a range of about 40 to 90 miles and a top speed of $56 \mathrm{mph}$. Horlacher is looking for production partners, including some in California.

Esoro produces the E301, a purpose-built Ev powered by nickel cadmium batteries. The E301 has a range of 60 to 90 miles, depending on driving conditions and speed, a top speed of $75 \mathrm{mph}$, and an acceleration of 0 to 30 mph in 7.5 seconds. The frameless composite body platform allows modular changes to create a coupe, a four-seater, or a small service vehicle. (See figure 3.2.) 


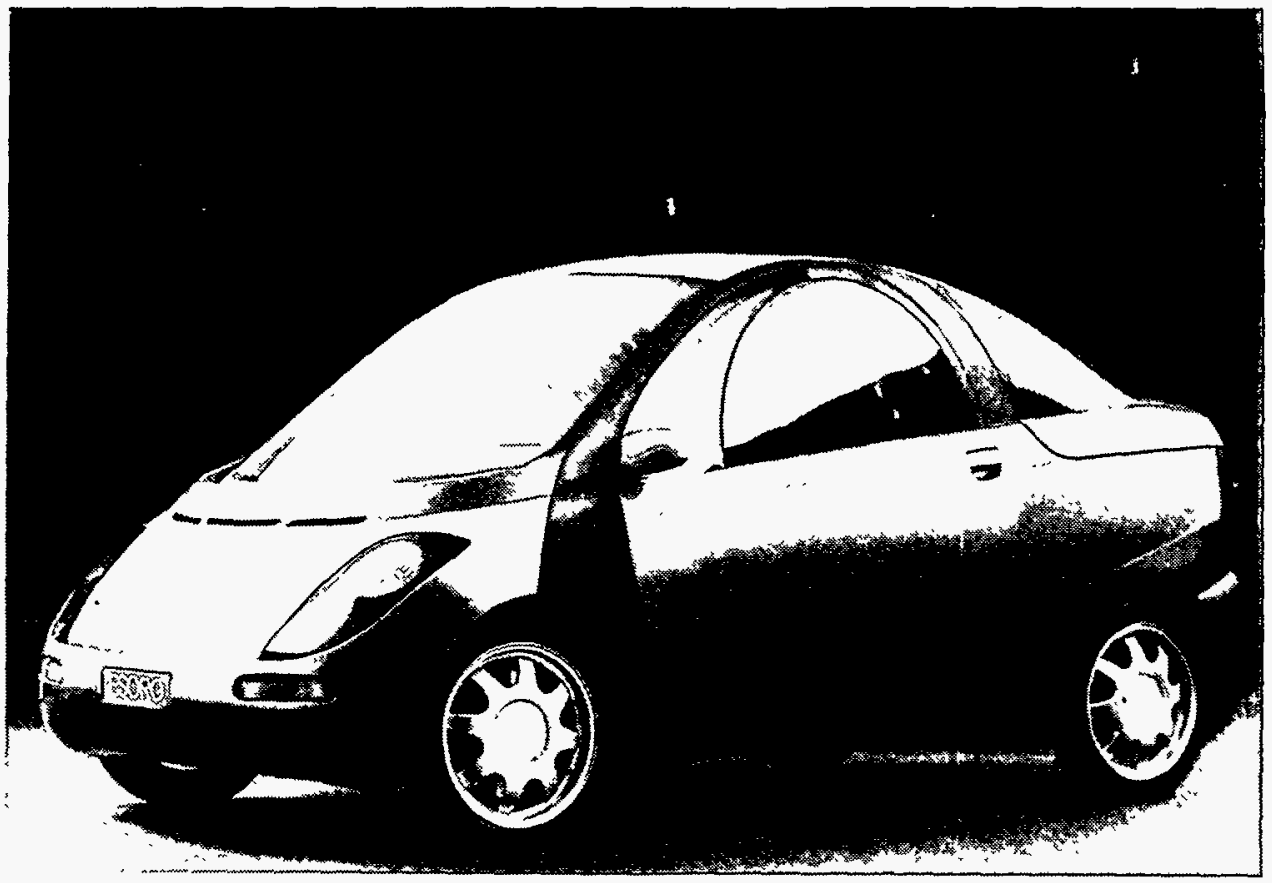

Note: The Swiss-manufactured Esoro E301 uses a frameless composite body platform that allows modular changes to create a coupe, a four-seater, or a small service vehicle. 

reasons have been cited: (1) most Swedish households own only one vehicle, thus making replacement with pure Evs impractical, and (2) Swedes generally travel within relatively long ranges and only hybrids can accommodate this pattern.

Volvo has unveiled its prototype, the Environmental Concept Car, a series hybrid, four-seater sedan. The car is powered by both nickel cadmium batteries and a gasoline turbine engine. When powered by batteries, it has a range of about 100 miles at $30 \mathrm{mph}$, a top speed of $109 \mathrm{mph}$, and acceleration of 0 to $60 \mathrm{mph}$ in 22 seconds. Using its gasoline engine, the car's range is extended to 418 miles at $55 \mathrm{mph}$. Volvo has made the point that the car's gasoline engine meets California's ultra low emission vehicle standards. Volvo has not announced its production plans.

Sweden's Clean Air Transport Inc. (CAT) received the contract to develop Los Angeles's LA301 car, a series hybrid sedan, along with United Kingdom's International Automotive Design. The LA301 is designed to be powered by lead acid batteries with a range of between 40 and 60 miles, a top speed of $75 \mathrm{mph}$, and an acceleration of 0-30 in 7 seconds. The LA301 can accommodate nickel cadmium or sodium sulfur batteries when they are commercially available. When we interviewed CAT officials in October 1992 , they had reportedly spent $\$ 12$ million to develop two prototypes. Representatives of Los Angeles Water and Power Company reported to us in March 1993 that they had committed $\$ 7$ million to the project but to date had disbursed $\$ 4.5$ million. They also confirmed that CAT would require an estimated $\$ 30$ million to establish mass production of the LA301. CAT was unable to raise the required funds. In January 1994, CAT declared bankruptcy and owes millions to the city of Los Angeles for noncompliance.

Solon Corporation in Uddevalla, Sweden, has developed a prototype sportscar powered by a series of new lead acid starter batteries that bind the acid to a thin fiberglass-floss separator material. The battery is unique in that it provides a large active surface area and much lower internal resistance than current lead acid batteries. Solon's cars are manufactured from readily available "off-the-shelf" materials. According to the manufacturers, this greatly increases manufacturing flexibility and reduces the cost of the vehicle. The car is currently a prototype, but the manufacturers state that they have 20 purchase orders at a price of about $\$ 28,000$. (See figure 3.3.) 


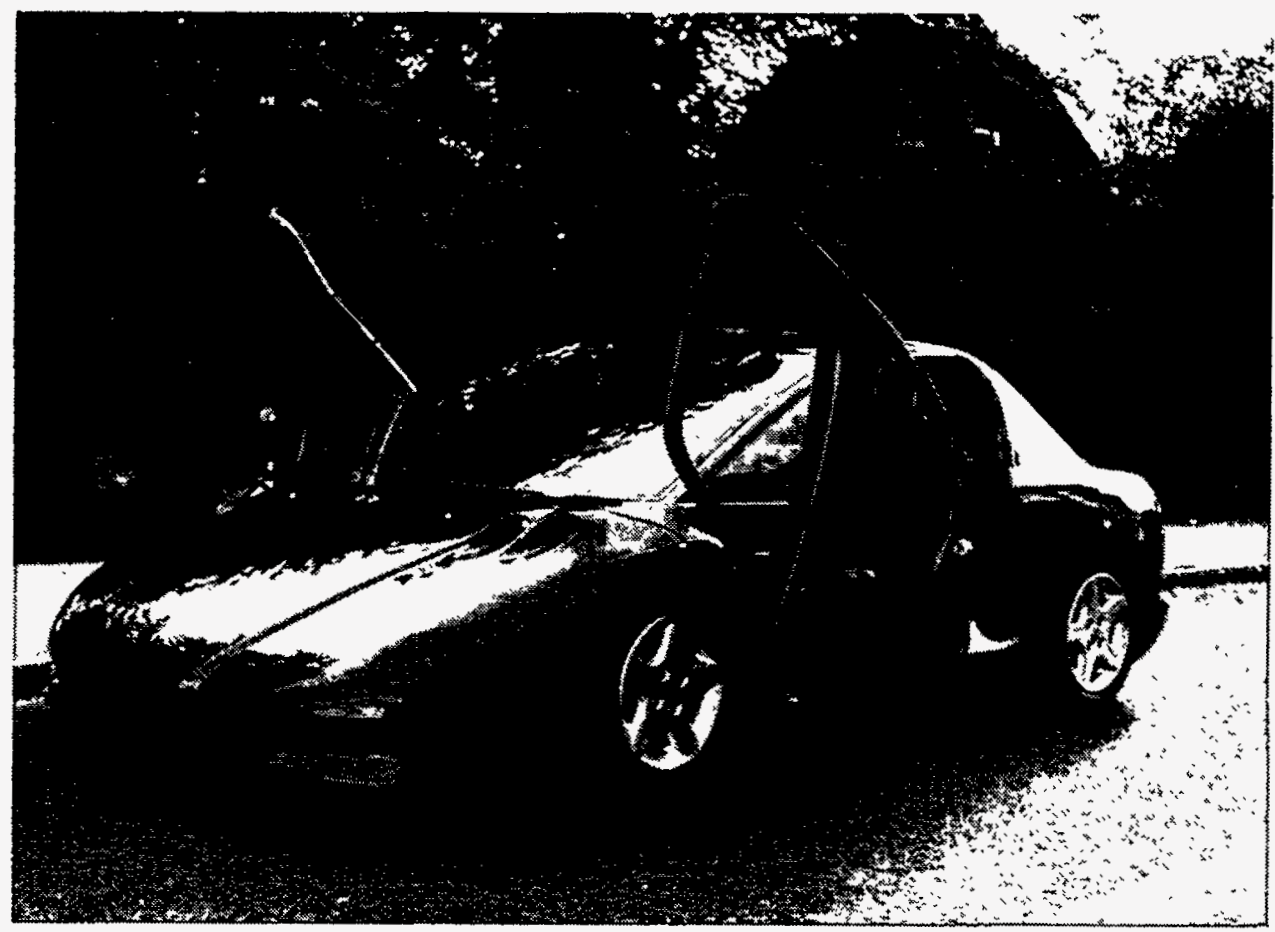

Note: Solon Corporation of Sweden uses off-the-shelf components to reduce costs and increase manufacturing flexibility. The hinged doors allow easier access to tight parking spaces. vans, the former tested in the United States as the General Motors Griffon. However, this program was suspended in 1986 as a result of corporate finance problems. The United Kingdom also recently suspended one of the largest and longest-running electric passenger car programs, the Enfield car project, in which electric utilities employed 70 purpose-built electric cars over a period of 14 years. utilities, government agencies, and personal consumers. With a lead acid battery, the vehicles have a top speed between 40 and $50 \mathrm{mph}$ and a range of about 45 miles in urban driving. The Cinquecento has the option of a nickel cadmium battery that increases the range by about half but the speed only marginally. 
The Fiat Evs have not been well received by the public or the government agencies that have purchased the vehicles and supported EV programs. The status of Fiat's EV program is not very clear today.

Infrastructure Development and Demonstration
Programs to develop and demonstrate infrastructure encompass efforts to create a critical mass of vehicles and recharging stations so that systematic evaluations of vehicle performance and requirements can be conducted. These efforts are often supported by a mix of funds from national and regional programs.
United States

At the federal level, we were able to identify $13 \mathrm{EV}$ demonstrations participating in DOE's Site Operators Users Task Force funded in fiscal year 1994 at $\$ 1.9$ million. In all, these programs include 119 vehicles. Yet 7 of the 13 programs had 5 or fewer vehicles. The large majority of site operators were electric utility companies or local municipal authorities. The site operator program began in the late 1970's with approximately 1,000 converted vehicles. By 1986 , only 500 vehicles remained in the program. A lack of technical support for the fleet operators was cited as the major reason for the dramatic decrease in vehicles.

We were also able to identify Ev demonstration projects in 20 states with a total of about 150 cars, vans, or buses. ${ }^{12}$ As in the federal program, these projects are sponsored primarily by utility companies, which are the main participants, and are located mostly on the East Coast and in three western states. However, with a few exceptions, most demonstration projects have fewer than 10 vehicles. The Sacramento Municipal Utility District (SMUD) has the largest EV fleet with 30 vehicles, over $70 \mathrm{EV}$ charging stations, and an EV loan program for local companies.

Also in California, the Santa Barbara Metropolitan Transit District operates eight electric shuttle buses on a downtown circuit. Officials state that ridership has increased from 100,000 to 1 million in the past 2 years. The electric shuttles are inexpensive to operate, costing 2.5 cents per mile compared to 16 cents per mile for a diesel-powered bus.

The Massachusetts Division of Energy Resources has begun implementing one of the more ambitious demonstration projects with a total of $\$ 2.6$ million in funds from private sources and the Federal Highway

${ }^{12}$ We did not conduct a complete survey of the states. We did survey the states that the Electric Transportation Coalition identified as having passed legislation regarding AFVs by January 1993. 
Adminstration's Intermodal Surface Transportation Act of 1991. The program is part of a congestion mitigation and air quality improvement plan that will use electrically powered commuter vehicles. Beginning in the summer of 1993 and extending for 5 years, commuters in the Greater Boston area will drive between their homes and a parking area near transportation stations where public transit to Boston is available. Data will be gathered from the vehicles and participants to evaluate efficiency and performance. All vehicles will have recharging capability at home, and half will have recharging capabilities at the public parking lot. The project's overall goal is $50 \mathrm{EVs} ; 20 \mathrm{EVs}$ have been procured in its first phase.

Generally, EV demonstration officials report that it is very difficult to obtain a sufficient number of Evs for a meaningful demonstration project. Indeed, some federal U.S. demonstration funding currently requires a minimum of 50 vehicles per program. Several officials we interviewed stated that they simply cannot find 50 vehicles.

The Energy Policy Act created two programs under the responsibility of DOE that specifically target EVs. The act authorized a $\$ 40$ million 5-year program to develop and demonstrate Ev infrastructure. Grants were scheduled to be awarded in 1994 to no more than 10 projects representing geographically and climatically diverse regions of the United States with individual project budgets capped at $\$ 4$ million.

Projects may focus on five aims: serviceability of Evs; installation of charging facilities; rates and cost recovery for utilities investing in infrastructure capital-related expenditures; development of safety and health procedures, such as guidelines for battery charging, watering, and emissions; and the conduct of information dissemination programs.

DOE's commercial demonstration project is authorized to solicit proposals from U.S. metropolitan areas with a 10-year budget of $\$ 50$ million. Each project must include at least 50 EVs and DOE will provide a maximum discount of $\$ 10,000$ per vehicle. A limit of 10 projects will be funded and no one project may be awarded more than 25 percent of the total funds authorized for the program.

The program is designed to accelerate the development and use of Evs and is structured to evaluate the performance of Evs in field operation. Consequently, selection criteria include the manufacturer's ability to develop and assist in the demonstration of the proposed EVs, the geographic and climatic diversity of the eligible metropolitan areas, the 
long-term technical and competitive viability of the Evs, the suitability of the Evs for their intended uses, the environmental effects of the Evs' use, the price differential between Evs and ICEVs and any proposed discounts, the extent of state or local government financial involvement, the proportion of domestic content of the EVs, and the safety of the EVs. However, as of May 1994, no funds had been appropriated for either program. Instead, $\$ 2.73$ million has been authorized to expand the Site Operator Users Task Force program with the planned purchase of a total of 40 to 45 additional Evs.

More to the point, it is possible that-even with full funding-these programs will encounter the same problem as those currently under way-namely, a paucity of commercially available Evs for participation in the programs. The three major U.S. automobile manufacturers together are thus far committed to producing fewer than 250 Evs-less than half of the vehicles needed for the commercial demonstration project alone.

In the area of technology development, the Advanced Research Projects Agency (ARPA) announced in July 1993 its selection of six regional consortia to participate in its ongoing hybrid and Ev program funded at $\$ 25$ million in fiscal year 1993. The ARPA program is funded at $\$ 46.25$ million in fiscal year 1994 and solicited new proposals through July 1994. In an effort to foster technology transfer, the agency's programs are designed for technologies that have both military and commercial applications.

The Northeast Alternative Vehicle Consortium received $\$ 4$ million to conduct $\mathrm{EV}$ infrastructure demonstrations in eight northeastern states, including commuter vehicle pilot projects for each state, four technology projects, and a multivehicle project (buses, trucks, vans, and cars) at Hanscom Air Force Base in Bedford, Massachusetts.

The Southern Coalition for Advanced Transportation will use $\$ 4$ million in the southeastern United States to evaluate high-efficiency climate controls and rapid battery recharging with pick-up trucks at Patrick Air Force Base, Florida, manufacture electric buses for Chattanooga, Tennessee, and Atlanta, Georgia, and conduct research on flywheel technologies. ${ }^{13}$

\footnotetext{
${ }^{13}$ Flywheel energy storage is based on the storage of rotational kinetic energy in a spinning mass. Energy added to the flywheel increases its speed of rotation. When no energy is added or removed from the flywheel, it continues to spin at a constant speed (in the absence of frictional losses), and when energy is removed from the flywheel, its speed decreases.
} 
The Mid-America Electric Vehicle consortium received $\$ 4$ million to test electrified Chevrolet S-10 trucks and buses in Chattanooga, Tennessee, Indianapolis, Indiana, and Warren, Michigan.

CALSTART was awarded $\$ 4$ million to establish new programs to develop EV technology and infrastructure. These include operating station cars around San Francisco's Bay Area Rapid Transit stations, building three military and two commercial hybrid electric buses to be managed by the Santa Barbara Air Pollution Control District, and building light-duty military trucks and commercial vehicles for use on and around California military bases.

Finally, SMUD received $\$ 2.5$ million and Hawaii Electric Vehicle Demonstration Project Consortium received $\$ 5$ million to conduct Ev technology development and infrastructure programs. 2000 plan is a two-phase project to add recharging and alternative fuel stations to some of Japan's approximately 60,000 service stations. In phase one (1993-95), MITI will promote the medium-range use of Evs by subsidizing the conversion of 100 service stations (13 in fiscal year 1993). In phase two (1996-2000), MTT will offer low-interest loans to build 2,000 "ecostations" along major highways and in cities.

Local governments, such as Osaka and Tokyo, are actively involved in promoting Evs. By the end of fiscal year 1993, Osaka had built 10 public quick-charging stations that would allow citizens to charge their batteries in daytime. The aims of the program are to demonstrate techniques for recharging 50 percent of battery capacity in 30 minutes and to show that users can recharge on a self-service basis. To build the stations, Osaka formed the Electric Vehicle Community System (EVOC) in cooperation with the private sector, including the automobile company Daihatsu and Japan Storage Battery Company. Through membership fees, the system rents out Evs and provides battery maintenance and free use of the charging stations. Evoc reportedly spent $\$ 3.59$ million in 1993 to build Osaka's charging stations and place $100 \mathrm{Evs}$ on the road. 

Society (DAUG), and Dresden College engineers. Both public citizens and local authorities will drive the cars at least the minimum mileage established to yield valuable test results. Research activities comprise evaluations of performance and reliability of different mixes of battery types and drive systems, suitability for the routine driving needs of several different applications, infrastructure needs, and vehicle crash testing to assess safety. Automobile manufacturers and battery makers were persuaded to join the project by the variety of testing combinations of vehicles, batteries, and users. The ultimate goal of this project is to demonstrate the applicability and suitability of each manufacturer's product rather than to identify the single best vehicle or battery.

The Federal Ministry for Research and Technology selected Rügen as its test site both because its size ( 25 miles by 25 miles) corresponds to the distance electric vehicles can travel without recharging and because it is widely recognized as an environmentally sensitive refuge for wild birds. Moreover, both its small size and pristine environment offer a better opportunity to monitor the environmental benefits of a small number of Evs than would be possible in a congested city. The range of users includes postal and utility workers, service and delivery companies, and community organizations. Specialized service and repair are available at the test center, and some local mechanics have been trained for routine maintenance. In addition to overnight recharging stations at each user's site, a public charging station can be used by authorized cardholders. However, demonstration project officials have found that the public charging station has not been used much if at all as users are content to recharge on-site.

Two other demonstrations are also under way. Project Telekom will demonstrate 40 electric and hybrid vehicles for 3 years and the Postal Service began a 2-year test in 1993 of a zinc-air battery system and infrastructure support with 20 to 25 vans. In December 1994, the Postal Service announced the extension of its program through 1996 with the purchase of more than 50 Mercedes Benz vans and light trucks powered by the zinc-air batteries manufactured by the Electric Fuel Corporation. The manufacturer claims that the batteries store enough energy to travel for a week without recharging, which is accomplished by removing the zinc and sending it to the factory for reprocessing. The total budget for the test is $\$ 14.8$ million. The Postal Service and Telekom have signed letters of 
intent to purchase as many as 40,000 Evs and batteries if the test is successful.

France has selected 10 cities to stage demonstrations of 20 to 50 electric cars and vans, complete with recharging and service stations, financing for purchase, and driver education. One of these cities, La Rochelle, has been cited as the first EV experiment under real conditions. In phase I, which began mid-1993, sponsors were to provide 50 Peugeot Citroën Evs to local citizens who agreed to participate for 1 year as data were collected regarding driver attitudes and behavior, battery function, cost and patterns of electricity consumption, maintenance, and effect on the urban environment. If phase I is successful, phase II will add 300 Evs.

In July 1992, French officials from the ministries of the environment, industry, and foreign commerce signed an important EV agreement with the French national electricity company, French automobile manufacturers (Renault and Peugeot Citroën), and G.I.V.E., an interministerial group for Evs. The major objectives of the agreement are to (1) develop a standard system of battery charging and equip at least 10 test sites by $1995,(2)$ design and create a system to disperse batteries (such as by leasing them) and guarantee their recycling at the end of their usefulness, (3) establish a viable Ev maintenance system, and (4) conduct education and training. rental agency leases 10 cars from different companies and countries. All use conventional lead acid batteries with a top speed of about $45 \mathrm{mph}$ and a range of 50 miles. They recharge with a conventional Swiss plug at a regular outlet. The rental agency has several coin-operated recharging stations outside its office where owners receive free parking while they recharge for about $\$ 1.70$ per day. Recently, the rental agency added a courier service to further promote Evs.

The Ev repair shop services all types of Evs and has trained mechanics in 10 area conventional repair shops. The service manager reported that the most typical repair problems are the result of owners overcharging batteries or neglecting to add water to the lead acid batteries. The owner reported that he has sold $600 \mathrm{Evs}$ but estimates that only 300 are still in the Basel area. For example, Czechoslovakian-produced Penguin Skodas are available at a price of $\$ 14,700$, including the $\$ 2,000$ battery. He has 
replaced several batteries at considerable expense to keep customers satisfied. He also noted that, in his opinion, more advanced batteries, such as nickel cadmium, offer few advantages over current lead acid batteries at six times the price. For example, a newly purchased taxi with nickel cadmium batteries costs $\$ 60,000$, of which $\$ 25,000$ was for the batteries. demonstration projects under way in which the ultimate goal is to create an initial market for Evs. ${ }^{14}$ Gothenberg has the lead in this effort and the most ambitious goals of 1,000 Evs by 1995 and 10,000 by 2000 . Gothenberg officials initiated this program hoping to break the "vicious circle" in which there are no products because they are waiting for a market and there is no market because it is waiting for the products. Toward this end, the short-term goal is to test 200 electric cars using a systems approach, in which a large number of cars are tested in a commercial transport environment. Tests will evaluate the performance of the cars, infrastructure needs, and local market incentives. In addition, a monitoring system in each car will record information about driving, traffic, and recharging patterns.

Sponsors of the project include Renault and Volvo, Vattenfall (the area electricity producer), Gothenburg Energie (the area electricity distributor), and the Swedish national government. ${ }^{15}$ The first 10 Renault Express vans powered by French SAFT's nickel cadmium batteries were delivered by Renault's partner, Volvo, in August 1993. Program officials are particularly interested in testing a new type of recharging connector manufactured by the French and German company Marechal. This connector uses springs to create varying amounts of pressure contact, which then determines recharging voltage and speed. Thus, the same contact mechanism can be used for three different charging speeds from very quick to overnight. For example, drivers can use an electronic money card to gain an additional 31 -mile range with a 30-minute charge at the local public recharging station.

Users are primarily private companies and municipal offices that will lease cars for 3 years with the requirement that 50 percent of the initial purchase price of $\$ 37,500$ will be repaid. Officials noted that the nickel cadmium

${ }^{14}$ We did not visit Malmo, but the characteristics of that city's program are similar to those of Gothenberg and Stockholm.

${ }^{15}$ Vattenfall is owned primarily by the Swedish national government, and Gothenberg Energie is owned primarily by Gothenberg City. 
Gothenberg has also instituted significant reductions in municipal parking fees for Evs (from $\$ 750$ to $\$ 6$ for 3 years) and will decide sometime in the next year whether to allow Evs to travel in public transport lanes and whether to create environmental zones in which only Evs could drive.

The Stockholm demonstration project is managed by Stockholm Materiel Procurement, a service organization for the city government, that recently purchased 12 Evs, mostly Volkswagen Citistromers with lead acid batteries at a cost of about $\$ 41,100$. These are leased to private companies and city offices for $\$ 1,370$ per month, or about three times the lease price of $\$ 400$ for a comparable ICEv. Based on fleet operating statistics, Stockholm estimates that about 300 of its 1,500-car inventory should be Evs, and it hopes to purchase more at an estimated future cost of about $\$ 24,700$.

Sweden's National Board for Industrial and Technical Development (NUTEK) is planning a large-scale demonstration program for 1993-97 that will use municipal and commercial fleets to test Evs, assess infrastructure needs, and conduct market surveys. The budget is not yet final and could range anywhere from $\$ 6.8$ million to $\$ 27$ million. The government hopes to offset consumer costs for batteries by about 50 percent. constitute a credible demonstration of the use of electrically propelled, slow speed service vehicles. However, their numbers are dwindling and their technology is dated. The government officials we interviewed did not anticipate any new $\mathrm{EV}$ demonstrations in the near future. municipal governments and public organizations. Italian officials representing the nonministerial Agency for New Technology, Energy, and the Environment (ENEA) reported that some of these demonstrations have been less than successful. For example, ENEA had demonstrated 6 Fiat

\footnotetext{
${ }^{16} \mathrm{Nickel}$ cadmium batteries replaced Gothenberg's initial choice of sodium sulfur batteries when officials considered the much shorter life cycle of sodium sulfur batteries as less cost-effective than the nickel cadmium batteries. While the longer range of sodium sulfur batteries can be useful, those benefits are offset by its short life cycle only if the car is driven often and far. This is because the corrosive nature of sodium sulfur batteries also reduces their life.
} 
Panda Evs that it described as very expensive with poor performance and reliability. ENEA staff eventually refused to drive them.

Two public Ev bus demonstrations are conducted in Rome ( 8 minibuses) and Trento ( 3 to 6 buses) by local Municipal Transport Authorities. Rome Transport Authority plans to introduce a larger fleet of 50 minibuses with the financial support of the regional government. Fiat has sponsored a rental program in Livorno Township with 5 passenger Evs.

\section{Vehicle and Battery Research and Development}

In this section, we discuss what we learned about major international vehicle and battery research and development programs. In addition to these nationally sponsored programs, many individual battery and vehicle manufacturers conduct their own research. Because they are proprietary, little information is available about these efforts.
United States
In an effort to improve upon current battery technology, USABC was formed in 1991 as a cooperative venture between industry and government. The major partners include Chrysler, Ford, General Motors, the Electric Power Research Institute, and DOE. Funding for a 5-year period is \$262 million divided evenly between government and industry.

To date, six of an anticipated seven research contracts have been made final for the development of nickel metal hydride, sodium sulfur, and two types of lithium batteries. Total funding amounts to date for the six contracts are $\$ 40.6$ million for the two nickel metal hydride contracts, $\$ 12.1$ million for the one sodium sulfur contract, and $\$ 77.6$ million for the three lithium contracts. In addition, eight cooperative research and development agreements funded at $\$ 18.9$ million guide efforts at five U.S. national laboratories. USABC has both mid-term and long-term objectives to be met by the end of fiscal year 1995. The intent of USABC is to develop by 1995 an advanced battery to meet mid-term performance criteria with pilot prototype production capability by 1996 and full-scale production by 2000 and to demonstrate the technical feasibility of an advanced battery that meets the long-term criteria by 1996 . The technical criteria for battery development specify required power-to-weight ratios for acceleration, energy-to-weight and energy-to-volume ratios for range, overall battery lifetime, and cost. (See appendix III.) Other criteria, such as safety and recyclability, are also considered. USABC funds advanced batteries, and many experts believe that none of the three currently funded battery types 
will be ready for large-scale commercial use before 2000 and that lithium batteries may take until 2010 or longer. and development budget on a par with U.S. efforts. With an aim to upgrade the performance and lower the cost of Ev batteries, MIT's Agency of Industrial Science and Technology has two research projects to improve battery energy storage technology. In fiscal year 1992, the agency launched a 10-year, \$125.6 million project to develop lithium batteries for $\mathrm{EV}$ and consumer electronics use. Administered by NEDO, the project brings together 11 companies in a lithium battery research and development consortium similar to USABC. MITI allocated $\$ 6.2$ million in fiscal year 1993 for research and development on battery technology. In addition, several Agency of Industrial Science and Technology laboratories are conducting research and development in support of corporate participants. In tandem with its lithium research goals, NEDo also administers a 4-year (1992-95) project to develop a polymer electrolytic fuel cell for use with durable lithium batteries. Funds are reported to be $\$ 8.9$ million, with $\$ 359,000$ for fiscal year 1992 . MII aims to have the resulting high-performance batteries mass produced at low cost within 3 years of their development.

Germany

In November 1993, USABC awarded a $\$ 12.1$ million contract to Germany's Silent Power $\mathrm{GmbH}$ to develop and produce sodium sulfur batteries. Silent Power has research and development facilities in Pennsylvania, Utah, and the United Kingdom. The contract obliges Silent Power to locate production facilities in the United States as a market develops for the battery technology. Until 1992, BMFT subsidized the development of sodium sulfur batteries by ABB, which is developing mass production techniques for $\mathrm{EV}$ batteries, and the German government has refocused its efforts to $\mathrm{EV}$ demonstration and evaluation programs. nickel cadmium batteries; it plans to mass produce its vented-type nickel cadmium batteries so as to reduce manufacturing costs. SAFT has received two USABC contracts. A midterm nickel metal hydride project is funded at $\$ 18.1$ million and a long-term lithium iron disulfide project is funded at $\$ 17.3$ million. Research continues on sealed-type nickel 
cadmium batteries, nickel zinc batteries, aluminum air batteries, hydrogen air fuel cells, and methanol air fuel cells. level of many other countries. Rather, the Ministry of the Environment's technology support program DIANE provides financial support to selected technologies that are sufficiently developed that small incremental funding can have a large effect. Evs are identified as one such technology and are funded at $\$ 1.4$ million per year. Each project can be subsidized by the national government at 30 percent of costs, with the regional cantons supplying an additional 20 percent maximum and private industry the remaining 50 percent of costs. The Swiss Federal Office for Energy Economy provided $\$ 2.8$ million for 1991-94 for safety and crash test research in the types of lightweight, plastic resin Evs for which Swiss producers are well known.

While funding amounts are relatively small compared to the United States and Japan, small Swiss manufacturers are considered by many to hold much promise in the development of purpose-built Evs. These Evs are constructed from lightweight, high-strength plastic resins that are expected to eliminate some of the weight problems associated with converting ICEVS into EVS.

NUTEK has funded EV-related research and development at about $\$ 1$ million per year since the 1970's. Most grants are provided to universities that work in conjunction with Volvo. In prior years, most of the funding went to battery research, but interest has shifted to electric drive systems and infrastructure, especially quick-charge technologies.

We interviewed engineers at Cattella Generics, an independent battery testing company based in Stockholm. These experts reiterated Sweden's interest in quick-charging capabilities. From extensive experience with batteries, it is their opinion that the prohibitive cost (and substantially increased weight) of a battery with enough energy to increase range significantly is not justified when one considers how infrequently the additional range is actually needed or used. Quick-charge technology would extend range only when needed. These experts also noted that although all batteries deteriorate slightly as a result of normal recharging, and extensively with improper recharging, comparatively little money and attention are devoted to the charging apparatus itself. 
The United Kingdom once had a longstanding commitment to Evs. However, the Department of Trade and Industry and the Department of Transport subsidies began to fall when large off-shore oil reserves were discovered. By 1989, no funds were devoted to Evs. Officials spoke of a waning interest in marketing Evs at home after many years of substantial research and development investment. Today, all funding for Evs comes from private sources, which hope to introduce products into the U.S. market in the near future.

Several companies based in the United Kingdom have forged relationships with other foreign corporations. For example, International Automotive Design joined with Sweden's CAT to develop the hybrid LA301 car, scheduled for production in the Los Angeles EV program. Beta R\&D has developed a sodium nickel chloride battery that will be commercialized with help from partners in Germany's AEG, a subsidiary of Daimler-Benz. Chloride Ltd. and its subsidiaries will produce and market (including to Ford) a sodium sulfur battery in a joint venture with Germany's electric power company, RWE. The United Kingdom's research and development division of Silent Power received a joint USABC sodium sulfur contract with the German Silent Power GmbH in November 1993. environment and industry, and the national electric power company (ENEL). The goals of the program are to (1) retrofit existing gasoline cars with batteries and (2) conduct research devoted to a battery breakthrough.

Primary funding for EV development comes from ENEA. Between 1980 and 1987, this agency and the National Council of Research (CNR) provided about $\$ 11.2$ million to support both near-term battery research (lead acid, nickel cadmium, and nickel iron) and advanced battery research (sodium sulfur, lithium, and supercapacitors). Each year since 1986, the agency has provided an additional $\$ 700,000$ in a parallel effort in cooperation with industry, research centers, and fleet users for field and bench testing of EVs and batteries. In September 1992, its proposed EV budget for the next 3 years totaled more than $\$ 35$ million; however, some doubt exists that full funding will be available.

Italy's transportation sector has devoted about $\$ 3.5$ million to vehicles and $\$ 7$ million to hybrid vehicle development and EV applications in urban areas. Italy's 3-year environment plan reserves about $\$ 9.8$ million for local public authorities to monitor Evs and the environment. In 1992, ENEL was 
scheduled to begin a $\$ 42$ million program for the development of stationary and mobile electrical energy storage systems. The program costs are shared with battery and vehicle manufacturers, and about $\$ 7$ million is devoted to EV development. The battery program focuses on sodium sulfur, lithium aluminum, and iron sulfur batteries. The aim is to introduce and adopt the latest overseas manufacturing technologies in Italy.

Summary and Conclusions
The foreign Ev efforts we reviewed varied in terms of the scope and maturity of their major ev production efforts as well as in the type and amount of national funding for $\mathrm{EV}$ research and development and promotion and demonstration programs. Of the countries we reviewed, we found that Ev programs in Japan, Germany, France, and Switzerland have elements that are different from those in the United States. Officials in all nations except Japan noted the difficulty in obtaining EVs in sufficient numbers for tests and demonstrations.

Japanese officials do not foresee a large personal consumer EV market in their country in the near future. Japanese automobile manufacturers do, however, plan to market in the U.S.-mandated markets. Toward that end, the Japanese national government provides research and development funding to major automobile and battery manufacturers, and large-scale demonstration projects are funded at both the national and local levels. Municipal governments throughout Japan have committed to fleet purchases and cost subsidies in a move toward both popularizing Evs and reducing production costs.

Germany and France, in contrast, have greatly reduced or eliminated their research and development budgets and are moving toward national funding of large-scale demonstration projects. France has initiated a 10-city project with 20 to 50 evs per city, recharging stations, purchase incentives, and driver education programs. Germany recently began a 60-vehicle demonstration on Rügen, a tourist island on the Baltic coast. The program highlights extensive data collection and evaluation of different combinations of drive systems and batteries as well as actual vehicle crash testing. Switzerland also has some pilot Ev infrastructure in place. But more importantly, Swiss automobile manufacturers are advancing the design of purpose-built, lightweight Evs that eliminate many of the problems associated with simply converting ICEVs into EVs. 
These substantial efforts notwithstanding, the international $\mathrm{Ev}$ industry is looking toward the United States as manufacturers await a battery breakthrough from USABC. However, the progress of developing $\mathrm{EV}$ batteries-or any new technology-cannot be predicted with great certainty. Although a technical breakthrough could occur at any time, we believe from our literature review and interviews with experts that none of the three USABC advanced battery types are likely to be ready for large-scale commercial use for the 1998 state mandates. In particular, sodium sulfur and nickel metal hydride batteries are unlikely to be fully developed technically before 2000 , and lithium batteries may take until 2010 or longer.

From a policy perspective, foreign governments are also looking toward the United States as they await the 1998 California and northeastern state mandates. Yet, in the United States, federal and state EV program managers are experiencing difficulties finding Evs in sufficient numbers for meaningful demonstrations, and technical and program supports appear to be less than what would be required for success. Within the U.S. federal fleet, only 10 of 15,000 planned AFv purchases will be Evs.

In sum, in direct contrast to many of the countries we visited, the United States has devoted proportionately less of its money and attention to comprehensive EV demonstration and promotion programs or infrastructure needs assessment and development. 


\section{National and Regional Effects: Economics, Energy, and the Environment}

While industrial policy appears to influence the level and type of EV funding, officials indicated that national and regional distinctions in energy and environmental issues often underlie a nation's interest in Evs as a solution to its own energy security and air quality problems. Thus, in this chapter, we address our third evaluation question: What are the likely effects of introducing Evs in a nation or region in terms of costs to the individual, national energy savings, and environmental effects? We considered costs likely to arise from owning and operating an EV in different nations. As for effectiveness, we looked at potential effects on energy savings and on pollution reductions at the national level. We also examined the potential range of regional environmental effects using the few region-specific studies we obtained.

We begin our discussion with an analysis of likely EV purchase costs in the near term and the more distant future. We present data that estimate the total consumer costs to own and operate an Ev in the nations we reviewed. Next, we focus on the potential effect of Evs on energy consumption and imported oil dependence in the nations we reviewed, providing transportation and petroleum use statistics for each nation and then analyzing how Evs might produce total energy savings, petroleum savings, and petroleum independence if they replace gasoline-powered ICEvs. This is followed by a discussion of each nation's pollution statistics and fuel mixes for electricity generation and how these factors might influence the potential effect of EV use on air pollution. Finally, we use data from four U.S. cities with different electricity fuel mixes and air pollution problems to demonstrate the potential range and magnitude of the effects of Evs for urban areas in the United States.
High cost is the greatest obstacle for private consumers who want to purchase Evs. EV costs can be considered in two ways: the price to purchase an EV (initial cost) and the cost to purchase, fuel, and maintain an EV over its lifetime (life-cycle cost).

Data showing the effects of production volume on initial purchase price do exist, but they are difficult to obtain and validate because they are proprietary to manufacturers. Even when sympathetic manufacturers volunteer such data, they often contain large information gaps. We did find one price-volume analysis that used data provided by an EV manufacturer who has relatively extensive experience producing Evs. 
In a report prepared for the German parliament, the Ministry of Transportation calculated initial purchase price changes as annual production increases to 100,000 vehicles for a midsized, four-seater electric Volkswagen Citistromer equipped with a lead gel battery. ${ }^{1}$ The Citistromer is currently produced by hand in annual volumes of fewer than 100 vehicles at a consumer cost of $\$ 42,700$, or nearly three times more than the ICEv version, which sells for $\$ 15,500$. As table 4.1 illustrates, the manufacturer expects initial prices to fall steadily until production reaches 100,000 , when the Evs are predicted to reach their ultimate price. The largest cost reductions are realized as production moves from handbuilt vehicles to annual production rates of 5,000 vehicles. However, even at a production volume of 100,000 vehicles, the Ev's initial cost would remain about 18 percent higher than that of the ICEV, or $\$ 18,250$.

Table 4.1: Initial Purchase Price of Electric Citistromers as a Function of Annual Production Level

\begin{tabular}{lcc}
\hline Annual production rate & $\begin{array}{r}\text { Initial price } \\
\text { reduction }\end{array}$ & $\begin{array}{c}\text { Comparison to } \\
\text { ICEV cost }\end{array}$ \\
\hline Hand built & 0 & $280 \%$ \\
\hline 1,000 & $-15 \%$ & 238 \\
\hline 5,000 & -34 & 185 \\
\hline 10,000 & -38 & 174 \\
\hline 50,000 & -45 & 154 \\
\hline 100,000 & -58 & 118 \\
\hline
\end{tabular}

Source: "Unterrichtung durch die Bundersregierung: Vierte Fortschreibung des Berichtes über die Förderung des Einsatzes von Elektrofahrzeugen," publication 12.3222, German Federal Parliament, session 12, Bonn, September 7, 1992.

These data are specific to the Volkswagen Citistromer with a lead gel battery. Since lead-based batteries are the least expensive of the various battery technologies, Citistromer purchase prices would be considerably higher if equipped with different batteries. This fact hampered our ability to generalize Citistromer cost projections to those for other Evs using different batteries.

We did, however, find a Japanese analysis of the effects of economies of scale on the costs to manufacture different batteries. ${ }^{2}$ The research was sponsored by MITI and conducted jointly by the Institute of Applied Energy and NEDO. The cost projections considered both economies of scale (for

${ }^{1}$ Costs include lead gel batteries estimated to cost about $\$ 5,570$ currently and decrease to about $\$ 3,900$ at higher production volumes.

${ }^{2} \mathrm{H}$. Hasuike et al. "Economic Study on Advanced Batteries for Electric Vehicles," in The 11th International Vehicle Symposium Proceedings, vol. 2 (Florence, Italy: September 1992). 


\section{Chapter 4}

National and Regional Effects: Economics,

Energy, and the Environment

example, by calculating changes in prices of raw materials and overhead costs at higher purchase volumes) and learning economies (for example, by factoring in projected improvements in manufacturing processes). The analysis also considered two important operational factors that influence battery cost: energy capacity and cycle life. As we noted in our discussion of battery technology in chapter 2, energy capacity (the total number of energy units in a battery) reflects range, and cycle life reflects the total number of times that a battery can be recharged before it must be replaced. Together, energy capacity and cycle life affect the total lifetime driving distance of a battery. Table 4.2 shows how differences in both costs per unit of energy and battery specifications affect consumers' initial battery costs and the costs to travel a specified distance (in our example, 100,000 total miles). 


\section{Table 4.2: Battery Cost Per Driving} Distance $^{\circ}$

\begin{tabular}{|c|c|c|c|c|}
\hline & $\begin{array}{l}\text { Sodium } \\
\text { sulfur }\end{array}$ & $\begin{array}{l}\text { Nickel } \\
\text { cadmium }\end{array}$ & $\begin{array}{r}\text { Nickel } \\
\text { iron }\end{array}$ & $\begin{array}{l}\text { Lead } \\
\text { acld }\end{array}$ \\
\hline $\begin{array}{l}\text { 1. Cost per kWh } \\
\text { Producing } 1,000 \\
\text { Producing } 100,000\end{array}$ & $\begin{array}{l}\$ 875 \\
\$ 172\end{array}$ & $\begin{array}{l}\$ 529 \\
\$ 345\end{array}$ & $\begin{array}{l}\$ 624 \\
\$ 332\end{array}$ & $\begin{array}{r}\$ 119 \\
\$ 89\end{array}$ \\
\hline 2.Battery capacity (kWh) & 44.0 & 41.6 & 41.9 & 28.1 \\
\hline $\begin{array}{l}\text { 3. Total battery cost } \\
\text { Producing } 1,000 \\
\text { Producing } 100,000\end{array}$ & $\begin{array}{r}\$ 38,500 \\
\$ 7,568 \\
\end{array}$ & $\begin{array}{l}\$ 22,006 \\
\$ 14,352 \\
\end{array}$ & $\begin{array}{l}\$ 26,146 \\
\$ 13,911 \\
\end{array}$ & $\begin{array}{l}\$ 3,344 \\
\$ 2,501 \\
\end{array}$ \\
\hline $\begin{array}{l}\text { 4.Operating range (urban miles) } \\
\text { Cycle life } \\
\text { Driving distance }\end{array}$ & $\begin{array}{r}100 \\
500 \\
50,000 \\
\end{array}$ & $\begin{array}{r}75 \\
2,000 \\
150,000 \\
\end{array}$ & $\begin{array}{r}75 \\
2,000 \\
150,000 \\
\end{array}$ & $\begin{array}{r}55 \\
500 \\
26,500 \\
\end{array}$ \\
\hline 5.Number of batteries ${ }^{d}$ & 2.00 & 0.67 & 0.67 & 3.64 \\
\hline $\begin{array}{l}\text { 6.Cost for } 100,000 \text { miles }^{\ominus} \\
\text { Producing } 1,000 \\
\text { Producing } 100,000\end{array}$ & $\begin{array}{l}\$ 77,000 \\
\$ 15,136\end{array}$ & $\begin{array}{r}\$ 14,671 \\
\$ 9,568\end{array}$ & $\begin{array}{r}\$ 17,430 \\
\$ 9,274\end{array}$ & $\begin{array}{r}\$ 12,160 \\
\$ 9,094 \\
\end{array}$ \\
\hline
\end{tabular}

aBattery capacity is a function of specific energy (measured in $\mathrm{Wh} / \mathrm{kg}$ ) and a reflection of the amount of energy per unit of weight and battery size $(\mathrm{kg})$. Battery capacity is specified by the manufacturer and varies as a function of vehicle type or required range. Range is a function of battery capacity and vehicle efficiency, as well as other variable factors, such as use of climate controls and type and speed of driving. The vehicle efficiency (in $\mathrm{kWh} / \mathrm{km}$ ) varies in this analysis from .365 for lead acid to .387 for nickel iron batteries and is based on a compact van with gasoline mileage of $22 \mathrm{mpg}$ driving in an urban environment without air-conditioning or heat.

The values for this table were derived directly from the Japanese analysis except for the correction based on DOE's technical comments, in which it noted an unrealistic battery capacity for sodium sulfur. This battery's capacity was originally reported as $85.7 \mathrm{kWh}$, which is not consistent with the requirements for a compact van with a reasonable operating range of 100 urban miles. We believe the original analyses failed to consider that the high specific energy of sodium sulfur batteries allows for substantial weight reduction for these batteries compared to the others. Because the battery capacity ultimately affects price, we reduced the Japanese estimate by almost halt. Our estimate is roughly consistent with the energy capacity of the Ford Ecostar's sodium sulfur battery ( $40 \mathrm{kWh})$.

'Total battery cost $=$ battery capacity $x$ cost per kilowatt hour.

'Driving distance $=$ range $\times$ cycle life.

Assumes purchaser could return the unused remainder of a battery at 100,000 miles.

${ }^{\circ}$ Cost for 100,000 miles $=(100,000$ miles/driving distance $) \times$ total cost.

At a low production rate of 1,000 sets per year, the consumer cost per unit of energy ( $\mathrm{kWh}$ ) of sodium sulfur batteries is expected to be more than seven times higher than that of lead acid; the costs of nickel cadmium and nickel iron batteries should be between four and five times higher than 
Chapter 4

National and Regional Effects: Economics,

Energy, and the Environment

lead acid. ${ }^{3}$ At a high production rate of 100,000 sets per year, the costs per unit of energy of the four batteries would all be reduced. Lead acid batteries would incur a 25-percent reduction; sodium sulfur batteries, an 80-percent reduction; nickel iron batteries, a 47-percent reduction; and nickel cadmium batteries, a 35-percent reduction. In relative terms, costs per unit of energy of sodium sulfur batteries would be about twice those of lead acid batteries and the nickel based batteries about quadruple.

As for economies of scale, the Japanese expect that increasing production rates of sodium sulfur batteries would introduce significant cost reductions in raw materials and manufacturing. Nickel cadmium and nickel iron batteries would benefit most from decreased manufacturing costs. Lead acid batteries would not gain much from increased production rates as they use low-cost, abundant materials and would be manufactured by an already established technology.

Thus, when price per unit of energy is considered, the sealed lead acid battery is by far the least expensive alternative. However, price per unit of energy is not the only contributor to the ultimate price of batteries. The four battery types vary considerably in terms of energy capacity. The amount of energy that is contained in the battery sets varies from 44 kilowatt hours for sodium sulfur batteries to about 28 kilowatt hours for lead acid batteries. The cost to purchase a complete battery set depends upon the cost per unit of energy and the battery capacity, or the total number of energy units contained in the battery set (see table 4.2 , row 1 ).

The cost to purchase a complete battery set varies considerably for the four batteries (row 3). At production volumes of 1,000 annually, sodium sulfur batteries are anticipated to cost $\$ 77,000$ each. The nickel-based batteries would cost between about 60 and 70 percent and lead acid batteries would cost about 9 percent of the price of a sodium sulfur battery. However, these price ratios change radically at production volumes of 100,000 annually: the nickel batteries would cost most at between $\$ 13,900$ and $\$ 14,350$. Sodium sulfur batteries would cost about 50 percent $(\$ 7,600)$ and lead acid about 20 percent $(\$ 2,500)$ of the cost of nickel batteries.

${ }^{3} \mathrm{As}$ a point of comparison, current $\mathrm{EV}$ lead acid batteries (vented type $\mathrm{PbA}$ ) are produced at a rate of 100 sets per year in Japan at a cost of 18 cents per watt hour (Wh). Total price per set is calculated by multiplying cost per unit of energy in watt hours $(\$ / W h)$ by battery capacity in kilowatt hours ( $k W h / s e t)$. A kilowatt hour is 1,000 watt hours. Thus, at 18 cents per watt hour and a capacity of 28.14 $\mathrm{kWh}$ per set, the cost of current vented PbA batteries is $\$ 5,116$ per set $(.18 \times 28.14 \times 1,000=5,116)$. 

distance of the battery takes into account its range on a single charge and cycle life, or the number of times it can be recharged (row 4). The total driving distances range from about 150,000 miles for nickel cadmium and nickel iron batteries to about 26,500 miles for lead acid batteries. A sodium sulfur battery has a total driving distance of about 50,000 miles. When these factors are considered, the relative costs of the four batteries are much different than when purchase prices are compared.

We calculated the total number of batteries (row 5) and the total costs of those batteries that would be required to travel a total of 100,000 miles (row 6). We prorated battery costs. For example, the driving distance for the lead acid battery was estimated at 26,500 miles; thus, we included costs for only 3-2/3 lead acid batteries with the assumption that the purchaser could recover the full value for the $1 / 3$ of the fourth battery's life that remained after 100,000 miles. $^{4}$

In general, it will always cost more initially to purchase a battery with extended range because extended range requires more energy capacity (energy units) within the battery. But overall operating costs can be offset considerably by how many times the battery can be recharged in its lifetime. For example, at production volumes of 100,000 batteries annually, the initial costs of nickel cadmium and nickel iron batteries are nearly six times higher than the cost of a lead acid battery (row 3), but these are offset by total lifetime driving distances, which are also nearly six times longer than the lead acid battery (row 4). In other words, while nickel cadmium and nickel iron batteries will cost more to purchase, they will last longer than the lead acid batteries. This offset is less good for the sodium sulfur battery: its initial cost is three times more than lead acid's, but its total driving life is only 1.9 times as long as lead acid's. Thus, a sodium sulfur battery's cost per driving distance is about 65-percent more than that of a lead acid battery's cost. If only 1,000 lead acid and sodium sulfur batteries are produced annually, the costs to travel 100,000 miles with sodium sulfur batteries would be about $\$ 77,000$, or six times more than the lead acid batteries' costs of $\$ 12,160$.

The final step in our analysis combined the German Citistromer cost analysis with the Japanese battery analysis. From this synthesis emerged a more general picture of likely purchase costs for a wider range of Evs than

${ }^{4}$ We did the same for the nickel-based batteries by including the costs of only $2 / 3$ of either a nickel cadmium or nickel iron battery. 

assumptions. First, we considered only two production volumes for the base vehicles and batteries: 1,000 and 100,000 per year. Second, we subtracted the cost of the Citistromer battery from the total purchase price and assumed that the vehicle could accommodate the four different advanced battery types. The current Citistromer battery contains only 18 kilowatt hours of power. Because energy capacity affects range, we assumed that the Citistromer would incorporate advanced batteries when they become available. Using the battery prices from the Japanese analysis and the vehicle prices from the German analysis, we calculated the total current cost to purchase the Citistromer and enough batteries to drive 100,000 miles. Figure 4.1 compares our estimates of the costs of the EV Citistromer with the different battery types at production volumes of 1,000 and 100,000 per year with the costs of a comparable ICEV Citistromer. From our calculations, we found that ICEV costs will remain lower than EV costs-even at high-volume production. 
Figure 4.1: Total Lifetime Purchase Costs to Travel 100,000 Miles in a Citistromer by Battery Type and Production Volume ${ }^{a}$

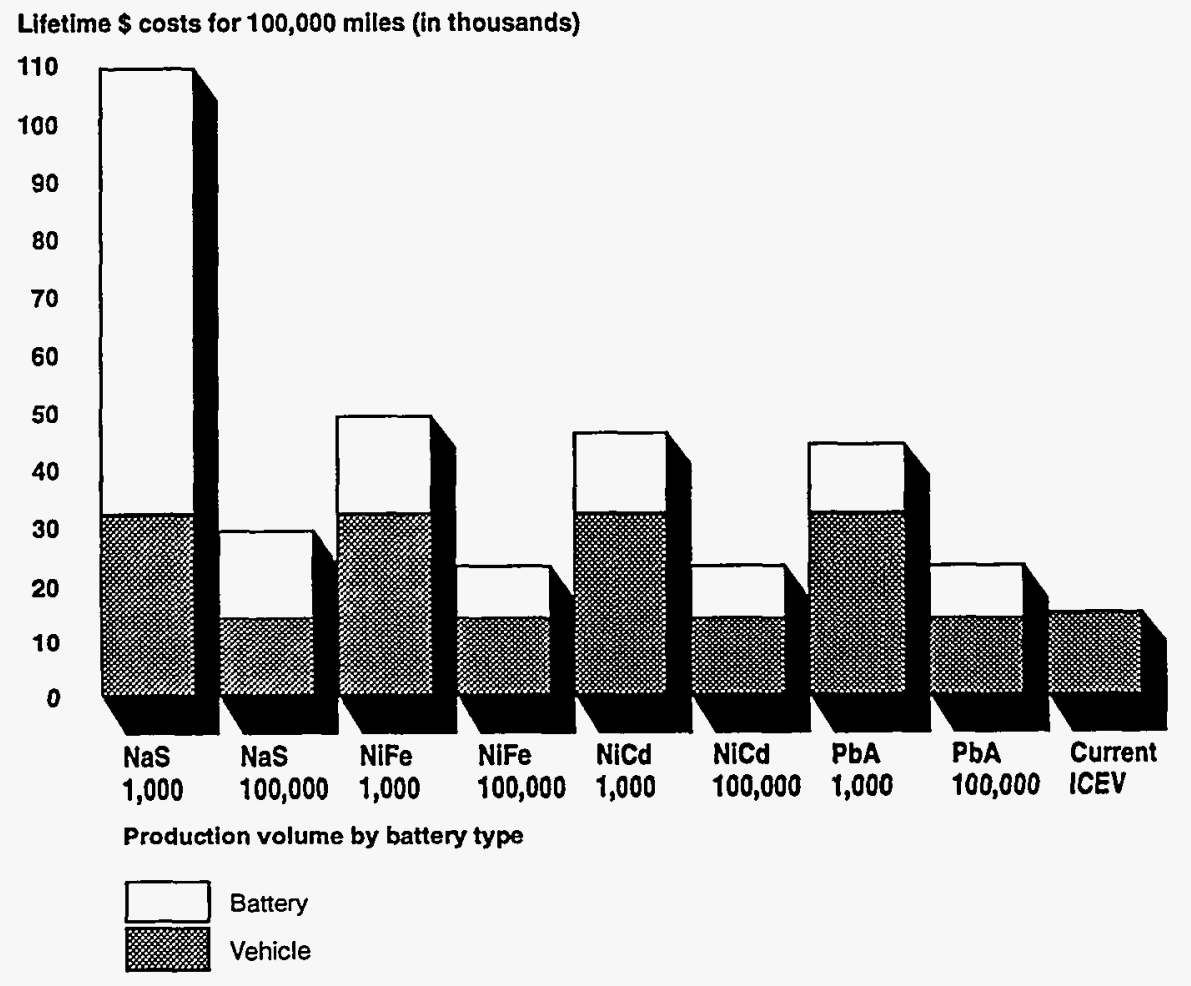

${ }^{\mathrm{NaS}}=$ sodium sulfur; $\mathrm{NiFe}=$ nickel iron; $\mathrm{NiCd}=$ nickel cadmium; $\mathrm{PbA}=$ lead acid.

The cost of the vehicle without a battery at low production volumes is estimated to be $\$ 33,000$, compared to $\$ 15,500$ for a complete ICEV. At low production volumes, the cost to travel 100,000 miles in a vehicle equipped with sodium sulfur batteries would be extraordinarily high at $\$ 110,000 .^{5}$ With nickel iron batteries, the cost would be about $\$ 50,400$; with nickel cadmium batteries, about $\$ 47,700$; and with lead acid batteries, about $\$ 45,200$.

At annual production volumes of 100,000 , the vehicle without a battery is expected to be $\$ 14,000$, making total costs with sodium sulfur batteries $\$ 29,100$; with nickel iron batteries, $\$ 23,300$; with nickel cadmium batteries, $\$ 23,700$; and with lead acid batteries, $\$ 23,100$. 

costs to operate and maintain the vehicle. While initial purchase costs are regarded as a universal barrier to the consumer, many of the experts we interviewed expect the costs to maintain and fuel an $\mathrm{EV}$ to be considerably less than comparable costs for an ICEv. However, the costs to fuel Evs and ICEvs vary considerably depending on a nation's gasoline and electricity costs.

We used actual electricity and gasoline prices in the eight nations when we compared the estimated life-cycle costs of the Ev and ICEV. From our review of the literature and interviews with electricity utility officials, we assumed an electricity price reduction of a third for off-peak recharging to reflect likely incentives as Evs create a sizable market for alternative uses of electricity. ${ }^{6}$ Maintenance costs are expected to be less for Evs; the Citistromer is estimated to cost approximately 4 cents per mile for the EV and 6 cents per mile for the ICEV. We reasoned that maintenance costs would be comparable across the eight nations we reviewed. Similarly, we reasoned that initial costs to purchase the Citistromer and batteries would be the same in these nations. ${ }^{7}$ We used the least expensive battery (lead acid) at production volumes of 1,000 to model likely near-term conditions and 100,000 to model likely final conditions.

Thus, in our analyses, differences in the costs to own and operate an Ev or an ICEV in a given nation stem from differences in initial costs, maintenance costs, and operating costs. However, any differences across nations in the costs to own and operate an EV or an ICEV stem solely from the costs of electricity and gasoline in these nations.

Figure 4.2 illustrates the likely near-term life-cycle costs of the Ev and ICEV in each of the eight nations. Life-cycle costs for Evs at low production volumes would be considerably higher than those of ICEvs in all nations and would range from more than twice the cost in the United States to about a third higher in Sweden and Italy. Generally, the high initial purchase costs that could be expected at low production volumes greatly offset any benefits that might be realized by lower Ev operating costs.

${ }^{6}$ Costs of daytime "opportunity" charging may be substantially higher than nighttime rates and could be as high as $\$ 0.50$ per $\mathrm{kWh}$ in the United States to discourage high use during peak daytime hours.

${ }^{7}$ As we noted in chapter 3 , financial purchase or tax incentives differ across nations; we did not include these in this analysis. 
Chapter 4

National and Regional Effects: Economics,

Energy, and the Environment

Figure 4.2: Near-Term Life-Cycle Costs of EVs and ICEVs ${ }^{a}$

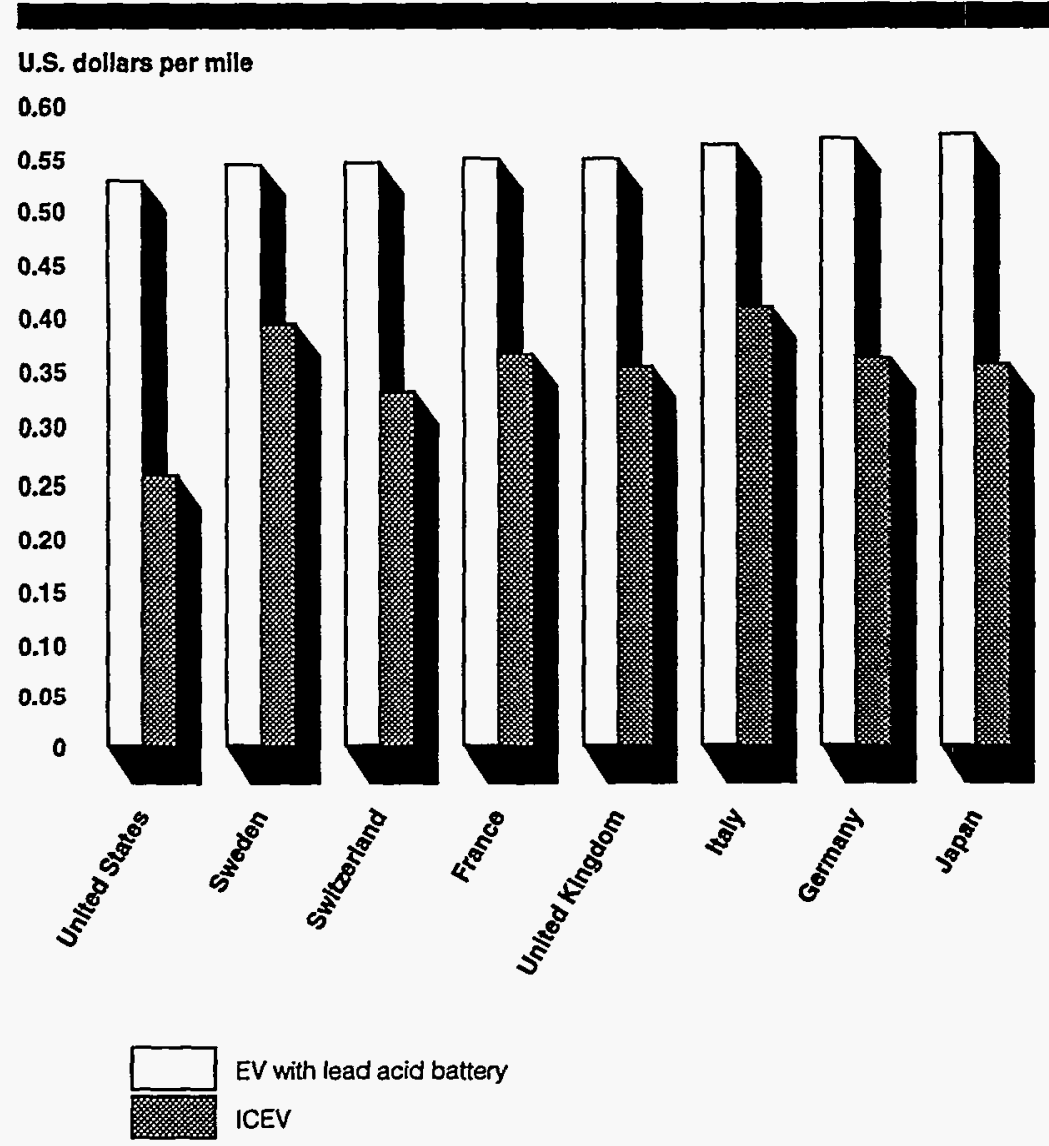

Annual production volume is 1,000 .

In contrast, figure 4.3 presents likely final conditions at high production volumes. In this analysis, the initial purchase cost is assumed to be considerably lower than it is at low production volumes and begins to approach that of the ICEV. Thus, the benefits of lower fueling costs are realized for nations with high ratios of gasoline to electricity costs. These would include all nations except the United States, where gasoline costs less and the ratio of gasoline to electricity costs is lower. Indeed, the United States is the only nation of the eight where the life-cycle costs of Evs would likely remain higher than those of comparable ICEVs. These findings correspond well with estimates suggesting that gasoline would have to cost more than $\$ 4.00$ per gallon before the costs of owning and operating an EV powered by batteries meeting the USABC midterm criteria 
Chapter 4

National and Regional Effects: Economics,

Energy, and the Environment

would approach those of an ICEV. ${ }^{8}$ The break-even gasoline price for Evs powered by batteries meeting the USABC long-term criteria (such as lithium batteries) is estimated at about $\$ 1.70$ per gallon.

Figure 4.3: Final Life-Cycle Costs of EVs and ICEVs ${ }^{\mathrm{a}}$

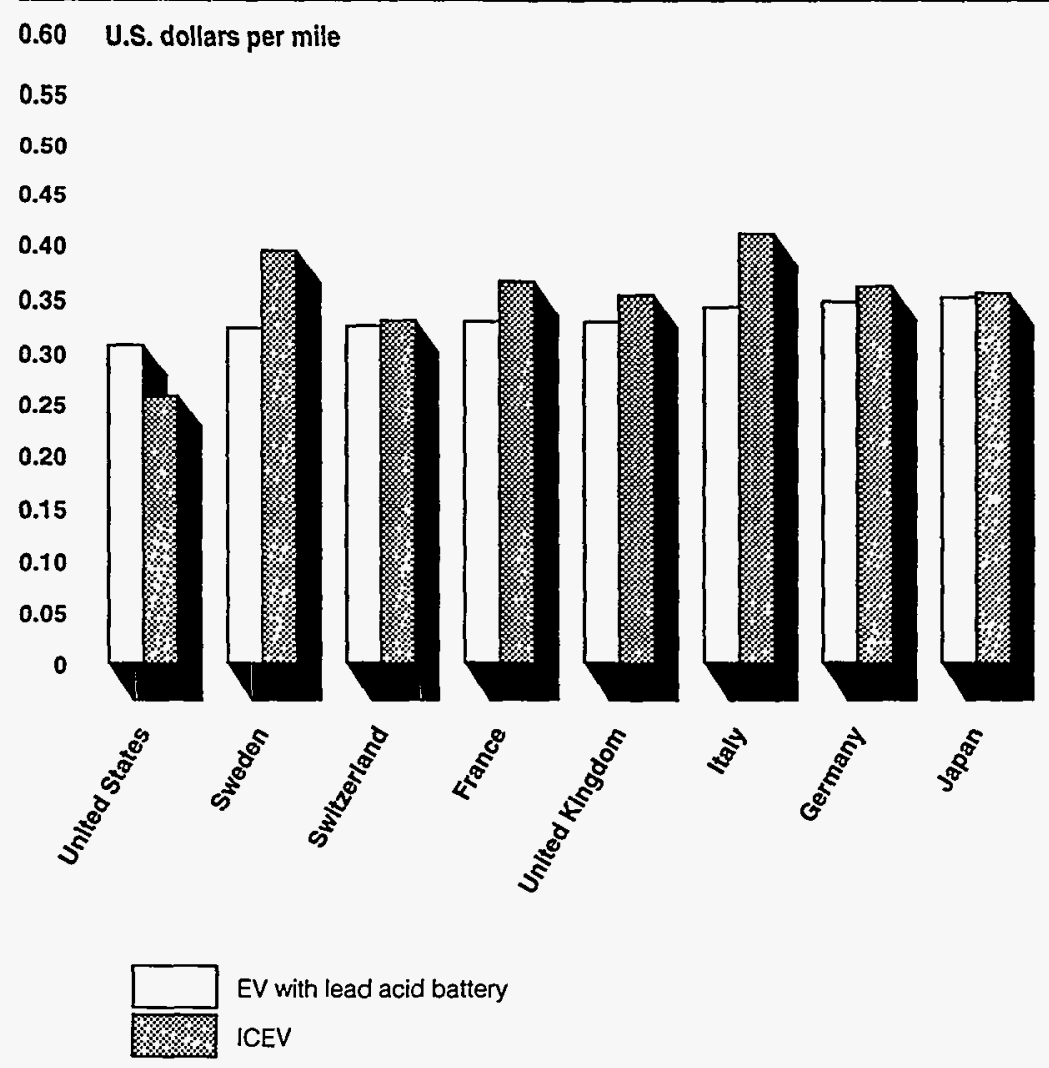

${ }^{a}$ Annual production volume is 100,000 .
Our analyses assumed that the costs of Evs-either the entire vehicle or the battery alone-would decrease as production levels increase, because of the effects of economies of scale and learning on the manufacturing process. While battery costs would remain the greatest contributor to the total costs of Evs, we estimate that different types of batteries would

${ }^{8}$ See International Energy Agency, Electric Vehicles: Technology, Performance and Potential (Paris, France: 1993) for an economic analysis that models additional factors that may affect the uitimate purchase and operating costs of EVs and ICEVs (for example, insurance, taxes, registration, and home recharging stations). 

the vehicle and its batteries for all battery types will be substantially higher than comparable ICEv costs at low production volumes, but as production volumes increase the costs of Evs equipped with all but sodium sulfur batteries will begin to approach those of ICEVs.

As a result of high purchase costs, near-term costs to own and operate an $\mathrm{EV}$ are likely to be significantly higher than those of ICEVs in every nation we reviewed. However, assuming that Ev purchase prices will decrease substantially and that electricity utilities will institute widespread residential off-peak rates, the costs to own and operate an EV would be lower than the costs of a comparable ICEV in every nation except the United States, where gasoline costs less and the ratio of gasoline to electricity prices is lower.

\section{EV Effects on Energy Independence}

OECD estimates that in 1990 the net imports of oil for the nations we reviewed were nearly 930 million tons, with the United States importing more than a third of the total, or 369 million tons. ${ }^{9}$ In this section, we examine the potential effects of introducing Evs on a nation's energy use and energy independence. We collected and analyzed transportation and energy data compiled by supranational organizations, such as OECD and IEA. We combined these data with statistics concerning the energy effects of introducing Evs in the nations we reviewed (except Switzerland, for which no Ev energy effect data were available). Specifically, we calculate the probable savings in energy consumption generally and oil consumption specifically as a result of introducing Evs in each nation based on the amount of oil currently used in both road transport and electricity generation.
Nations' Transportation Statistics
As table 4.3 illustrates, the United States leads the world in total number of automobiles registered, population per vehicle, and percentage of total petroleum consumed by its road transportation sector (56 percent). In absolute terms, the U.S. road transportation sector consumed 368 million metric tons of petroleum products in 1990. 
Table 4.3: Transportation Statistics for Eight Nations, 1990

\begin{tabular}{|c|c|c|c|}
\hline Nation & $\begin{array}{r}\text { Passenger and } \\
\text { commercial } \\
\text { vehicle } \\
\text { registration }\end{array}$ & $\begin{array}{r}\text { Population per } \\
\text { vehicle }\end{array}$ & $\begin{array}{r}\text { Percent of total } \\
\text { petroleum } \\
\text { consumption } \\
\text { used by road } \\
\text { transport }\end{array}$ \\
\hline Switzerland & $3,297,237$ & 2.0 & $37 \%$ \\
\hline Sweden & $3,924,633$ & 2.1 & $\overline{44}$ \\
\hline United Kingdom & $26,301,748$ & 2.2 & 54 \\
\hline France & $28,460,000$ & 2.0 & $\overline{46}$ \\
\hline Italy & $29,727,000$ & 1.9 & 48 \\
\hline \multicolumn{4}{|l|}{ Germany } \\
\hline Federal Republic & $32,684,490$ & 1.9 & 42 \\
\hline Democratic Republic & $5,591,784$ & 2.9 & b \\
\hline Japan & $57,697,669$ & 2.1 & 35 \\
\hline United States & $188,655,462$ & 1.3 & 56 \\
\hline
\end{tabular}

aStatistics are presented in the literature separately for the two Germanys; thus combining them might be misleading.

'Not available.

Source: Motor Vehicle Manufacturers Association of the United States, World Motor Vehicle Data (1992); International Energy Agency, Energy Statistics of OECD Countries, 1989-1990 (París, France: 1992)

Japan had the second highest number of cars registered in 1990, yet, relative to the United States, Japan registered less than one third the number of automobiles, and its road transport sector consumed only 35 percent of its total oil supply. In absolute terms, Japan's road transport sector consumed more petroleum than any other nation's except the United States. However, its consumption of 57 million metric tons was only 15 percent of the amount consumed by the U.S. transport sector.

The number of persons per vehicle in the seven other nations is much higher than that in the United States. Many households in Europe and Japan own only one car. Most of the nations we reviewed have well-developed intra- and intercity public transportation systems that make the personal automobile less necessary for mobility than it is in some U.S. cities. The dominant trend in U.S. road transportation over the last century has been the rise of the automobile as the principal form of travel. While many metropolitan areas have extensive public transportation systems, the preferred form of transportation for most Americans is still their own automobile. In 1990, total personal passenger 
Chapter 4

National and Regional Effects: Economics,

Energy, and the Environment

vehicle miles traveled in the United States exceeded 1.5 trillion miles and consumed nearly 73 billion gallons of fuel, or 54 percent of the total road transportation sector's motor fuel consumption.

\section{Estimates of EV Effects on Energy Consumption and Independence}

Energy Consumption
EVs would reduce energy consumption if they consumed less energy in the form of electricity than ICEvs consumed in the form of gasoline. Evs would reduce petroleum consumption if they were recharged by electricity produced by sources other than petroleum. Evs would increase petroleum independence if their use resulted in decreases in net oil imports.

With regard to energy consumption, OECD compared the total amount of primary energy (that is, petroleum in oil fields, coal in coal mines, or natural gas in gas fields) required to travel a kilometer in either an EV or an ICEV. ${ }^{10}$ Primary energy consumption considers the fuel efficiencies of vehicles themselves as well as the energy efficiencies of converting primary fuels into usable end products (gasoline and electricity). For ICEvs, this would include energy losses associated with extracting, refining; and transporting petroleum as well as the major energy loss that occurs during gasoline combustion in the engine. For Evs, the major energy loss occurs during electricity generation at power plants, but losses through power transmission, the charger, battery, controller, motor, and transmission also contribute.

Three different electricity fuel sources are considered: coal, natural gas, and oil. Results of the analyses for small vans are shown in table 4.4 for two different compact vans: low-performance Evs (for example, sodium sulfur batteries using $.65 \mathrm{kWh}$ per mile that meet the USABC midterm criteria) compared to high fuel economy ICEvs ( $28 \mathrm{mpg}$ ) and high-performance Evs (for example, lithium batteries using .41 kWh per mile that meet the USABC long-term criteria) and low fuel economy ICEVS (21 mpg). ${ }^{11}$ OECD made these comparisons to illustrate the likely best and worst case scenarios.

${ }^{10}$ OECD's work is based in part on D. Sperling and M. D. DeLuchi, "Alternative Fuels and Air Pollution Impacts, " prepared for OECD by the Institute of Transportation Studies, University of California, Davis, California, 1991, and Q. Wang and M. A. DeLuchi, "Impacts of Electric Vehicles on Primary Energy Consumption and Petroleum Displacement, "Energy, 17 (1992), 351-66.

${ }^{11}$ A fuel economy of $21 \mathrm{mpg}$ for the low-performance ICEV may be somewhat misleading, given that the average fuel economy for 1994 model minivans as reported by Consumer Reports (April 1994) was only $17.4 \mathrm{mpg}$. 
Table 4.4: Changes in Primary Energy Consumption by EVs Relative to ICEV Energy Consumption ${ }^{\mathrm{a}}$

\begin{tabular}{|c|c|c|c|c|c|c|}
\hline \multirow[b]{2}{*}{ Nation } & \multicolumn{3}{|c|}{$\begin{array}{l}\text { Low-performance EVs and } \\
\text { high-performance ICEVs }\end{array}$} & \multicolumn{3}{|c|}{$\begin{array}{l}\text { High-performance EVs and } \\
\text { low-performance ICEVs }\end{array}$} \\
\hline & Coal & Natural gas & Oil & Coal & Natural gas & Oil \\
\hline France & $27.3 \%$ & $-14.4 \%$ & $51.5 \%$ & $-40.2 \%$ & $-59.8 \%$ & $-28.8 \%$ \\
\hline Germany & 27.3 & 37.5 & 10.9 & -40.2 & -35.4 & -47.9 \\
\hline Italy & 20.1 & 26.0 & 29.9 & -43.6 & -40.8 & -39.0 \\
\hline Japan & 2.5 & 10.6 & 8.2 & -51.8 & -48.0 & -49.1 \\
\hline Sweden & 121.2 & 126.8 & 89.4 & 3.9 & 6.6 & -11.0 \\
\hline United Kingdom & 31.3 & 74.5 & 42.1 & -38.3 & -18.0 & -33.3 \\
\hline United States & 27.3 & 33.4 & 33.7 & -40.2 & -37.3 & -37.2 \\
\hline
\end{tabular}

${ }^{\mathrm{a}} \mathrm{A}$ negative percentage indicates that $\mathrm{EV}$ s decrease primary energy consumption. A positive percentage indicates that EVs increase primary energy consumption. These calculations are based on a model developed by Q. Wang and M. A. DeLuchi ("Impacts of Electric Vehicles on Primary Energy Consumption and Petroleum Displacement," Energy, 17 (1992), 351-66) that predicts EV electricity consumption based on the fuel economy of a comparable ICEV. EV power train efficiency relative to ICEV power train efficiency, EV battery and charger efficiencies, and the energy efficiency penalty of added EV weight. Power plant conversion and distribution efficiencies are from D. Sperling and M. D. DeLuchi ("Alternative Fuels and Air Pollution Impacts," prepared for OECD by the Institute of Transportation Studies, University of California, Davis California, 1991) and range from a low of 19 percent for coal-fired plants in Sweden to a high of 53 percent for gas-fired plants in France.

Source: OECD, Electric Vehicles: Technology, Performance and Potential (Paris, France: 1993).

Thus, EVs that meet the USABC midterm criteria may fare poorly in terms of the amount of primary energy they would consume in the form of electricity compared to the amount of primary energy that would be consumed in the form of gasoline by an ICEV with high fuel economy. Sweden could be expected to incur the largest increases in primary energy consumption, and only France might reduce primary energy consumption with Evs, providing they are powered by electricity produced from natural gas.

If EVs achieve the high performance goals set by the USABC and ICEVs do not achieve a markedly better fuel economy than they have today, then Evs will significantly reduce primary energy consumption relative to ICEvs in all nations using all electricity generation sources except for those Evs powered by coal- or natural gas-generated electricity in Sweden.

Thus, reductions in primary energy consumption are based primarily on EV technology, ICEV fuel economy, and power-plant efficiency. While it is not known at this time the extent to which EVs or ICEvs will achieve their 
Chapter 4

National and Regional Effects: Economics,

Energy, and the Environment

respective performance goals, it appears reasonable to assume that Evs would be more likely to realize greater improvements than ICEvs simply because Evs are less advanced technically than ICEVs and thus have greater room for improvement. The power trains of Evs (from the battery to the tires) are already more energy efficient than those of ICEvs (from the gas tank to the tires). Wang and DeLuchi project that the propulsion efficiency of a $1995 \mathrm{EV}$ (from the electricity outlet to the tires) will be more than twice that of an ICEv's efficiency (from the gas tank to the tires). In 2010, the ratio should double to 4:1, mainly because of improved batteries with higher energy densities that allow reduced battery weights.

Projected savings in petroleum consumption are estimated by comparing the amount of petroleum consumed by Evs to charge their batteries with the amount of petroleum consumed by ICEVs in the form of gasoline. ${ }^{12}$ Primary energy consumption is one factor that must be considered. The others are the actual amounts of oil used in road transport and electricity generation in each nation. ${ }^{13}$

Table 4.5 presents our analysis of the projected savings in total oil consumption and imported oil consumption if Evs were to replace 10 percent of ICEvs in each nation. The analysis assumes the current state of both EV and ICEV technology and would have to be modified if the energy efficiency of either were to change.

${ }^{12}$ The EV fuel cycle may use petroleum to generate electricity as well as smaller amounts of petroleum to process other forms of energy (natural gas, coal, uranium, and so on) for electricity. The ICEV fuel cycle uses petroleum in the form of gasoline as its primary fuel source, but petroleum is also used to process crude oil into gasoline. Both the direct and indirect uses of petroleum are considered for EVs and ICEVs.

${ }^{13}$ More realistic estimates of $\mathrm{EV}$ petroleum consumption would require an examination of the marginal, or off-peak, sources of electricity generation when EVs will most likely recharge. However, such information is typically unavailable. 
Chapter 4

National and Regional Effects: Economics,

Energy, and the Environment

Table 4.5: Nations' Oil Use Statistics and Projected Annual Savings in Oil If EVs Replace 10 Percent of ICEVs

\begin{tabular}{|c|c|c|}
\hline Nation & $\begin{array}{r}\text { Amount oil in road } \\
\text { transport }^{\mathrm{a}} \% \text { of total } \\
\text { supply) }\end{array}$ & $\begin{array}{l}\text { Amount oil in } \\
\text { electricity generation } \\
\text { (\% of total supply) }\end{array}$ \\
\hline France & $36.94(41 \%)$ & $1.56(2 \%)$ \\
\hline Germany & $45.14(40)$ & $2.64(2)$ \\
\hline Italy & $30.84(34)$ & $21.67(24)$ \\
\hline Japan & $60.59(24)$ & $34.57(14)$ \\
\hline Sweden & $6.23(42)$ & $0.14(1)$ \\
\hline Switzerland ${ }^{c}$ & $4.86(36)$ & $0.10(1)$ \\
\hline United Kingdom & $37.04(45)$ & $7.65(9)$ \\
\hline United States & $391.53(52)$ & $29.19(4)$ \\
\hline
\end{tabular}




\begin{tabular}{|c|c|c|c|c|c|}
\hline $\begin{array}{r}\text { Amount oil used by } \\
\text { EV as \% used by } \\
\text { ICEV }\end{array}$ & $\begin{array}{r}\text { Total amount of oil } \\
\text { saved with } 10 \% \text { EVs } \\
(\% \text { of totals) }\end{array}$ & $\begin{array}{l}\text { Proportion of oil } \\
\text { supply imported }\end{array}$ & $\begin{array}{r}\text { Amount of imported } \\
\text { oil saved with } 10 \% \\
E^{2} s^{\mathrm{a}}(\% \text { of total) }\end{array}$ & $\begin{array}{r}\text { Savings in } \\
\text { imported oil } \\
(\$ \text { million })^{\mathrm{b}}\end{array}$ & Savings as $\%$ of GDP \\
\hline $2.6 \%$ & $6 \quad 3.6(9.7 \%)$ & 0.99 & $3.55(4.0 \%)$ & $\$ 496$ & $.050 \%$ \\
\hline 2.7 & $4.39(9.7)$ & 0.97 & $4.25(3.9)$ & $\$ 593$ & .045 \\
\hline 27.7 & $2.23(7.2)$ & 1.00 & $2.23(2.4)$ & $\$ 311$ & .032 \\
\hline 14.6 & $5.18(8.5)$ & 1.00 & $5.17(2.0)$ & $\$ 723$ & .031 \\
\hline 8.5 & $0.57(9.2)$ & 1.00 & $0.57(3.7)$ & $\$ 80$ & .054 \\
\hline$d$ & & 0.99 & ${ }^{d}$ & & \\
\hline 14.9 & $3.15(8.5)$ & $-0.13^{\circ}$ & -0.41 & $(\$ 57)$ & $(.006)$ \\
\hline 6.8 & $36.5(9.3)$ & 0.49 & $17.80(4.8)$ & $\$ 2,488$ & .044 \\
\hline
\end{tabular}

aAmounts in million metric tons of oil equivalent (Mtoe). One Mtoe is equal to 7.35 million barrels of oil.

bThe 12-month average price of a barrel of oil was $\$ 19.00$ for the period ending June 27, 1994 .

Information about petroleum displacement was unavailable. Therefore, savings in petroleum and imported oil could not be calculated.

Not available.

eUnited Kingdom realized a net export of oil in 1990.

Source: International Energy Agency, Energy Balances of OECD Countries (1989-90) (Paris, France: 1992), and Electric Vehicles: Technical, Performance, and Potential (Paris, France: 1993).

In absolute terms, the United States would realize the largest savings in oil (36.5 Mtoe, or 9.3 percent of the total currently consumed by its road transportation sector). Japan would save 5.18 Mtoe of oil, but in relative terms it would save only 8.5 percent of its current total road transport consumption. Italy would save the least in relative terms-only

\section{2 percent.}

These statistics imply that nations, such as Japan and Italy, that use large proportions of their total oil supply to generate electricity will not see savings in oil as large as those in other nations that rely very little on oil to generate electricity. To the extent that such nations turn to other sources of electricity, such as nuclear power, their savings would increase.

The final issue we considered was the probable effect of introducing Evs on petroleum independence. Most of the nations we reviewed imported nearly all their oil in 1990 . The exceptions were the United Kingdom, which realized a net export of oil, and the United States, which imported about half of its oil. For nations that import most of their oil, savings in 
imported oil are roughly equal to savings in total oil. For the United States, savings in imported oil are half the total oil savings, or 17.8 Mtoe. The United Kingdom would presumably realize a surplus of oil for export of 0.41 Mtoe annually. Italy and Japan would realize a smaller reduction in total oil imports with the introduction of Evs than the other nations we reviewed.

In monetary terms, all nations would save substantial sums with the introduction of EVs. Savings in total oil consumed would range from $\$ 80$ million in Sweden to $\$ 5.1$ billion in the United States. All nations except the United States and the United Kingdom import virtually all their oil and therefore would save approximately the same amount in the total imported oil consumed. The United States imports nearly half of its oil and would save $\$ 2.5$ billion with the introduction of Evs. ${ }^{14}$ The United Kingdom might stand to profit $\$ 57$ million annually from its surplus oil for export.

We examine the relative effect of these savings by presenting them as a percentage of gross domestic product in each nation. In relative terms, Sweden would save more (.054 percent of GDP) than any other nation, and France and Germany would save more than the United States. Italy and Japan would realize smaller relative savings than any other nation.

From our review of the literature, it appears that near-term Evs may consume more energy than conventional gas vehicles, but projections of the amount of petroleum that will be used to generate future electricity in the United States are so low that Evs would still save significant amounts of petroleum. On a per-mile basis, it is estimated that Evs could reduce U.S. transportation petroleum use by over 90 percent in 1995 and 96 percent in 2010. Of the nations we reviewed, only Italy and Japan rely heavily on imported oil to generate electricity (49 percent and 32 percent, respectively) and therefore could not be expected to decrease their reliance on imported oil as a result of EV use as much as other countries.

The United States imported 1-1/2 to 370 times more oil than any other nation we reviewed and consumed 5 to 70 times more energy in the forms of coal, petroleum, gas, and electricity. Thus, in terms of decreasing petroleum fuel consumption and producing long-term energy savings, the United States clearly stands to gain significantly from replacing its ICEvs with EVs. Moreover, because U.S. households tend to own more than one

${ }^{14}$ The extent to which EVs would displace imported oil or domestic oil would, in fact, depend upon the relative end prices of these two sources. If domestic oil costs exceed imported oil costs, then it is possible that the United States could choose to displace domestic oil. 
car, they may be in a better position to incorporate the current limited-range Ev into household schedules.

EV Effects on Air Quality
We begin our discussion of the estimated effects of Evs on poliution reduction with a discussion of the primary sources and health effects of a variety of air pollutants. We follow this with data on each nation's pollution status and current fuel mixes for electricity generation and a discussion of how these factors might influence the potential effect of $\mathrm{EV}$ use on air pollution. Following this section, we present data from four U.S. cities with different electricity fuel mixes and air pollution problems to demonstrate the potential range and magnitude of the effects of Evs for urban areas in the United States.

\section{Sources and Health Effects of Air Pollutants}

The effect of air pollution on health is a relatively new field of inquiry and direct causal relationships are difficult to measure. We did not review research that attempts to uncover the causal health effects of air pollution. The information in table 4.6 presents an overview of the sources of common air pollutants and potential health effects that have been discussed in the literature we reviewed.

Table 4.6: Health Problems Commonly Associated With Air Pollutants

\begin{tabular}{|c|c|c|}
\hline Pollutant & Source & Problem \\
\hline Carbon monoxide & $\begin{array}{l}\text { Vehicle exhaust, fossil fuel electricity } \\
\text { generation, agricultural land clearing }\end{array}$ & $\begin{array}{l}\text { Interferes with blood's ability to absorb } \\
\text { oxygen, which impairs perception and } \\
\text { thinking, slows reflexes, causes } \\
\text { drowsiness, and can cause } \\
\text { unconsciousness and death; if inhaled by } \\
\text { pregnant women, may threaten growth and } \\
\text { mental development of fetus }\end{array}$ \\
\hline Carbon dioxide & $\begin{array}{l}\text { Vehicle exhaust, fossil fuel electricity } \\
\text { generation, agricultural land clearing }\end{array}$ & $\begin{array}{l}\text { As the major component of greenhouse } \\
\text { gas emissions, has an indirect effect on } \\
\text { increased possibility of skin cancers }\end{array}$ \\
\hline Airborne lead & Fuel additives, metal smelters, batteries & $\begin{array}{l}\text { Affects circulatory, reproductive, nervous, } \\
\text { and kidney systems; suspected of causing } \\
\text { hyperactivity and lowered learning ability in } \\
\text { children; accumulates in bone and other } \\
\text { tissues and, therefore, hazardous even } \\
\text { after exposure ends }\end{array}$ \\
\hline Nitrogen oxides & $\begin{array}{l}\text { Vehicle exhaust, fossil fuel electricity } \\
\text { generation, industrial boilers }\end{array}$ & $\begin{array}{l}\text { Can increase susceptibility to viral } \\
\text { infections such as influenza, irritate lungs, } \\
\text { and lead to bronchitis and pneumonia }\end{array}$ \\
\hline
\end{tabular}


Chapter 4

National and Regional Effects: Economics,

Energy, and the Environment

\begin{tabular}{ll}
\hline Pollutant & Source \\
\hline Sulfur dioxide & $\begin{array}{l}\text { Fossil fuel electricity generation, metal } \\
\text { smelting, vehicle exhaust }\end{array}$ \\
\hline Volatile organic compounds & \\
\hline behicle exhaust, refineries, gas stations, \\
industry, solvents
\end{tabular}

Problem

Potent respiratory irritant; can impair lung function by constricting airways and damaging lung tissue; can aggravate asthma and emphysema

Depending on the compound, effects include eye irritation, respiratory irritation, and cancer

Ozonec

Fossil-fuel electricity generation, vehicle exhaust, paints and solvents

An oxidizing agent that attacks cells and breaks down body tissues, even at low concentrations; irritates mucous membranes of respiratory system; causes coughing, choking, damaged lung tissue, and impaired lung function; reduces resistance to colds and pneumonia; can aggravate chronic heart disease, asthma, bronchitis, and emphysema

Toxic emissions ${ }^{d}$

Industry, vehicle exhaust, coal-source

A broad category including many different electricity generation compounds that are suspected or known to cause cancer, reproductive problems, and birth defects

${ }^{a}$ Carbon dioxide accounts for the largest share of radiative forcing from increased greenhouse gas emissions, but other contributors are methane (from solid waste, livestock, coal mining, rice cultivation, and natural gas production), chlorofluorocarbons (industry), and nitrous oxide.

'The most abundant are hydrocarbons. Condensation of volatile organic compounds and sulfur dioxide creates particulates, including smoke, soot, and dust.

cOzone (the primary component of urban smog) is a reactive gas formed when energy from sunlight causes hydrocarbons (a byproduct of many industrial processes and engines) to react with nitrogen oxides (produced by both cars and power plants).

'These include toxic hydrocarbons such as benzene, toluene, xylene, and ethylene dibromide.

Source: Adapted from Environmental Protection Agency, World Watch Institute, International Energy Association, and Organization for Economic Cooperation and Development sources.

Motor vehicle use causes more air pollution than any other human activity, contributing nearly half of the human-caused nitrous oxides, two thirds of carbon monoxide, and about half of the hydrocarbons in industrialized countries around the world. Evs emit no direct pollutants. However, electricity power plants pollute if they use fossil fuels (coal, oil, or gas) to generate electricity.

Nations' Pollution Statistics
While industry and electric power generation contribute substantially to pollution, addressing vehicle emissions is an essential element in reducing both local and regional air pollution. As table 4.7 illustrates, the extent of 
Table 4.7: Percentage Share of Global Greenhouse Gas Emissions and Per Capita Emissions With Greenhouse Index Rankings, 1989 pollution problems varied greatly among the nations we reviewed in terms of their 1989 percentage shares of global emissions and per capita emission estimates (and world rank among the 50 highest polluting nations) for the major greenhouse gases of carbon dioxide, methane, and chlorofluorocarbons. The United States ranked number 1 in the world in terms of its contribution to world greenhouse gas emissions in 1989 and number 6 for per capita emissions. ${ }^{15}$ At the other end of the spectrum, Sweden and Switzerland did not emit enough greenhouse gases to rank among the top 50 polluting nations, although their respective rankings were 46 and 49 for per capita emissions.

\begin{tabular}{lcrrr}
\hline Nation & $\begin{array}{c}\text { Percent } \\
\text { share }\end{array}$ & Rank & $\begin{array}{r}\text { Per capita } \\
\text { emissions }\end{array}$ & Rank \\
\hline United States & $18.4 \%$ & 1 & 9.8 & 6 \\
\hline Japan & 5.6 & 4 & 6.0 & 19 \\
\hline Germany & 3.6 & 7 & 6.1 & 16 \\
\hline United Kingdom & 2.4 & 8 & 5.5 & 27 \\
\hline Italy & 1.8 & 10 & 4.2 & 41 \\
\hline France & 1.7 & 11 & 4.1 & 43 \\
\hline Sweden & b & b & 3.9 & 46 \\
\hline Switzerland & b & b & 3.7 & 49 \\
\hline
\end{tabular}

Includes both the Federal Republic of Germany and the Democratic Republic of Germany.

'Not ranked among the 50 highest-polluting nations.

Source: The World Resources Institute, the United Nations Environment Programme, and the United Nations Development Program, World Resources: 1992-93 (Oxford, Eng.: Oxford University Press, 1992).

While the carbon dioxide resulting from burning fossil fuels is widely considered to be the most potent greenhouse gas, all emissions contribute to global pollution problems. Table 4.8 shows that transportation contributes substantially to emissions of nitrogen oxides, carbon monoxide, and carbon dioxide. Transportation-related emissions of sulfur dioxide are quite low; most sulfur dioxide is emitted by coal-burning electricity generators.

${ }^{16}$ Nations ranked numbers 1-5 for per capita emissions are United Arab Emirates (15.7), Qatar (12.4), Luxembourg (10.5), Ivory Coast (10.4), and Bahrain (10.2). 
Table 4.8: Percentage of Emissions Attributable to Various End Use Sectors
Estimates of EV Effects on Pollution Emissions
Electricity Fuel Mixes

\begin{tabular}{lcccc}
\hline Sector & $\begin{array}{c}\text { Nitrogen } \\
\text { oxide }\end{array}$ & $\begin{array}{c}\text { Carbon } \\
\text { monoxide }\end{array}$ & $\begin{array}{c}\text { Carbon } \\
\text { dioxide }\end{array}$ & $\begin{array}{c}\text { Sulfur } \\
\text { dioxide }\end{array}$ \\
\hline Transport & $54 \%$ & $89 \%$ & $28 \%$ & $6 \%$ \\
\hline Industry & 22 & 1 & 34 & 65 \\
\hline Other & 24 & 10 & 38 & 29 \\
\hline
\end{tabular}

Source: Organization for Economic Cooperation and Development and International Energy Association, Energy Efficiency and the Environment (Paris, France: 1991).

In many respects, Evs have the potential to reduce the transportation sector's adverse consequences on environmental quality. From both our literature review and interviews with experts, we found wide agreement that Evs could be a cleaner alternative to ICEVs, particularly in highly polluted and congested urban areas where poor ambient air quality poses a serious health threat. Evs produce virtually no tailpipe emissions and the net effect on air quality - the savings from reducing tailpipe emissions minus the additional smokestack emissions associated with increased electricity generation-is generally considered to be significantly less than that of ICEVS.

Hydrocarbon and carbon monoxide emissions from Evs are typically estimated to be 10 to 20 times lower than those from ICEVs. If Evs are charged by electric utilities employing hydropower, nuclear power, or other renewable resources, they contribute almost no nitrogen oxides, sulfur dioxide, or carbon dioxide to the atmosphere. However, electricity generation from coal, oil, or gas does emit these pollutants. The central factor determining the effect of Evs on pollution emissions, then, is the source of fuel used to generate electricity. ${ }^{16}$

As table 4.9 illustrates, the projected mix of fuels that will be used to produce electricity in 2005 is expected to vary greatly in the nations we reviewed. Because nuclear and hydropower plants emit the least amount of pollutants, France, Sweden, and Switzerland will benefit most from replacing ICEVs with EVs. However, Germany, Italy, Japan, the United Kingdom, and the United States will have more "carbon-intensive" electricity generation mixes. ${ }^{17}$ That is, they will obtain substantial portions of their electricity from less clean fuel sources, such as solid fuels (mainly coal), gas, and oil, which emit significant amounts of pollutants. While

${ }^{16}$ Our analysis of pollution considers only air pollution. We recognize that fuel chains can also result in the destruction of natural habitat and other forms of environmental damage.

${ }^{17}$ In the United States, the regional variations in power generation sources are large. Thus, the regional distribution of EVs in the United States will have a large influence on the environment. 
Chapter 4

National and Regional Effects: Economics,

Energy, and the Environment

nations that produce electricity from coal, gas, and oil fuels may still reduce pollution emissions using Evs, the overall effect will be less than that of nations using more nuclear and hydropower plants.

Table 4.9: Projected Electricity Generation Mixes in Eight Nations in $2005^{\mathrm{a}}$
Estimated Emission Effects of Electric Vehicles

\begin{tabular}{lccccc}
\hline Nation & Nuclear & $\begin{array}{c}\text { Hydro-and } \\
\text { geothermal } \\
\text { power }\end{array}$ & Gas & Oil & Coal \\
\hline France & $77 \%$ & $11 \%$ & $3 \%$ & $2 \%$ & $7 \%$ \\
\hline Sweden & 46 & 45 & 3 & 5 & 1 \\
\hline Switzerland $^{d}$ & 43 & 54 & 1 & 1 & 1 \\
\hline Japan & 36 & 12 & 20 & 15 & 17 \\
\hline Germany & 25 & 6 & 15 & 1 & 53 \\
\hline United States & 16 & 15 & 14 & 5 & 50 \\
\hline United Kingdom & 11 & 3 & 33 & 11 & 42 \\
\hline Italy & 0 & 20 & 26 & 24 & 30 \\
\hline
\end{tabular}

aPercentages within nations may not add to 100 because of rounding.

bOECD did not include projected hydropower or geothermal power for 2005. We estimated these for each nation by subtracting the sum of the other sources from 100 percent. We confirmed the validity of our results by comparing them with 1990 statistics for actual hydropower and geothermal electricity generation in these nations.

'Fuel mix in 2000 is used for 2005.

'OECD did not include Switzerland in these projections; we used actual 1990 electricity generation mixes.

Source: Organization for Economic Cooperation and Development and International Energy Association, Electric Vehicles: Technology, Performance and Potential (Paris, France: 1993).

More specifically, replacing gasoline and diesel-fueled vehicles with Evs would decrease the emissions of carbon dioxide, nitrogen oxides, and sulfur dioxide in nations with less carbon-intensive electricity but might actually increase emissions of sulfur dioxide and produce either increases or almost no net change in nitrogen oxides and carbon dioxide in nations with more carbon-intensive electricity.

From these projected electricity fuel mixes, OECD calculated the estimated effect on emissions of replacing a small gasoline-powered van with an electric version in each nation. ${ }^{18}$ ICEV emissions were assumed to adhere to model year 2000 U.S. standards in Germany, Japan, Sweden, and the United States, and model year 2000 ICEVs sold in France, Italy, and the

${ }^{18}$ Switzerland was not included in the OECD analyses. Switzerland's electricity generation mix is similar to that of Sweden. Thus, the effects of introducing EVs in Switzerland may be inferred from estimates for Sweden. 

as they are today. ICEV emissions include both exhaust and evaporative emissions as well as those from crude oil refining. Calculations of power plant emissions were based on the relevant emission standards for each nation, fuel, and pollutant wherever possible. ${ }^{19}$ Finally, emissions per unit of electricity delivered to end users were derived from each nation's power plant conversion and electricity distribution efficiencies. ${ }^{20}$

In sum, although actual emissions from Evs and ICEvs will not be exactly equal to their respective estimated emissions standards, no more exact measure exists. Equating actual emissions with emission standards favors ICEVs because their actual tailpipe emissions are typically higher than applicable standards, yet actual emissions from power plants are generally very close to applicable standards because of frequent monitoring.

Two scenarios were employed in OECD's emissions estimates. The first assumed a high-fuel-economy ICEV ( 28 miles per gallon) and a low-performance EV (based on USABC midterm performance goals, such as with a sodium sulfur battery). The second assumed a low-fuel-economy ICEV (21 miles per gallon) and a high-performance EV (based on USABC long-term performance goals, such as with a lithium polymer battery). ${ }^{21}$

Figures 4.4 and 4.5 illustrate the estimated effects on greenhouse gas emissions under two scenarios of introducing an EV in seven nations. ${ }^{22}$ The model estimates emissions of methane, nitrous oxide, carbon monoxide, nitrogen oxides, nonmethane hydrocarbons, and carbon dioxide from the entire fuel-production and use cycle: materials production and assembly of the vehicles, feedstock recovery, feedstock transport, fuel production, fuel distribution, and end use by ICEVs and power plants. ${ }^{23}$

${ }^{19}$ This was not the case for estimates of sulfur dioxide emissions from natural gas-fired plants and hydrocarbon and carbon monoxide emissions from all power plant types. These were all assumed to be equal to the average uncontrolled emission rate in the United States.

${ }^{20}$ Power plant conversion and distribution efficiencies ranged from 53 percent for natural gas-fired plants in France to 19 percent for coal-fired plants in Sweden.

${ }^{21}$ Low-performance EVs were assumed to have a range of 124 miles and an energy consumption of 0.65 $\mathrm{kWh} /$ mile; high-performance EVs were assumed to have a range of 200 miles and an energy consumption of $0.41 \mathrm{kWh} / \mathrm{mile}$.

${ }^{22}$ Data for Switzerland may be inferred from those for Sweden.

${ }^{23}$ Each pollutant is converted into units of "carbon dioxide equivalents." That is, 1 gram of the noncarbon dioxide gases is equated to the warming effect of 1 gram of carbon dioxide gas over a given period. 
Chapter 4

National and Regional Effects: Economics,

Energy, and the Environment

Figure 4.4: Percent Change in

Emissions of Greenhouse Gases:

Low-Efficiency EV Versus

High-Fuel-Economy ICEVa

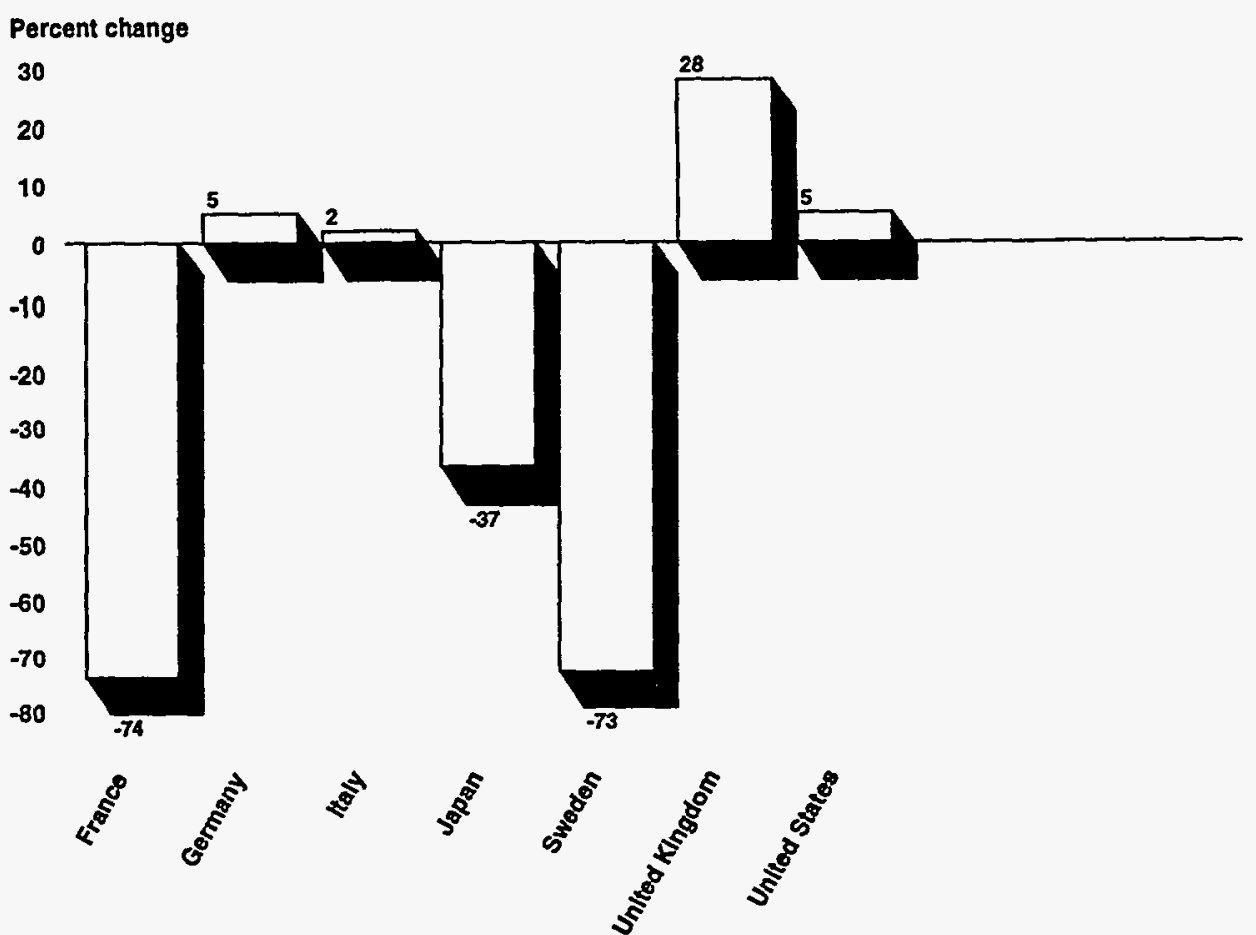

aNumbers shown equal 1 - (EV emissions/ICEV emissions) $\times 100$. Emissions are in grams per mile carbon dioxide equivalent emissions over the entire fuel production and use cycle. 
Figure 4.5: Percent Change in Emissions of Greenhouse Gases: High-Efficiency EV Versus Low-Fuel-Economy ICEV
Percent change

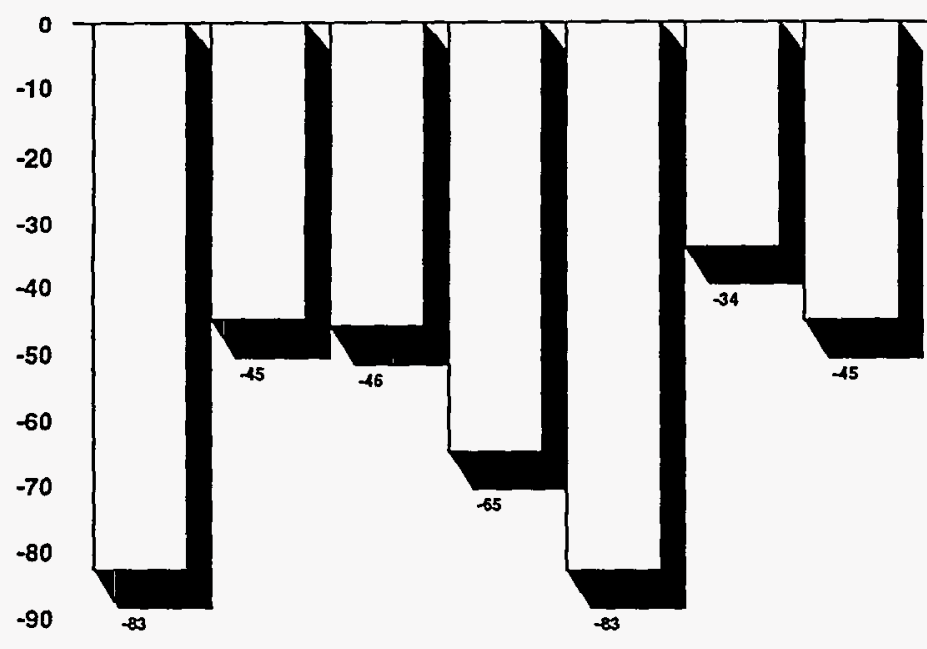

एक

aNumbers shown equal $1-$ (EV emissions/ICEV emissions) $\times 100$. Emissions are in grams per mile carbon dioxide-equivalent emissions over the entire fuel production and use cycle.

Relative to a high-fuel-economy ICEV, a low-performance EV would result in higher emissions in nations that rely heavily on coal-generated electricity. Germany, Italy, the United Kingdom, and the United States would be among these. However, even low-performance Evs might reduce greenhouse gas emissions in nations that rely on low-carbon, nonfossil fuels for electricity, such as France, Japan, and Sweden.

If a high-performance battery is developed and ICEvs do not achieve markedly higher fuel economy (figure 4.5), then all nations could expect to achieve reductions in greenhouse gas emissions with the introduction of Evs. However, those reductions would depend on the carbon intensity of the electricity generation mix: Germany, Italy, the United Kingdom, and the United States would gain fewer emissions benefits by substituting electricity for gasoline. 
Fossil-fuel-fired power plants emit sulfur dioxide, as do gasoline and diesel ICEVS. Emissions of sulfur dioxide from ICEvs are not regulated. However, the sulfur content of gasoline and diesel fuels is regulated. OECD assumed that the emission of sulfur from ICEVs is equal to the sulfur content of unburned fuel. In the United States, the sulfur content of gasoline is about 0.03 percent by weight and will decrease to 0.005 percent for reformulated gasoline available in 2005. France, Germany, Italy, and Sweden regulate the sulfur content of gasoline at 0.1 percent; gasoline in the United Kingdom contains 0.2 percent sulfur. These European nations are expected to reduce the sulfur content of gasoline by half by 2005. Data on the sulfur content of gasoline in Japan are not available; OECD assumed regulations as stringent as those in the United States, as they have been historically. Again, applicable regulations and standards governing power plants were used to estimate sulfur dioxide emissions.

Figures 4.6 and 4.7 show the likely effect on sulfur dioxide emissions of introducing Evs into the seven nations. Substituting a low-performance EV for a high-fuel-efficiency ICEV would result in substantial increases in sulfur dioxide emissions in nations with high-carbon intensity electricity sources. For example, the United States might expect to increase sulfur dioxide emissions by 760 percent with a low-performance Ev. Only France and Sweden (and most likely Switzerland) would reduce sulfur dioxide emissions with low-performance Evs. 
Chapter 4

National and Regional Effects: Economics,

Energy, and the Environment

Figure 4.6: Percent Change in Emissions of Sulfur Dioxide: Low-Efficiency EV Versus High-Fuel-Economy ICEV

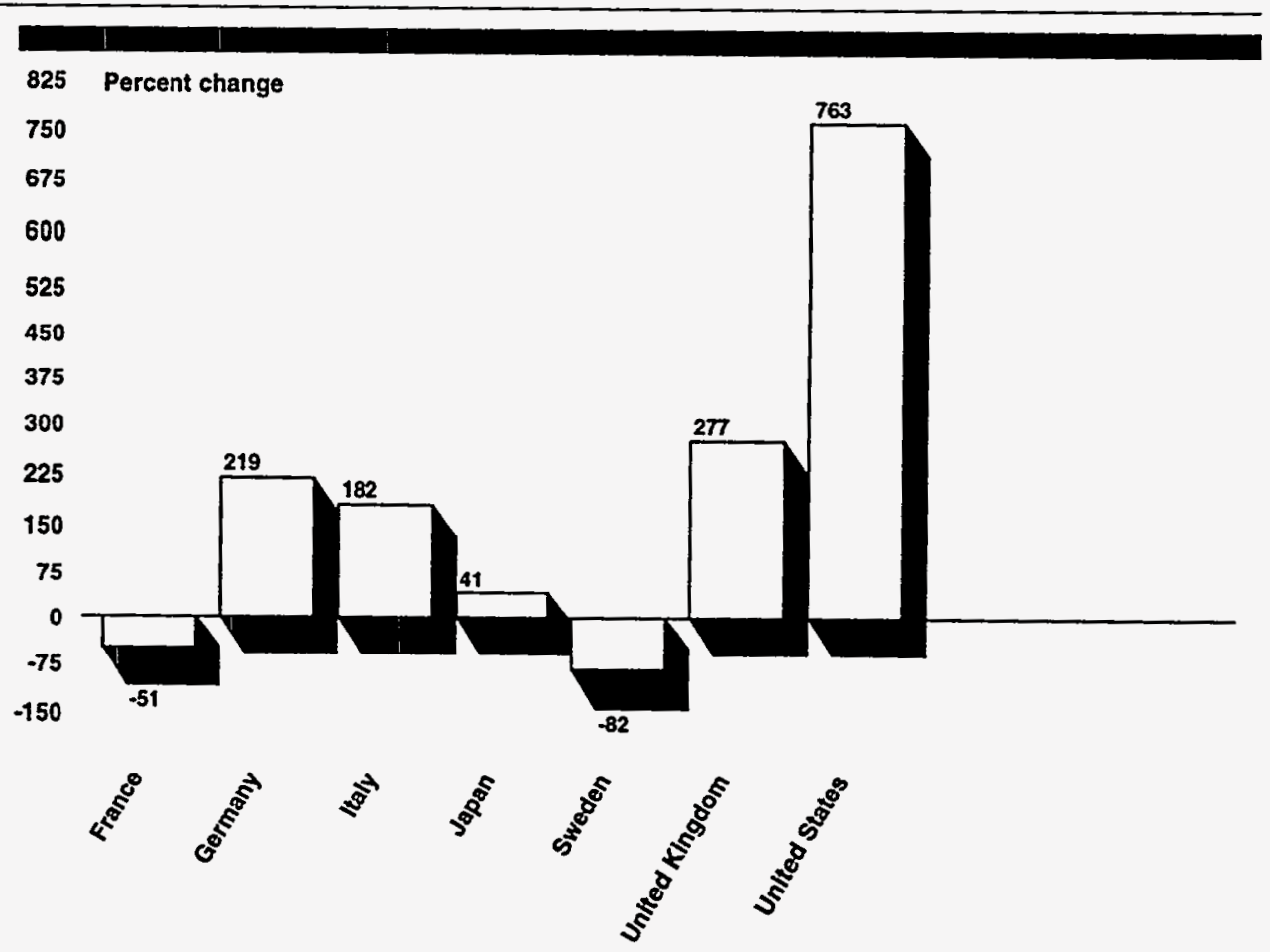

aNumbers shown equal 1 - (EV emissions/ICEV emissions) $\times 100$. Emissions are in grams $/ \mathrm{km}$ over the entire fuel production and use cycle. 
Figure 4.7: Percent Change in Emissions of Sulfur Dioxide: High-Efficiency EV Versus Low-Fuel-Economy ICEV ${ }^{a}$

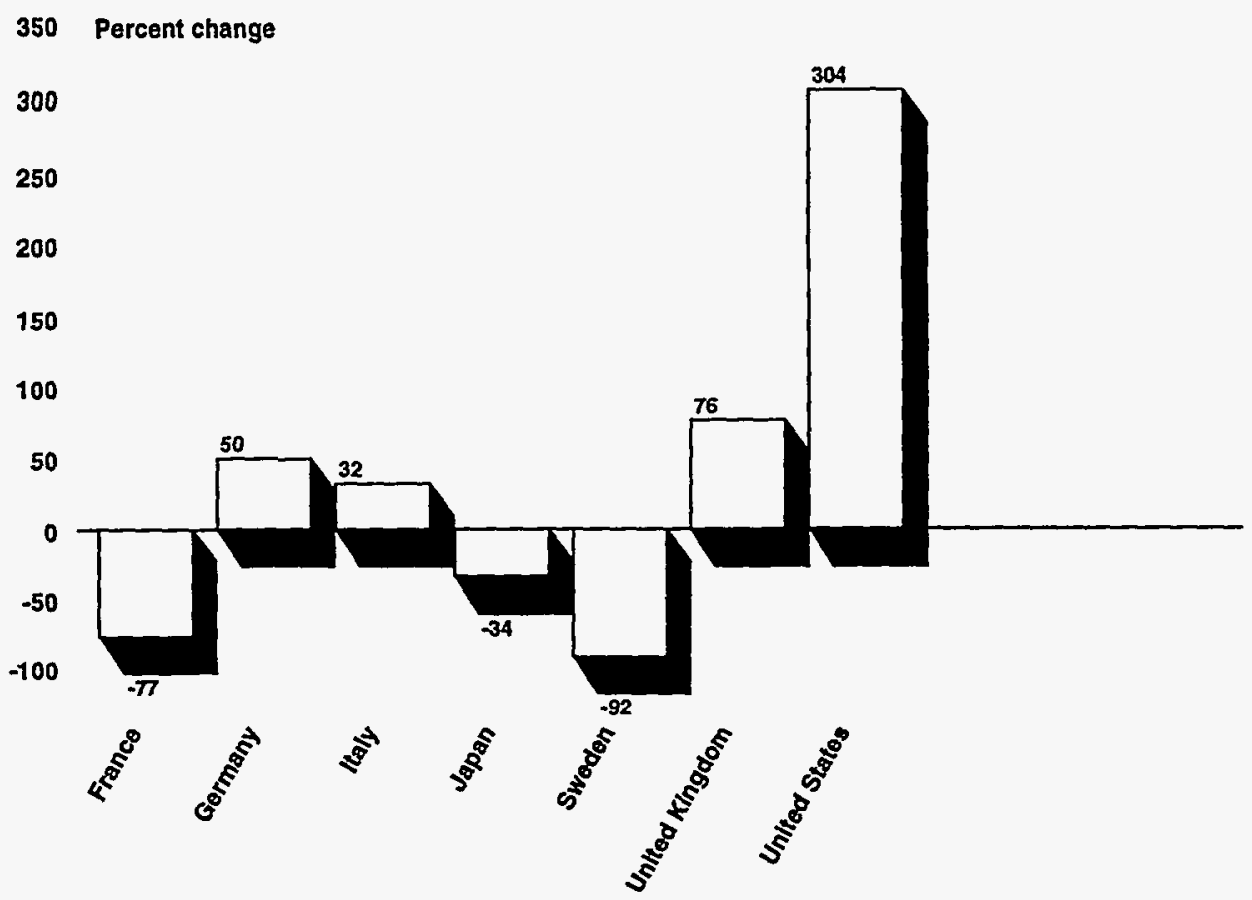

aNumbers shown equal 1 - (EV emissions/lCEV emissions) $\times 100$. Emissions are in grams/km over the entire fuel production and use cycle.

Substituting a high-performance Ev for a low-fuel-economy ICEV would lessen sulfur dioxide emissions in all nations, but the United States might still increase sulfur dioxide emissions by 300 percent, and only Japan would switch from "more" to "less" emissions if Evs improved in performance relative to ICEVs. However, gasoline vehicles are a minor source of sulfur dioxide emissions, which means that in the aggregate, $\mathrm{EV}$ use will not greatly alter these emissions.

The Clean Air Act Amendments require power plants to significantly reduce nitrogen oxide and sulfur dioxide emissions. Yet, costs will increase if additional emissions must be monitored at the power plant. Moreover, other nations we reviewed do not all have air quality restrictions as stringent as those in the United States. Thus, the introduction of EVs in these nations could contribute to increased global emissions of nitrogen oxides and sulfur dioxide. 
Chapter 4

National and Regional Effects: Economics,

Energy, and the Environment

\section{Tailpipes Versus Smokestacks}

In sum, the extent to which evs might reduce air pollution in a given nation is highly dependent on the source of fuel used to generate electricity. Ideally, Evs would be recharged overnight using excess electricity. The fuel used at these off-peak times can be just one of a nation's entire mix. Few analyses consider this "marginal electricity mix." Nor do analyses often generalize beyond the estimated effects of introducing a single Ev for an ICEV to the estimated effects of a larger proportion of Evs in the total fleet (for example, 10 percent as California has mandated for 2003). Finally, although power plant smokestacks pollute, they do not move and are thus easier to monitor and control. The overall effectiveness of introducing Evs should consider the likely costs of monitoring such stationary pollution.

Comparing emissions of carbon monoxide and hydrocarbons is straightforward and unambiguous. Evs have a great advantage over ICEvs as they "emit" virtually none of either pollutant directly or at the power plant, regardless of the electricity fuel source. ${ }^{24}$ However, comparisons of emissions of the other major pollutants are less clear cut. For example, nitrogen oxides emissions of fossil-fuel electricity power plants with varying levels of emissions control could range from 93 percent less than to 95 percent more than emissions from gasoline vehicles. ${ }^{25}$ Several examples illustrate the complexity of determining changes in emissions if EVs replace ICEVS.

Researchers at the Federal Environment Agency of the Federal Republic of Germany used two models to compare pollution emissions for ICEVs and Evs. ${ }^{26}$ The first model used emissions data from the different types of power plants in the Federal Republic of Germany, which was then weighted by the proportion of the total electricity generated by that type of fuel. For example, 38 percent of electricity in 1989 was generated by nuclear power and hydropower, which emit no pollutants; therefore, their contribution to the composite emissions model was zero. The composite emissions scores for each pollutant were used to calculate the emissions of an EV charged by this mix of fuels, and these emission rates were compared to the known emission rates of a comparable catalyst-equipped ICEV.

\footnotetext{
${ }^{24} \mathrm{EVs}$ do not "emit" pollutants in the traditional sense of tailpipe exhaust. We use the term "emit" here to mean the emissions associated with electricity power plants used to charge EV batteries.

${ }^{25}$ M. DeLuchi et al., "Electric Vehicles: Performance, Life-Cycle Costs, Emissions, and Recharging Requirements," Transportation Research A, 23A:3 (1989), 255-78.

${ }^{26} \mathrm{H}$. Blumel, " $\mathrm{CO}_{2}$ and Pollutant Emissions of Catalyst-Equipped, Battery-Powered and Hybrid Cars: A Comparison," in Organization for Economic Cooperation and Development, The Urban Electric Vehicle: Policy Options, Technology Trends, and Market Prospects (Paris, France: 1992).
} 

current electricity generation mix would result in about the same amount of carbon dioxide and nitrogen oxides emissions and ten times more sulfur dioxide than a catalystequipped ICEV. Shorter daily operating ranges substantially increased EV emissions relative to those of ICEVs.

Evs are expected to cause additional electricity demand in Germany, and nearly all surge capacity in Germany is generated by coal-fired plants. Thus, a second emissions model used pollution data from only coal-fired plants (49 percent of total capacity in 1989). Attributing the electricity used to charge batteries to coal-fired power plants dramatically increased the estimated emission-related disadvantages of EVs. At a 30-mile-per-day range, a "coal-charged" EV would result in about 1-1/2 times more carbon dioxide, 2-1/4 times more nitrogen oxides, and 24 times more sulfur dioxide entering the atmosphere than a catalyst-equipped ICEV would emit by its tailpipe. Again, shorter driving ranges increased relative EV emissions.

Thus, the Federal Environment Agency researchers concluded that the discernible increases in global emissions and only minor reductions in local pollution levels imply that the broad-scale introduction of Evs into the Federal Republic of Germany is justifiable only if the zero emission at the place of use is considered more important than the increased emissions at the power plant. Of higher priority in that nation is the introduction of fuel-efficient, catalyst-equipped petroleum vehicles that meet the California requirements for ultra-low emissions-or cleaner power plants.

In direct contrast, French researchers from ADEME found that an EV powered by the French electricity mix would substantially reduce pollution both globally and locally. ${ }^{27}$ France generated 75 percent of its electricity from nuclear power in 1990. Electricity generated by nuclear energy produces virtually no pollutants. Thus, in France charging an EV is predicted to result in nearly 10 times less carbon dioxide, 50 times less carbon monoxide, 5 times less hydrocarbons and nitrogen oxides, and 3 times less sulfur dioxide than a comparable ICEV emits from its tailpipe.

Despite these encouraging predictions for individual EV emissions, the French researchers concluded that the net emissions reductions in France that could be achieved by replacing 10 percent of ICEVs with Evs would be

${ }^{27} \mathrm{~A}$. Morcheoine and G. Chaumain, "Energy Efficiency, Emissions, and Costs: What Are the Advantages of Electric Vehicles?" in The Urban Electric Vehicle. 

carbon dioxide and carbon monoxide with emissions of hydrocarbons, nitrogen oxides, and sulfur dioxide actually increasing.

\section{Environmental Effects of EVs in Four U.S. Cities}

We regard the effect of unique, regional characteristics as central to the debate about whether Evs can substantially reduce air pollution. In the United States, both air pollution problems and fuel mixes vary substantially from region to region. Evs are promoted for urban areas where pollution is typically more of a problem than in rural areas. Yet, our review uncovered few studies that have analyzed the effect of introducing Evs into U.S. urban areas that differ along the critical dimensions discussed above. Wang and Santini analyzed the effect of introducing Evs in 2000 into Chicago, Denver, Los Angeles, and New York City, whose electricity fuel mixes and air quality problems differ from one another. ${ }^{28}$

Table 4.10 presents the marginal power plant mix for $\mathrm{EV}$ recharging as projected by utility companies in about the year 2000 in each of the four cities. Chicago plans to generate all its off-peak electricity from nonpolluting fuels, whereas Denver and New York will receive more than half of their off-peak electricity from highly polluting coal and oil. Los Angeles expects to import much of its off-peak power from natural gas generating plants. However, it is important to note that as of 1990 , Denver, New York, and Los Angeles used coal as their primary high-demand off-peak fuel source. ${ }^{29}$

\footnotetext{
${ }^{28} Q$. Wang and D. Santini, "Magnitude and Value of Electric Vehicle Emissions Reductions for Six Driving Cycles in Four U.S. Cities with Varying Air Quality Problems," presented at the 72nd annual meeting of Transportation Research Board, Washington, D.C., January 10-14, 1993.

${ }^{29}$ The timeline for converting to these cleaner electricity sources may be somewhat optimistic. For example, the North American Electric Reliability Council reported that as of 1990,63 percent of planned capacity additions for 1998 were not yet under construction. (U.S. General Accounting Office, Energy Policy: Developing Strategies for Energy Policies in the 1990s, GAO/RCED-90-85 (Washington, D.C.: June 16, 1990), and Argonne National Laboratory, Three Scenarios for Electric and Hybrid Vehicle Commercialization (Argonne, Ill.: U.S. Department of Energy, 1990).
} 
National and Regional Effects: Economics,

Energy, and the Environment

Table 4.10: Projected Marginal Power Plant Mix for EV Recharging

\begin{tabular}{lrrrr}
\hline Fuel & Chicago & Denver & $\begin{array}{c}\text { Los } \\
\text { Angeles }\end{array}$ & New York \\
\hline Coal & 0 & $52.6 \%$ & $7.5 \%$ & $24.0 \%$ \\
\hline Gas & 0 & 35.2 & 85.0 & 28.0 \\
\hline Oil & 0 & 3.3 & 0 & 48.0 \\
\hline Nuclear, hydro, and other ${ }^{a}$ & $100.0 \%$ & 8.9 & 7.5 & 0 \\
\hline
\end{tabular}

aWang and Santini assumed that power plants fueled by these sources have zero emissions.

Source: Q. Wang and M. D. Santini, "Magnitude and Value of Electric Vehicle Emissions Reduction for Six Driving Cycles in Four U.S. Cities with Varying Air Quality Problems," presented at the 72 annual meeting of Transportation Research Board, Washington, D.C., January 10-14, 1993.

Figure 4.8 presents Wang and Santini's estimates of per-mile emission reductions of an EV relative to emissions of an ICEV for each pollutant in each of the four cities using the Simplified Federal Urban Driving Cycle, a model that estimates emissions for vehicles traveling at an average speed of $18.5 \mathrm{mph}$. As in the German study we discussed above, emissions data from the different types of power plants in the different cities were weighted by the proportion of the total electricity generated by that type of fuel to create composite emissions scores. The composite emissions scores for each pollutant were then used to calculate the emissions of an EV charged by this mix of fuels, and these emission rates were compared to the known emission rates of a comparable ICEv. 
Figure 4.8: Percent Change in Emissions If an EV Replaces an ICEV

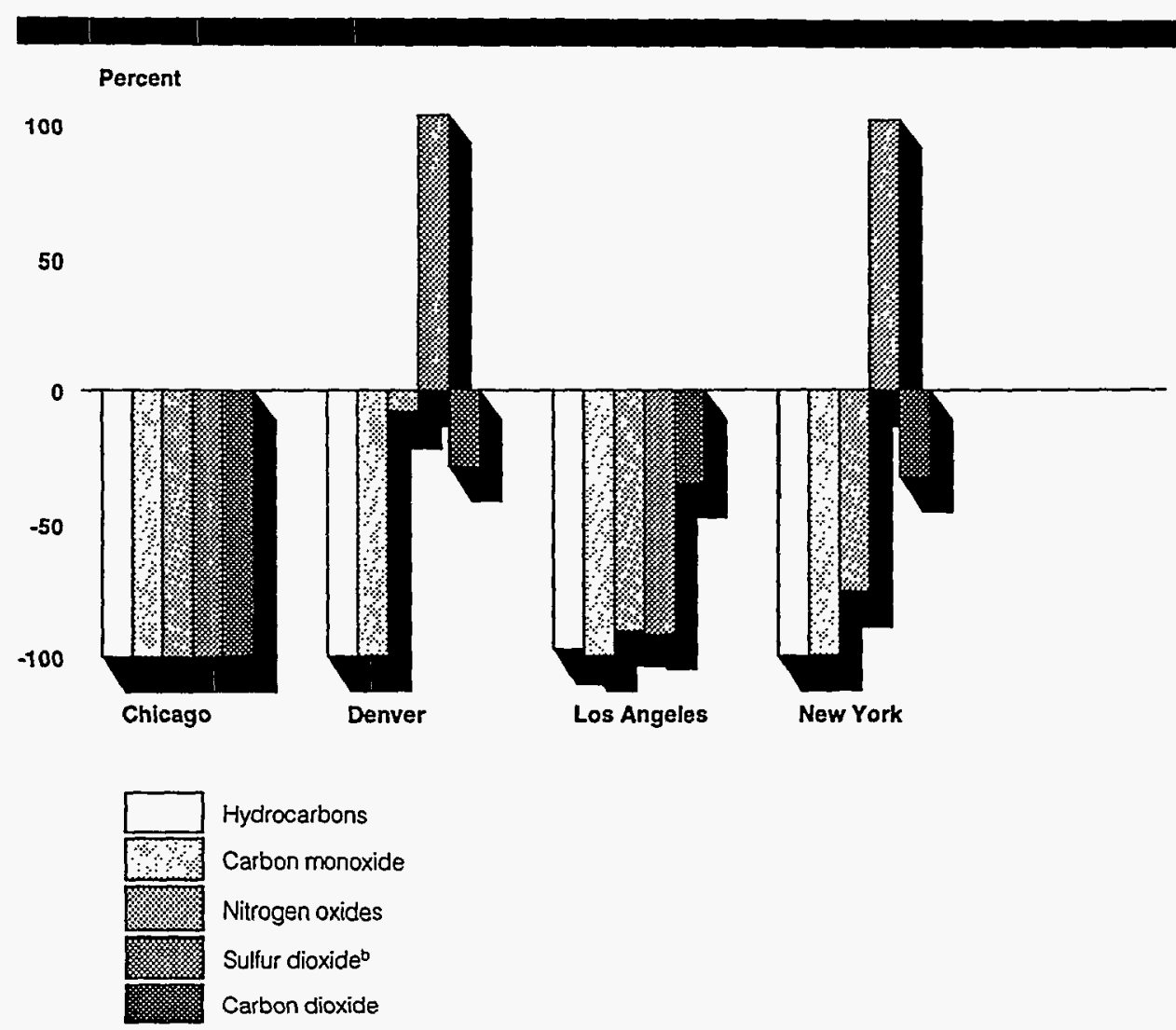

"Changes in per-mile passenger car emissions because of EV use were calculated based on an ICEV with 50,000 accumulated miles and a fuel economy of 26.1 miles per gallon and a four-passenger EV similar to the Ford Ecostar with a fuel economy of $0.37 \mathrm{kWh} / \mathrm{mile}$.

'Sulfur dioxide for New York $\times 10$.

As figure 4.8 illustrates, emissions reductions estimates vary considerably by city. In Chicago, where nuclear power is expected to supply EV electricity, emissions reductions for all pollutants are estimated at 100 percent. Electricity generation-regardless of the fuel source-emits virtually no carbon monoxide or hydrocarbons. In all four cities, the operation of an EV is expected to result in 99-percent less carbon monoxide and more than 97-percent less hydrocarbons than the operation of an ICEV.

In Denver, Los Angeles, and New York, differences in electricity generation mixes would affect potential emissions reductions. With respect to nitrogen oxides, an $\mathrm{EV}$ in Denver (where coal is expected to be 
the primary electricity source) would result in only 8-percent less pollution than an ICEV; in New York, an EV would result in about 75-percent less nitrogen oxides; and an EV in Los Angeles would result in 90-percent less nitrogen oxides. The scenario with sulfur dioxide is expected to be mixed. The sulfur dioxide emitted by an ICEV would be reduced by approximately 90 percent when an EV replaced it in Los Angeles. But an EV would emit 100-percent more sulfur dioxide in Denver and 1,000-percent more in New York, where coal and oil are expected to produce the majority of electricity for $\mathrm{Ev}$ recharging. Some reduction in carbon dioxide emissions is predicted; this varies from about 28 to 35 percent, depending on the carbon intensities of the fuel used to generate electricity.

How much an EV is worth in terms of predicted emissions reduction depends, in part, upon each city's emissions reductions needs and estimated avoided costs per pollutant ${ }^{30}$ Table 4.11 shows the recent status of the four cities in terms of meeting Environmental Protection Agency (EPA) ambient air quality standards. Emissions of hydrocarbons and nitrogen oxides combine to create ozone (photochemical smog) for which Chicago, Los Angeles, and New York currently fail to meet air quality standards. Denver, Los Angeles, and New York have not attained air quality standards for carbon monoxide. And Los Angeles is not in compliance with nitrogen oxides standards. All four cities meet attainment levels for sulfur dioxide.

Table 4.11: Attainment of EPA's Ambient Air Quality Standards in Four Cities

\begin{tabular}{lllll}
\hline City & Ozone & Nitrogen oxides & Carbon monoxide & Sulfur dioxide \\
\hline Chicago & No & Yes & Yes & Yes \\
\hline Denver & Yes & Yes & No & Yes \\
\hline Los Angeles & No & No & No & Yes \\
\hline New York & No & Yes & No & Yes \\
\hline & & $\begin{array}{l}\text { Source: Q. Wang and M. D. Santini, "Magnitude and Value of Electric Vehicle Emissions } \\
\text { Reduction for Six Driving Cycles in Four U.S. Cities with Varying Air Quality Problems, presented } \\
\text { at the 72nd annual meeting of Transportation Research Board, Washington, D.C., January 10-14, } \\
\text { 1993. }\end{array}$
\end{tabular}

${ }^{30}$ Wang and Santini judgmentally correlated estimated costs of pollution reduction (from California Energy Commission) with the seriousness of pollution violations (from the Environmental Protection Agency, EPA). Included are the costs to stay in attainment for each pollutant as well as the costs to offset sulfur dioxide emissions at electricity generation plants. The estimated costs of pollution emissions reductions (on a dollar per ton per year basis) were spread over a 10-year vehicle lifetime assuming 11,000 driving miles per year. 
Chapter 4

National and Regional Effects: Economics,

Energy, and the Environment

As table 4.12 suggests, Evs would be particularly valuable in reducing carbon monoxide air pollution problems in Denver, Los Angeles, and New York. Reductions in hydrocarbons and nitrogen oxides in Chicago, Los Angeles, and New York would decrease ozone levels. And even considering the costs of sulfur dioxide control at coal and oil power plants in Denver and New York, an Ev's overall value is still positive.

Table 4.12: Estimated Avoided Pollution Costs of EVs in Four U.S. Cities $^{\mathbf{2}}$

\begin{tabular}{lrrrr}
\hline Pollutant & Chicago & Denver & $\begin{array}{r}\text { Los } \\
\text { Angeles }\end{array}$ & New York \\
\hline Hydrocarbons & $\$ 2,383$ & 0 & $\$ 2,062$ & $\$ 2,549$ \\
\hline Carbon monoxide & 0 & $\$ 8,314$ & 13,637 & 8,203 \\
\hline Nitrogen oxide & 2,008 & 0 & 2,113 & 1,582 \\
\hline Sulfur dioxide & 50 & -52 & 303 & -506 \\
\hline Total & $\mathbf{\$ 4 , 4 4 6}$ & $\mathbf{\$ 8 , 2 6 2}$ & $\mathbf{\$ 1 8 , 1 1 5}$ & $\mathbf{\$ 1 1 , 8 2 8}$ \\
\hline
\end{tabular}

${ }^{a}$ Over 13 years if driven 1.6 hours per day, equivalent to 209,853 total urban miles traveled.

Source: Q. Wang and M. D. Santini, "Magnitude and Value of Electric Vehicle Emissions Reductions for Six Driving Cycles in Four U.S. Cities with Varying Air Quality Problems," presented at the 72nd annual meeting of Transportation Research Board, Washington, D.C., January 10-14, 1993.

Note: Table has been revised since first printing to reflect updated data provided by Wang and Santini.

In sum, regional electricity fuel mixes affected results in all the environmental impact studies we reviewed. But important distinctions in analytical methods contributed to differences among findings. For example, calculations of pollution reduction benefits produced by Evs often used projected electricity fuel mixes for 2000 and beyond. In many cases, calculations based on current (and often less clean) fuel sources would result in less promising estimates. The wide range of pollution reduction predictions is also partly the result of the physical and operational characteristics of the EV and ICEV used in the comparison. That is, some studies compared EV emissions to those of new catalyst-equipped ICEVS while others used ICEV emission rates after 5 years and 50,000 accumulated miles. Other differences of note included daily miles operated, level of emissions control at the electricity generating plant, vehicle operating speed, and comparisons to gasoline- or diesel-fueled ICEVs. Thus, the findings and conclusions of any one study must be considered within the context of the assumptions used in the comparisons. We also found that while each $\mathrm{EV}$ may significantly reduce emissions of most pollutants relative to what a comparable ICEV emits 
Chapter 4

National and Regional Effects: Economics,

Energy, and the Environment

from its tailpipe, the net air quality benefits that could be achieved by substituting large numbers of Evs for ICEvs may be substantially less optimistic.

Summary and Conclusions
To examine costs to own and operate an $\mathrm{EV}$ as well as likely effects on energy savings and pollution reduction, we reviewed the literature, interviewed experts, and made a number of international site visits. We found that costs to purchase an EV are likely to be substantially higher than those of a comparable ICEV in the near term, when production volumes of EVs are expected to be low. As economies of scale and learning take place, the costs to purchase an EV will begin to approach those of an ICEV. However, purchase costs of different types of Evs will depend heavily on the type of battery used. The costs of different batteries will vary widely, but this variation may be offset somewhat by the number of miles a battery can be used before it must be replaced.

The likely near-term costs to own and operate an Ev in the eight nations is expected to be substantially higher than those of an ICEV. As initial purchase prices decrease, the benefits of lower Ev fueling costs would be realized in all the nations except the United States, where the ratio of gasoline to electricity costs is lower. In the United States, the cost to own and operate an $\mathrm{EV}$ is expected to remain higher than the cost of an ICEV, even at high volumes of production.

Petroleum-based transportation contributes substantially to overall pollution problems and petroleum dependence around the world. We concluded that Evs have the potential to increase energy security, produce energy savings, reduce petroleum consumption, and reduce pollution. However, the likelihood and magnitude of these effects are highly dependent on national and regional variations.

Whether and to what extent a nation reduces reliance on imported oil and petroleum consumption as a result of introducing Evs depends both on the proportion of the total energy supply derived from imported oil and the proportion of electricity generated by oil. Of the eight nations we reviewed, only Italy and Japan may fail to see substantial decreases in the amount of imported oil that would be required by the transportation sector if Evs were to replace ICEVs. Even these nations would save over $\$ 300$ million and $\$ 700$ million, respectively, worth of imported oil annually through replacing 10 percent of their ICEVs with EVs. 
Chapter 4

National and Regional Effects: Economics,

Energy, and the Environment

We also concluded from our review of the literature that, at least in the United States, Evs using current technology may consume more primary energy in the form of electricity than ICEvs consume in the form of petroleum, but future advances should result in Evs using 30 to 35 percent less energy than ICEVs. Moreover, an EV could immediately displace 90 percent or more of the petroleum consumed by an ICEV.

Local and regional pollution is a serious problem in many of the nations we reviewed, including the United States. Evs would eliminate almost entirely the hydrocarbons and carbon monoxide emissions associated with ICEV tailpipes. Reductions in hydrocarbons and nitrogen oxides would decrease ozone, otherwise known as urban smog. However, because many countries and regions of the United States still rely heavily on coal and oil for electricity production, some areas could see substantial increases in sulfur dioxide emissions and no change or moderate increases in carbon dioxide and nitrogen oxides. Yet, the costs-at least in the United States-associated with controlling sulfur dioxide emissions at power plants may be offset by the cost savings realized by reducing the emissions of other pollutants. 


\section{Summary and Conclusions}

\section{Current Barriers to Widespread EV Use}

Current barriers to the widespread introduction of EVs are five: battery technology, infrastructure support, safety, market prospects, and price. Current battery technologies vary in their ability to overcome these and other barriers, which are important to their success. Table 5.1 indicates the outstanding issues that must be resolved for the specific battery types that appear to be the most promising.

Table 5.1: Battery Issues to Be Resolved

\begin{tabular}{|c|c|c|c|c|c|}
\hline Issue & Lead acid & Nickel cadmium & Nickel hydride & Nickel iron & $\begin{array}{l}\text { Sodium sulfur and } \\
\text { sodium chloride }\end{array}$ \\
\hline Range & $x$ & & $\mathrm{a}$ & $x$ & \\
\hline Power & $x$ & & $\mathrm{a}$ & $x$ & $x$ \\
\hline Cycle life & $x$ & & $\mathbf{a}$ & & $x$ \\
\hline Self-discharge & & & & & $x$ \\
\hline Temperature control & & $x$ & $x$ & & $x$ \\
\hline Safety & & $x$ & & $x$ & $x$ \\
\hline Recycling & & $x$ & $\mathrm{X}$ & $x$ & $x$ \\
\hline $\begin{array}{l}\text { Service and } \\
\text { maintenance }\end{array}$ & & & $x$ & $x$ & $x$ \\
\hline Production technology & & & $x$ & $x$ & $X$ \\
\hline Raw materials cost & & $x$ & $\underline{x}$ & $x$ & $x$ \\
\hline Raw materials supply & & $x$ & $x$ & $x$ & \\
\hline Initial price & & $x$ & $x$ & $x$ & $x$ \\
\hline
\end{tabular}

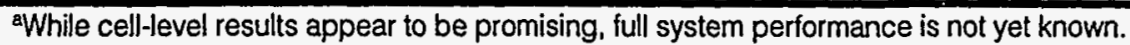

Major EV infrastructure supports that are currently not in place include residential and commercial fleet charging facilities, public charging stations, battery replacement and recycling, emergency road service, and electrical generating capacity. The type and amount of infrastructure support that must be in place when Evs are introduced is not yet certain, but some early infrastructure availability is necessary for consumer acceptance.

EVs exhibit operational and maintenance hazards that are not experienced or do not occur to the same degree in current ICEVs. In particular, risks are associated with the considerable mass and volatile nature of $\mathrm{EV}$ batteries, but the available data are scarce and inconclusive about the severity of these risks. Nevertheless, Evs should not be granted special exemptions from vehicle crashworthiness standards. 
The nature and extent of the private Ev market are not yet well defined. Estimates of the potential consumer EV market range from 60 percent of U.S. households to as few as 6 percent of U.S. automobile consumers. The typical methods used to produce these estimates have limited validity as forecasts of the likely market for this new technology.

Most corporate and government fleets make up a "niche" market that would not be hampered by current limitations in EV range and recharging. These fleets represent the most feasible opportunity to put Evs on the road today.

The initial costs of Evs will likely remain the largest obstacle to their purchase. Notwithstanding national and regional purchase incentives, the incremental costs of buying an Ev will most likely be borne primarily by consumers. Standardization and high demand are two prerequisites to achieving the economies of scale and learning that reduce production costs. To date, Evs have achieved neither. When they do, production costs should decrease, as will consumer costs.

Among other nations' policies and programs to develop, produce, and promote Evs, those in France, Germany, Japan, and Switzerland offer elements that may contribute to a more comprehensive U.S. EV program.

While other nations focus efforts on demonstration programs, infrastructure support, and production economics, they await a battery breakthrough from the U.S. Advanced Battery Consortium. In direct contrast to many of the countries we visited, the United States devotes proportionately less money to public Ev demonstration and promotion programs or infrastructure needs assessment and development. Evs are not available in sufficient numbers to satisfy the mandatory requirements of some U.S. demonstration programs.

Several foreign officials cite the California-type legislation as a major stimulus for increased interest in Evs in their countries. Five automobile manufacturers with large volumes of sales in the United States-three in Japan, one in Germany, and one in Sweden-are producing and testing Evs using current-generation, limited-performance batteries. If production and demonstration goals succeed, some foreign manufacturers will most likely have low-cost, performance-tested vehicles ready to receive advanced batteries developed by the United States. 


\section{National and Regional Concerns}

Battery costs would remain the largest contributor to the initial costs of EVs. Different types of batteries would command widely different prices, which could, in part, be offset by differences in overall driving life. High initial purchase costs mean that near-term Ev life-cycle costs are likely to be significantly higher than comparable costs of ICEVs. If EV purchase prices decrease substantially as production volume increases and electricity utilities institute widespread residential off-peak rates, then $\mathrm{EV}$ life-cycle costs in every nation except the United States would be lower than the life-cycle costs of comparable ICEVs. Among the nations we reviewed, the United States has the least favorable ratio of gasoline to electricity prices for reducing consumer automobile operating costs with EVS.

EVs have the potential to increase energy security and reduce pollution. However, net gains in either would be highly dependent upon future advances in EV and ICEV technologies as well as the fuel sources and processes used to generate electricity. Of the eight nations we reviewed, the U.S. current electricity fuel mix is among the most conducive to achieving petroleum savings and the least conducive to achieving pollution reduction goals.

EVS meeting the USABC midterm criteria may fare poorly compared to ICEVS in terms of the amount of primary energy consumed. If Evs achieve the USABC long-term goals and ICEVs do not achieve substantially improved fuel economy, then EVs will significantly reduce primary energy consumption under nearly all conditions.

Introducing Evs would increase independence from imported oil in all eight nations. The United States would save more annually ( $\$ 2.5$ billion) by replacing 10 percent of ICEVs with Evs than any other nation. Although Italy and Japan generate substantial amounts of electricity from oil and therefore would save less imported oil than the other nations, they would still save annually $\$ 300$ million and $\$ 700$ million, respectively.

Local and regional pollution is a serious problem in many nations, including the United States. Evs would almost entirely eliminate the hydrocarbons and carbon monoxide emissions associated with ICEV tailpipes, thus reducing ozone, or urban smog. However, because many countries and regions of the United States still rely heavily on coal and oil for electricity production, some areas could see substantial increases in sulfur dioxide emissions and no change or moderate increases in carbon dioxide and nitrogen oxides. 
Sulfur dioxide and nitrogen oxide emissions associated with electricity generation are regulated in the United States by the Clean Air Act Amendments of 1990. However, costs will increase if additional emissions must be monitored and controlled at the power plant. Moreover, other nations do not all have air quality restrictions as stringent as those in the United States; the introduction of Evs in these nations could contribute to increased global emissions of nitrogen oxides and sulfur dioxide. now be ensured. The lack of conveniences, such as longer-range batteries or public quick-recharging stations, and assurances, such as verification and publicity of EV safety and crashworthiness, hinder consumer acceptance. Current tax and purchase incentives are not adequate to ease the considerable financial burden for those now desiring to purchase Evs. No firm commitments for larger government or corporate fleet purchases currently exist to encourage higher production rates that might reduce consumer costs.

Industry and government officials in the eight nations we visited emphasized the perceived significance of USABC and the California mandate in the reemergence of Evs. Some nations are not anticipating large domestic EV markets, yet their automobile manufacturers are preparing for the mandated U.S. markets.

The dual role the United States is playing in the worldwide support of EV development, both by investing in advanced battery research at the national level and by mandating zero-emission vehicles at the state level, may be prerequisite to successful commercialization. However, U.S. policy toward Evs is fragmented in two ways. First, already limited federal funds for field testing are divided among programs in the departments of energy, defense, and transportation. Consequently, no single program has sufficient funds to purchase adequate numbers of Evs or to conduct rigorous field demonstrations and evaluations. Second, the lack of emphasis on the barriers that can be addressed before a battery breakthrough and that ultimately must be resolved to market a viable vehicle-namely, issues of infrastructure support, market development, and production economics--has created a void between state policies mandating EV markets and federal policies supporting battery technology initiatives. 
Meanwhile, other nations are focusing more directly on the elimination of these barriers by funding public demonstrations to field test vehicles and infrastructure, to assess consumer market characteristics, and to create an immediate market that increases production economies of scale. As a result, the possibility exists that the United States may introduce a critical technology-a high performance battery-that other countries can more easily adapt to performance-tested vehicles that are ready for the 1998 U.S. marketplace created by state legislation.

The aim of the current U.S. fuel-neutral energy policy is to diversify this nation's energy and transportation options by focusing on desirable end results - such as cleaner air-without prescribing the means for achieving them. Similarly, U.S. transportation program funding is divided among many fuel types, in part to maximize the likelihood that viable alternative fuels will be developed and commercialized.

One consequence of fuel neutrality may be fragmentation of funding and support. Full funding of currently legislated U.S. Ev programs will not guarantee the commercial viability of EVs produced in the United States. Nevertheless, without the full implementation of a comprehensive national energy plan that includes some threshold level of support for Evs, it is highly unlikely that EV technology will achieve commercial success. Such a program would be best designed with the interest, cooperation, and consolidation of resources from federal, state, local, and private partnership sources. In particular, common goals and resources, better coordinated and directed, would eliminate many of the fragmented policies and duplicated efforts that characterize U.S. EV efforts.

A fuel-neutral policy also recognizes that no single strategy or fuel could solve this nation's assorted transportation-related problems. Indeed, the diversity and range of economic, energy, and pollution effects associated with alternatively fueled vehicles generally, and electric vehicles in particular, suggest the need for a well-developed, clear consensus concerning the optimal mix of strategies by which the transportation sector can contribute to achieving this nation's stated goals for reducing energy dependence and global and regional pollution problems. Additional emphasis on environmentally and geographically sensitive criteria for the selection of AFvs would help underscore the ultimate goals of fuel neutrality.

The federal policy stance toward the development of EVs is incongruent with state initiatives and, in some instances, with itself. EPA has given 
approval to state plans to reduce air pollution that imitate the California plan by creating an EV market through mandate. DOE continues to fund USABC. And small-scale EV demonstrations have been funded through DOD appropriations. Yet, the field testing and demonstration provisions of the Energy Policy Act of 1992 have not been fully funded.

The tentativeness of U.S. policy toward Evs may reflect the inherent riskiness of supporting a nascent technology. Yet, its currently fragmented state raises the additional risk of spending millions of dollars on advanced battery research only to lose early market share in state mandated markets. 


\section{Comments From the Department of Energy}

Note: GAO comments supplementing those in the report text appear at the end of this appendix.

See comment 1.

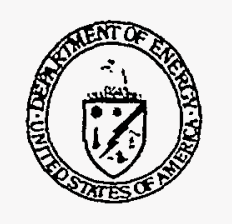

\section{Department of Energy \\ Washington, DC 20585}

September 9, 1994

Mr. Kwai-Cheung Chan

Director, Program Evaluation and Methodology Division

U.S. General Accounting office

Hashington, DC 20548

Dear Mr. Chan:

The Department of Energy appreciates the opportunity to review and comment on the General Accounting office draft report titled "Electric Vehicles: A Comparative Study of International Programs and Policies." The Department's comments address the report's findings with respect to the three evaluation questions that the General Accounting office has sought to answer.

\section{CURRENT BARRIERS TO UIDESPREAD INTRODUCTION OF ELECTRIC VEHICLES:}

Limitations of Battery Technology: Electric vehicle battery technology is evolving rapidiy in response to the requirements for zero emission vehicles in California and the Northeast States. Several prototype vehicles with advanced batterfes have denonstrated the capability of improving vehicle range and performance. The Department believes that advanced batteries could easily provide the 100-mile range that market studies indicate is necessary to meet the commuting, shopping, and other daily travel requirements of many urban consumers. A cooperative agreement between the Department of Energy and the United States Advanced Battery Consortium is focusing on the development of advanced batteries that will satisfy this requirement for the mid-term (five to ten years). In the long-term, the goal of the consortium is to provide batteries that will allow electric vehicles to be competitive with conventional gasoline-powered vehicles in both performance and cost. The current projections are that the mid-term batteries may become available in commercial quantities by the year 2000 . In the interim, many potential customers, such as electric utilities and fleet operators, may be satisfied with the range and performance of vehicles with lead-acid batteries. However, field experience shows that leadacid battery packs have a service life of, at best, three years, which imposes significant battery replacement costs. The life of these batteries needs to be improved if they are to be conmercially attractive. The General Accounting office report compares the advantages and disadvantages of various batteries but does not clearly differentiate between mature technologies, such as lead acid, and those that are still undergoing development. Many of the disadvantages identified for the less mature technologies are the focus of extensive development activities. An example is nickel metal hydride. The United States Advanced Battery Consortium is concentrating a major effort on reducing the cost of nickel metal hybrid batteries. Although the cost may never be comparable with lead acid, it will certainly be lower than 
Appendix I

Comments From the Department of Energy

See comment 2 .

See comment 3 . for nickel cadmium batteries. Five nickel metal hydride full size vehicle battery packs have been delivered to the United States Advanced Battery Consortium and are currentiy undergoing laboratory testing and field testing in Chrysler, Ford, and General Motors prototype electric vehicles.

Gaps in Required Infrastructure: The Department recognizes the importance of ensuring that the first generation of mass-marketed electric vehicles is problen-free, meets customer requirements, and is supported by the requisite infrastructure. There are severa] related activities supported by the Department that the General Accounting office should note. The Department's Site Operator Program is a joint effort by government, utilities, and educational institutions to test and evaluate near-term electric vehicles and their associated infrastructure in a realistic operating environment. The participants are located in various regions of the country al lowing electric vehicles to be tested in a wide range of climate, weather conditions, and terrain. Electric vehicles are used as delivery vans and trucks, commuter vehicles, and in mixed categories of transportation; others are used primarily for demonstrations to increase public awareness of these vehicles. The vehicles being tested are provided by original equipment manufacturers, as well as by small conversion companies. A participant in the program, York Technical College in Rock Hill, South Carol ina, is working closely with auto manufacturers and other organizations to develop a curriculum for training electric vehicle technicians. Site Operator Program participants also provide increased public exposure to electric vehicles. Under the Federal Fleet acquisition program, the Department is working with the General Services Administration and other agencies to purchase 10 to 15 electric vehicles for the Federal fleet this year. In fiscal year 1995, we expect to increase purchases through the federal Fleet program to $100-150$ vehicles. The vehicle purchases through the Site Operator Program and the Federal Fleet acquisition program will provide valuable information to the manufacturers as well as assist in creating an introductory market for electric vehicles.

Recharging infrastructure issues and problems are being addressed primarily by the Electric Power and Research Institute sponsored Infrastructure Horking Council and its four committees (Connecting and Connecting Stations, Health and Safety, Load Management, Distribution and Power quality, and Data Interfaces). These committees have representatives from the electric utility, automobile, battery, and electrical component industries, as well as standards setting organizations such as the Society of Automotive Engineers. The Department participates in the Infrastructure Working Council and is al so working within the framework of the International Energy Agency toward uniform standards for recharging electric vehicles.

Electric Vehicle Safety: Recognizing the unique requirements of electric vehicles, the Department sponsors the Electric Vehicle Battery Readiness Korking Groups, which meet about twice a year to address invehicle safety and battery shipping and recycling issues. Participating agencies include the Department of Transportation, National Highway 
Appendix I

Comments From the Department of Energy

3

Traffic Safety Administration, Environmental Protection Agency, and Bureau of Mines. Extensive voluntary participation by the vehicle and battery manufacturers is al so part of this process. In addition, the National Renewable Energy Laboratory, with the Department's support, is conducting environmental, health, and safety assessments of advanced batteries for electric vehicles. In fiscal year 1992, a series of reports were issued on environmental, health, and safety issues relevant to cell and battery design, shipping, in-vehicle use, and recycling and reclamation of sodium/sulfur batteries. In addition, a training film was developed for educating local fire departments on the procedures for dealing with vehicle fires involving sodium sulfur batteries. In fiscal year 1993, an environmental, health, and safety assessment was conducted on nickel metal hydride batteries and the results published.

See comment 4 .

Uncertain Market Potential: The Department's Electric Vehicle Program is focused on the development of technologies that will allow the automobile industry to commercialize electric vehicles with the range, perfo.mance, 1 ife, and amenities that consumers have come to expect from automobiles and 7 ight trucks, and at a cost close to that of

conventional vehicles. A key element of the Department's program is the cooperative effort with the United States Advanced Battery Consortium to develop advanced batteries with much greater energy and power

capability. In addition, the industry is independently conducting field trials with about 200 limited production electric vehicles to test consumer acceptance. For example, under the "PrEView Drive Program", General Motors and leading utifities throughout the United States wili provide more than 1,000 consumers with the opportunity to test drive a General Motors Impact for periods of two to four weeks. This program began in spring 1994. The Program is designed to determine how potential customers will respond to electric vehicles in real-iife circumstances. Since March 1993, as part of a larger Electric Vehicle Evaluation Program, Southern California Edison has been conducting customer trials of electric vehicles to generate critical information on driving habits, trip patterns, and charging tines. The response from consumers, so far, is reported to be very positive.

See comment 5 .

High Initial Purchase Price: The Department of Energy has studied electric vehicle costs under the requirements of Section 615(b) of the Energy Policy Act of 1992 . These findings will be reported to the congress shortly. The preliminary results of these studies indicate that the expected differential cost for electric vehicles will be about $\$ 7,500$ in 1998. By the year 2005, electric vehicles are expected to be competitive with conventional vehicles.

See comment 6 .

\section{MATIONAL ELECTRIC VEHICLE PROGRAMS:}

The General Accounting Office Report refers to the "multidimensional" strategies of national electric vehicle programs in France, Germany, Japan, and Switzerland. These programs are compared with the United States' approach that emphasizes battery development at the national level, combined with legislative mandates and incentives at the State

leve1. The General Accounting Office finds that the United States de- 
Appendix I

Comments From the Department of Energy

emphasizes infrastructure development and assessment as compared to other national programs that were reviewed. The Department of Energy has historically maintained a lead role in electric vehicle development and commercialization, as determined by its overall mission, industry requirements, internal policy decisions, and Congressional guidance and appropriations. In 1991, the auto industry indicated that the Department should concentrate its efforts on advanced batteries and requested the Department's support for the United States Advanced Battery Consortium. Industry's stated position was that the electric drivetrain and auxiliary systems technologies were sufficiently developed and the Federal resources could be best devoted to the critical battery area. The Department's research and development focus has since been on advanced batteries under a cooperative agreement with the United States Advanced Battery Consortium. In 1992 and 1993, the Department also refocused the electric drivetrain development effort to pursue hybrid vehicle concepts.

See comment 7.

In the infrastructure arena, the Energy Policy Act includes provisions of what could be termed a "national electric vehicle program." In addition to expanding research and development programs, the Energy Policy Act authorizes electric vehicle commercial denonstration and infrastructure development programs through Title VI. However, Congress has not appropriated funding for Titie VI programs in fiscal year 1994 , nor is any funding anticipated in fiscal year 1995. Only limited funds are available to the Department under the Site Operator Program for these purposes.

As compared to the role played by national programs in other countries, it is important to recognize the significant interest and prominent roie of electric utilities in the United States in purchasing and using electric vehicles and developing the infrastructure. The Electric Vehicle Association of the Americas, the Edison Electric Institute, the Electric Transportation Coalition, and the Electric Power and Research Institute have initiated the EV America program and have formed a joint ad hoc steering committee to promote the large-scale demonstration and early market introduction of electric vehicles. This program seeks to incrementally place up to 5,000 road-worthy electric vehicles in a controlled market demonstration. The Chief Executive Officers of major electric utilities have been invited to participate in the program, and several have signed on. The EV America plan calls for Federal and/or other government support. The Department has participated in recent discussions with creators and leaders of the EV America concept and is exploring possible ways of integrating the ongoing site Operator Program and the Federal fleet acquisition program into an EV America concept to help achieve market introduction of new technology advancements.

See comment 8 .

The General Accounting office report suggests that several foreign countries and manufacturers are devoting their resources to developing and testing near-term vehicle technology and addressing infrastructure barriers while waiting for a breakthrough in battery technology from the United States Advanced Battery Consortium. This may position them to 
Appendix I

Comments From the Department of Energy

See comment 9 .

See comment 10 .

See comment 11.

quickly take advantage of advanced battery products developed in the United States. Information available to the Department indicates that the large potential market for electric vehicles has spawned an international race with considerable overseas efforts to develop advanced batteries for electric vehicles. European manufacturers are working on several advanced technologies, including sodium/nicke] chloride, sodium/sulfur, lithium fon, and ithium/polymer technologies. In Japan, the focus of advanced battery development is lithium ion technology. Japan is already the world leader in the introduction of this technology for the consumer electronics market. Recent visitors from Japan have explained that their program involves technology development and scaleup to create high energy lithium ion batteries for electric vehicles by about the year 2000 . Japanese companies also claim to have developed prototype nickel metal hydride battery technology for electric vehicles.

\section{MATIONAL AND REGIOHAL EFFECTS OF INTRODUCING ELECTRIC VEHICLES}

Economics: Relative to electric vehicle economics, the Department recognizes that the United States has an unfavorable electricity-togasoline price ratio. A higher price of gasoline to the consumer would result in more widespread use of alternative fuels, including

electricity. However, despite the relatively low gasoline price, a recent Departmental study of electric vehicle economics in the United

States (referred to earlier) concluded that life cycle costs of electric vehicles will be comparable with that of conventional vehicles by 2005 .

Energy: The Department fully agrees with the General Accounting office finding that (1) advanced electric vehicles will significantly improve the primary energy efficiency of the transportation fleet, and (2) increased independence from imported oil will result from successfully introducing electric vehicies. These conclusions remain the cornerstone of the Department's rationale for supporting the development and comercialization of electric vehicles. However, the General Accounting office conclusion that near-term electric vehicles may use 20 to 35 percent more primary energy than conventional vehicles is not consistent with the Department's analyses and determinations.

Environment: The decision to mandate the use of electric (zero emission) vehicles is made by States under the authority granted by the Clean Air Act Amendments of 1990. California and the Northeast States have extensively documented the technical and analytical bases for their decisions and their expectations for significant air quality improvements. (Analysis for the Northeast States has been done by NESCAUH - Northeast States for Coordinated Air Use Management.

The Generai Accounting Office's finding that electric vehicles will drastically reduce carbon monoxide and hydrocarbon emissions as compared to conventional vehicles is well established. However, the General Accounting Office's findings on sulfur dioxide and nitrogen oxide emissions associated with electric vehicles in the United States do not consider the expected impacts of the Clean Air Act Amendments of 1990. 
Appendix I

Comments From the Department of Energy

\section{6}

The electric utility industry is required by the Clean Air Act

Amendments to make significant reductions in emissions of oxides of nitrogen and sulfur. Specifically, sulfur oxide emissions are capped. Thus, the electric utility industry will not be allowed to increase emissions of sulfur oxides in supplying additional energy for electric vehicles. Overall, the Department believes that the emissions impacts of introducing electric vehicles are quite favorable. This has been establ ished by several credible independent studies that were performed by such organizations as the Electric Power Research Institute, the California Air Resources Board, the Environmental Defense Fund, and the North East States for Coordinated Air Use Management.

More extensive technical and editorial comments are being provided to the General Accounting office under separate cover. The Department hopes that the comments in both letters will be helpful in the preparation of the final report.

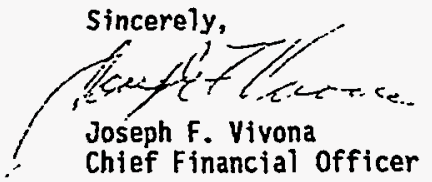


The following are GAO's comments on the September 9, 1994, DOE letter.

\section{GAO Comments}

Most of the Department of Energy's comments reflect a basic agreement with us over the wide range of assumptions that can be adopted regarding the ultimate performance of electric vehicles relative to those of future internal combustion engine vehicles. DOE also provided us under separate cover with a number of technical and editorial comments. We have not reprinted these, but we have made changes in the body of the report as appropriate. We address DOE's more general comments below.

\section{Comment 1}

We agree with DOE that electric vehicle battery technology is evolving rapidly and that a breakthrough could occur at any time. However, our objective in this report was to evaluate the current status of electric vehicle development. For this reason, we believe that the comparison of the advantages and disadvantages of batteries at various stages of technical development was both proper and unavoidable. Such a presentation in no way implies that these limitations are insurmountable with further research and development. address gaps in required electric vehicle infrastructure. Nevertheless, we believe that many outstanding issues remain to be resolved before the infrastructure support for electric vehicles could be considered adequate to sustain a substantial number of electric vehicles in the private and commercial marketplace.

We note in our report that GSA plans to purchase 10 to 15 electric vehicles to add to the 10,200 alternatively fueled vehicles that were in the federal fleet in July 1994. According to GSA officials in September 1994, current plans for 1995 include no electric vehicles among the 9,000 planned alternatively fueled vehicle purchases. Nevertheless, DOE continues to foresee sufficient 1995 appropriations to provide GSA with incremental funding for the purchase of 100 to 150 electric vehicles. Yet, even if these 1995 goals are met, electric vehicles would, on balance, continue to constitute a very small proportion of GSA's 1995 plans to purchase 9,000 alternatively fueled vehicle purchases for the federal fleet. 
Appendix I

Comments From the Department of Energy

\section{Comment 3}

We believe that the activities DOE cited to address electric vehicle safety issues are an implicit acknowledgment that these issues are some distance from final resolution. We continue to believe that the safety of electric vehicles remains a critical issue for their ultimate viability.

\section{Comment 4}

We have acknowledged these and other efforts to evaluate the potential market for electric vehicles throughout our report. However, we suggest that neither dispersing small numbers of electric vehicles throughout U.S. utility fleets nor providing limited production electric vehicles to 1,000 consumers for 2 to 4 weeks will have a marked effect on the awareness and acceptance of electric vehicles by the estimated 170 million licensed drivers in the United States.

\section{Comment 5}

We reviewed the assumptions DOE used to estimate the life-cycle costs of electric vehicles. Generally, DOE projects that certain electric vehicle batteries will demonstrate substantial performance and cost improvements by 1998 and 2005. We are less optimistic that, within these periods, these batteries can achieve such performance, commercial production, and cost goals. Based in part on this reasoning, our cost models include different batteries with less advanced performance characteristics and produced in smaller quantities in 1998.

\section{Comment 6}

While we accept the automobile industry's position in 1991 that battery research was a more critical need than electric drive train development, we continue to believe that other important aspects of electric vehicle development receive disproportionately less attention than battery research. We concur with DOE that appropriated funding for the electric vehicle sections of the Energy Policy Act of 1992 have fallen short of authorization.

\section{Comment 7}

The Ev America program is in the early development stages, and we were unable to evaluate its potential effect on electric vehicle demonstration. The introduction of 5,000 roadworthy vehicles would constitute a positive step toward addressing the current barriers that impede the widespread introduction of electric vehicles. However, doubts must remain whether such a goal can be achieved in the near term. As we noted in the report, current electric vehicle demonstration programs of much smaller scale are experiencing difficulty finding a sufficient number of electric vehicles to 
form demonstration programs of the size mandated by the Energy Policy Act. Given that the three large U.S. automobile manufacturers are currently planning to produce 250 electric vehicles, the Ev America program's success depends, in part, upon substantially greater commitments from these manufacturers.

\section{Comment 8}

Our purpose in comparing the amount of public funds dedicated to battery research and development in different nations was not to evaluate the level of funding of the U.S. Advanced Battery Consortium nor to suggest that battery research and development is not progressing in foreign countries (particularly in Japan). Rather, our intent was to contrast the balance of governmental support between battery research and development and infrastructure development in different nations.

Comment 9

As noted earlier, we reviewed the assumptions DOE used to project likely electric vehicle economics. Given the current status of battery development, we believe the assumptions we used in our report are more realistic projections of electric vehicle performance and costs.

Our analysis of the primary energy use of electric vehicles and conventional vehicles uses a range of assumptions about the likely performance of electric and internal combustion engine vehicles. Our model analyzes conditions both favorable and unfavorable to electric vehicles and highlights the likely consequences of focusing research and development efforts on either improving electric vehicle fuel economy or improving gasoline vehicle fuel economy. We evaluated the assumptions used in the energy analysis DOE sponsored and cited in its technical comments on our report. We found three major differences between the assumptions in our models and those in DOE's model.

1. DOE's base case analysis assumes that the electricity for the electric vehicle is generated only by advanced natural gas facilities with fuel conversion efficiencies higher than most currently in operation. High electricity conversion efficiencies substantially reduce the primary energy requirements of electric vehicles. Advanced natural gas facilities are projected to account for 6 percent of the U.S. fuel mix in 2001. We use the conversion efficiencies of the current average fuel mix in each nation in our analysis. 
2. The internal combustion engine van in DOE's analysis has a projected fuel economy of $25 \mathrm{mpg}$ in 2001. The projected fuel economies in our analysis range from $21 \mathrm{mpg}$ (low performance) to $28 \mathrm{mpg}$ (high performance).

3. DOE assumes that the energy consumption from the plug to the wheels of a van with a battery meeting the USABC midterm criteria (for example, sodium sulfur) will be $0.30 \mathrm{kWh}$ per kilometer in 2001 . We assume an energy consumption of $0.40 \mathrm{kWh}$ per kilometer for this battery and 0.25 $\mathrm{kWh}$ per kilometer for a battery meeting the USABC long-term criteria.

These and other minor differences in the two analyses explain why DOE concurs with our findings when we model conditions favorable to electric vehicles (high-performance electric vehicles versus low-performance internal combustion engine vehicles) but disagrees with our findings when we model conditions unfavorable to electric vehicles (low-performance electric vehicles versus high-performance internal combustion engine vehicles).

We recognize that sulfur dioxide and nitrogen oxide emissions associated with electricity generation are regulated in the United States by the Clean Air Act Amendments of 1990. However, costs will increase if additional emissions must be monitored and controlled at the power plant. Moreover, other nations we reviewed do not all have air quality restrictions as stringent as those in the United States. Thus, the introduction of electric vehicles in these nations could contribute to increased global emissions of nitrogen oxides and sulfur dioxide. 


\section{Adopted State Legislative Initiatives Regarding Alternative Fuels}

Arizona

Arkansas
Discounted annual license tax rate to Evs ( $\$ 4$ per $\$ 100)$

Income tax credit ( 25 percent or $\$ 5,000$ ) over 3 years to alternative fuel vehicles (AFvs)

Conversion tax credit (up to $\$ 3,000$ ) over 3 years

Private refueling stations qualify for $\$ 5,000$ credit (50 percent of interest for tax credits can also be a tax credit)

\$8.7 million in 1993-94 and 1994-95 to convert and provide AFvs and infrastructure for schools and state agencies

Air Resources Board low-emissions vehicle program mandating zero-emission vehicles adopted September 1990

Tax credit (15 percent or $\$ 1,000$ )

75 percent of Petroleum Violation Escrow Account Funds defense conversion initiatives

\$1 million state matching of funds from National Energy Policy Act of 1992 for energy conversion and development programs

$\$ 1$ vehicle registration fee (total $\$ 9$ million per year) for clean fuel projects

$\$ 100,000$ tax deduction for clean-fuel refueling property

$\$ 2,000$ tax deduction to AFvs excludes Evs

$\$ 1,000$ state income tax credit limited to 750 LEvs per year (expires December 1994)

Partial sales tax exemption for LEvs (expires December 1994)

$\$ 2$ million for EV development consortium

$\$ 224,000$ for EV and AFV infrastructure master plan 
$\$ 5$ million from state Employment Training Panel for EV development and clean fuel vehicle industry

Requires state agency plan by 1994 to support consumer recharging and refueling of AFvs

5-percent tax credit for Evs (not to exceed 50 percent of cost of electric fuel system) through 1998

Rebate for certain AFvs (up to $\$ 1,000$ )

Mechanics certification program for AFV conversion state in 1993 and 1994 be powered by compressed natural gas (CNG) or electricity (can be suspended if refueling is not available or sufficient numbers of Evs are not available or not cost competitive)

$\$ 200,000$ per year for loans and credit lines for businesses that convert to CNG or diesel fuel and a clean alternative fuel

10-percent corporate business tax credit for purchase of Ev recharging equipment, conversion equipment for natural gas and electricity, and the incremental cost of vehicles run exclusively on CNG or electricity

Business tax exemptions for research, design, manufacture, sale, or installation of vehicles powered in whole or in part by electricity, natural gas, or solar power

Sales tax exemption for purchase of clean-fueled vehicle or conversion equipment

10-percent tax credit for individuals and corporations on the incremental cost of purchasing an $\mathrm{EV}$

Mandated discounts for state purchases of clean-fueled vehicles

Study commissioned on adoption of California program 
Alternative fuels in all possible vehicles by 2000 .

Iowa

Beginning in 1992, 5 percent of new state vehicles to be equipped for alternative fuels; increases to 10 percent by 1994

Louisiana

Requires 30 percent of new state vehicles to have clean-fuel capability by September 1994; increases to 50 percent in 1996

Maine

Maryland

\section{Adopted California LEv program}

Requires adoption of California LEv standards by 2000; contingent on similar legislation by four of the following five states by 2000: Delaware, District of Columbia, New Jersey, Virginia, or Pennsylvania

Motor fuel tax reduced for alternative fuels (from 24.25 cents to 23.5 cents per gasoline-equivalent gallon)

Exempts from property tax certain refueling equipment and machinery (20 percent of assessed value in tax year 1998, 40 percent in 1999 , 60 percent in 2000,80 percent in 2001 , and 100 percent thereafter)

Exempts from sales and use taxes for conversion machinery or equipment for certain fuels

State agencies and university required to purchase AFvs in accordance with Energy Policy Act of 1992

Established an evaluation of use of AFvs in state fleet 

in mid-1996, 30 percent in mid-1998, 50 percent by mid-2000. By mid-2002, 30 percent of government fleet must operate solely on alternative fuels

Nevada Requires public hearings and report of use of alternative fuels; requires adoption of conversion regulations for state and municipal fleets in surrounding states (Delaware, Maryland, Massachusetts, New York, and Pennsylvania) mid-1993; percentage increases to 60 percent in 1994 and 100 percent in 1995. Postsecondary institutions required to convert to AFvs

$\$ 5$ million loan fund for conversions

\section{Adopted California LEV program}

Exemption from retail sales tax for incremental costs of an EV and the refueling infrastructure

New York City ordinance requires city to purchase 385 AFvs by mid-1992 and establishes purchase schedule of alternative fuel buses

\section{North Carolina} Requires study of use of clean fuels in state vehicles and development of a natural gas demonstration project for state-owned vehicles 
10-percent discount of the entire vehicle cost (up to $\$ 1,500$ )

\$1.5 million conversion fund for state, county, municipal, and school district vehicles $(\$ 3,500$ per conversion and $\$ 100,000$ per refueling station)

Oregon

Pennsylvania 35-percent business tax credit on purchase price of AFvs

Exemption from retail sales tax for incremental costs of an EV

\$3.5 million grant fund for school districts, municipalities, and corporations for conversion or purchase of AFvs; grants cover 60 percent of eligible costs, decreasing biannually to 20 percent

Exemption from annual registration fee
Authority to regulate tailpipe emissions and promulgate regulations for LEV program in 1994 if such a program is shown necessary to attain and maintain air quality standards in the state

\section{South Carolina}

Tennessee

\section{Established a study of clean alternative fuels}

Resolution urging the development and use of environmentally sensitive domestic alternative fuels

Texas

Created a council to develop state AFV policy and a fund for conversion and purchase of AFVs

\section{Virginia}

Beginning in 1998, a certain percentage of new fleet purchases in certain regions must be AFvs

Income or gross receipts tax credit of 10 percent of the amount allowed as a deduction by the federal government for clean-fuel vehicles and certain refueling property

Reduced fuel tax rate (from 16 cents to 10 cents per gallon) 
Annual tax on vehicles that "fuel" at home and do not pay the special fuels $\operatorname{tax}$

Reductions (from 3 percent to 1.5 percent) of the tax on the sales price of vehicles using natural gas, liquified natural and petroleum gases, hydrogen, or electricity

Requires that 50 percent of vehicles purchased in 1992 use alternative fuels

License fee waived from 1991-96 for taxicabs and for-hire vehicles using alternative fuels

$\$ 132,500$ fund to implement alternative fuels pilot program

Requires 30 percent of state vehicles purchased to use clean fuels after mid-1992, increasing 5 percent each year

West Virginia

Provides for the purchase and use of AFvs in fleets owned by.political subdivisions and states. Specifies minimum purchase requirements for 1995-97 and continuation thereafter subject to review of 3-year program

2-year program to assist municipalities in fleet conversions with up to $\$ 30,000$, or a maximum of $\$ 2,000$ per vehicle

Established a task force to monitor state fleet pilot program and to develop state policy on alternative fuels 


\section{Advanced Battery Consortium Technical Criteria}

Table III.1: Primary Criteria With Mid-Term and Long-Term Goals

\begin{tabular}{lrr}
\hline Primary criteria & Mid-term goals & Long-term goals \\
\hline Power density W/L & 250 & 600 \\
\hline Specific power W/kg (80\% DOD/30 sec) & $150^{\mathrm{a}}$ & 400 \\
\hline Energy density Wh/L (C/3 discharge rate) & 135 & 300 \\
\hline Specific energy Wh/kg (C/3 discharge rate) & $80^{\mathrm{b}}$ & 200 \\
\hline Life (years) & 5 & 10 \\
\hline $\begin{array}{l}\text { Cycle life (cycles) } \\
\text { (80\% DOD) }\end{array}$ & 600 & 1,000 \\
\hline $\begin{array}{l}\text { Power and capacity degradation } \\
\text { (\% of rate spec) }\end{array}$ & $20 \%$ & $20 \%$ \\
\hline Ultimate price $(\$ / \mathrm{kWh})(10,000$ units at $40 \mathrm{kWh})$ & $<150$ & $<\$ 100$ \\
\hline Operating environment & -30 to $65^{\circ} \mathrm{C}$ & -40 to $85^{\circ} \mathrm{C}$ \\
\hline Recharge time & $<6$ hours & 3 to 6 hours \\
\hline Continuous discharge in 1 hour (no failure) & $75 \% \%^{\mathrm{c}}$ & $75 \%^{\circ}$ \\
\hline
\end{tabular}

a200 desired.

${ }^{b} 100 \%$ desired.

cof rated energy capacity.

Table III.2: Secondary Criteria With Mid-Term and Long-Term Goals ${ }^{a}$

\begin{tabular}{|c|c|c|}
\hline Secondary criteria & Mid-term goals & Long-term goals \\
\hline Efficiency: $\mathrm{C} / 3$ discharge, 6-hour charge & $75 \%$ & $80 \%$ \\
\hline Self-discharge & $<15 \%$ in 48 hours & $<15 \%$ per month \\
\hline Maintenance & $\begin{array}{r}\text { No maintenance; } \\
\text { service by qualified } \\
\text { personnel only }\end{array}$ & $\begin{array}{r}\text { No maintenance; } \\
\text { service by qualified } \\
\text { personnel only }\end{array}$ \\
\hline Thermal loss (for high temperature batteries) & $\begin{array}{r}3.2 \text { WMh } \\
15 \% \text { of capacity } \\
48 \text {-hour period }\end{array}$ & $\begin{array}{r}3.2 \mathrm{~W} / \mathrm{K} \text { whr } \\
15 \% \text { of capacity } \\
\text { 48-hour period }\end{array}$ \\
\hline Abuse resistance & $\begin{array}{l}\text { Tolerant; minimized } \\
\text { by on-board controls }\end{array}$ & $\begin{array}{l}\text { olerant minimized by } \\
\text { on board controls }\end{array}$ \\
\hline
\end{tabular}

${ }^{8}$ Criteria specified by contractor: Packaging constraints, recyclability, environmental, impact, reliability, safety overcharge and overdischarge, tolerance. 
Major Contributors to This Report

\section{Program Evaluation and Methodology Division}

Far East Regional Office

Denver Regional Office

Detroit Regional Office
Robert E. White, Assistant Director Jacqueline D'Alessio, Project Manager Barbara A. Chapman, Adviser

Penny Pickett, Communications Analyst

Joyce L. Akins, Evaluator

Arthur Gallegos, Senior Evalutor

Alan J. Dominicci, Evaluator

Anthony A. Krukowski, Senior Evaluator

Javier J. Garza, Evaluator 


\section{Ordering Information}

The first copy of each GAO report and testimony is free. Additional copies are $\$ 2$ each. Orders should be sent to the following address, accompanied by a check or money order made out to the Superintendent of Documents, when necessary. Orders for $\mathbf{1 0 0}$ or more copies to be mailed to a single address are discounted 25 percent.

Orders by mail:

U.S. General Accounting Office

P.O. Box 6015

Gaithersburg, MD 20884-6015

or visit:

\section{Room 1100}

700 4th St. NW (corner of 4th and G Sts. NW)

U.S. General Accounting Office

Washington, DC

Orders may also be placed by calling (202) 512-6000

or by using fax number (301) 258-4066, or TDD (301) 413-0006.

Each day, GAO issues a list of newly available reports and testimony. To receive facsimile copies of the daily list or any list from the past 30 days, please call (301) 258-4097 using a touchtone phone. A recorded menu will provide information on how to obtain these lists. 